\title{
Evaluation of exposures and respiratory health at a coffee roasting, flavoring, and packaging
}

facility

Rachel L. Bailey, DO, MPH Matthew G. Duling, MS, REHS Stephen B. Martin, Jr., PhD, PE

Marcia L. Stanton, BS

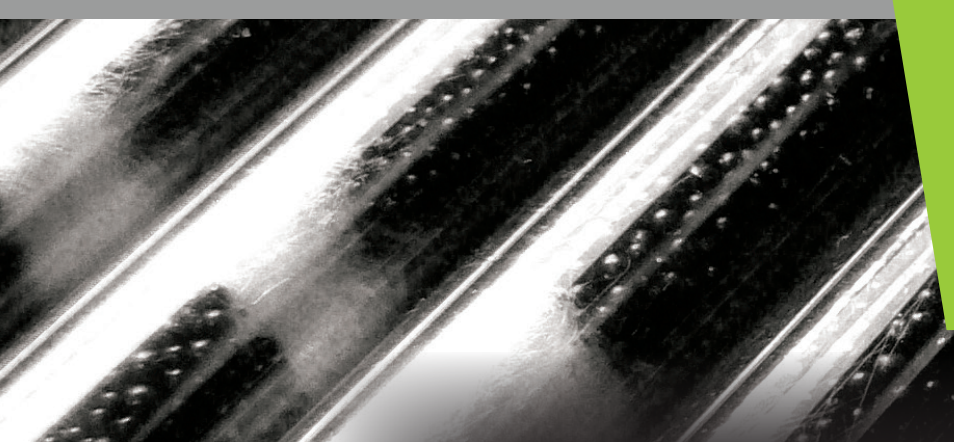

Tia L. McClelland, MS Ryan F. LeBouf, PhD, CIH

Nicole T. Edwards, MS

Kathleen B. Fedan, BS Jean M. Cox-Ganser, PhD

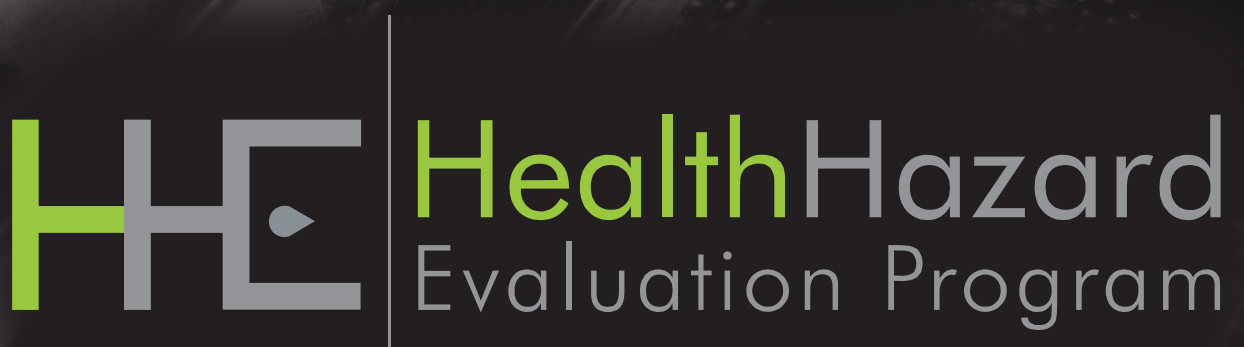

Report No. 2012-0170-3372

April 2020

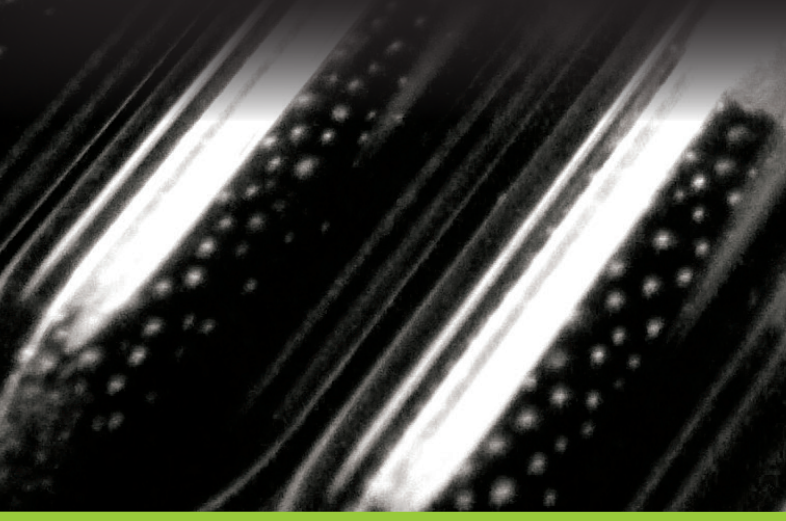




\section{Contents}

Highlights................................................... i

Abbreviations ....................................... 1

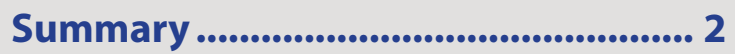

Introduction .......................................... 3

Background............................................ 4

Facility and Process Description......... 8

Methods ............................................. 13

Results ................................................ 23

Discussion .......................................... 37

Conclusions .......................................... 47

Recommendations.............................. 48

Appendix A: Tables ............................. 53

References........................................... 78

Acknowledgements............................ 88

The employer is required to post a copy of this report for 30 days at or near the workplace(s) of affected employees. The employer must take steps to ensure that the posted report is not altered, defaced, or covered by other material.

The cover photo is a close-up image of sorbent tubes, which are used by the HHE Program to measure airborne exposures. This photo is an artistic representation that may not be related to this Health Hazard Evaluation. 


\section{Highlights of this Evaluation}

The Health Hazard Evaluation Program of the National Institute for Occupational Safety and Health received a confidential request from employees at a coffee roasting, flavoring, and packaging facility regarding concerns about respiratory symptoms, lung disease, and eye irritation related to substances used in the manufacturing of coffee products, including ingredients mixed in the flavoring process.

\section{What We Did}

- We conducted a walkthroug visit of the facility in July/August 2012.

- We performed a medical survey in September 2012.

- We administered a health questionnaire, performed breathing tests, and offered blood tests.

- We notified participants of their individual medical test results.

- We performed a medical survey in September 2012.

- We administered a health questionnaire, performed breathing tests, and offered blood tests.

- We notified participants of their individual medical test results.

- We performed an industrial hygiene survey in November 2012.

- We collected full-shift (hours), task (minutes), and instantaneous (seconds) air samples to measure concentrations of diacetyl and 2,3-pentanedione over multiple days.

- We measured airborne dust concentrations throughout the facility.

○ We collected bulk samples of liquid flavorings to measure their emission potential for diacetyl, 2,3-pentanedione, and 2,3-hexanedione.

- We performed an industrial hygiene survey in April 2017.

○ We collected full-shift (hours), task (minutes), and instantaneous

We evaluated respiratory health and airborne exposures to alpha-diketones (diacetyl, 2,3-pentanedione, and 2,3-hexanedione), dust, other volatile organic compounds, carbon monoxide, and carbon dioxide during coffee roasting, grinding, flavoring, and packaging. Diacetyl and 2,3-pentanedione were detected in a majority of full-shift personal breathing zone air samples. During the November 2012 visit, the maximum concentration of diacetyl was 166.0 parts per billion in a personal sample from a packaging employee while the maximum 2,3-pentanedione concentration was 199.0 parts per billion from a personal sample collected on an employee in the flavoring room. In April 2017, personal samples from employees in the flavoring room gave maximum concentrations of 163.8 parts per billion diacetyl and 899.6 parts per billion 2,3-pentanedione. In November 2012, 58 of 59 full-shift personal samples exceeded the NIOSH recommended exposure limit for diacetyl of 5 parts per billion and 42 of 59 samples exceeded the NIOSH recommended exposure limit for 2,3-pentanedione of 9.3 parts per billion. In April 2017,28 of 29 full-shift personal samples exceeded the NIOSH recommended exposure limits for diacetyl and 2,3-pentanedione. The production volume in April 2017 was approximately $70 \%$ higher than our first visit which likely contributed to the higher concentrations measured in some areas. During the medical survey, eye and nose symptoms were the most commonly reported symptoms; 1.6-fold excess of employees reported shortness of breath compared to the U.S. population with a similar demographic distribution, and 2.7 times as many employees as expected had spirometric obstruction than in the U.S. population. We recommend installing local exhaust and dilution ventilation and implementing administrative controls such as modification of work practices. Until engineering and administrative controls are in place, we recommend respiratory protection to reduce exposures to alpha-diketones. The choice of respirator should be guided by personal exposure sampling for diacetyl and 2,3-pentanedione and be made only by qualified personnel. We also recommended continuing the medical surveillance program. 
(seconds) air samples to measure concentrations of diacetyl, 2,3-pentanedione, and 2,3-hexanedione.

- We measured real-time air levels of carbon monoxide and carbon dioxide.

- We collected additional bulk samples of liquid flavorings.

- We assessed the ventilation system at the facility in November 2012 and April 2017.

- We provided seven interim reports with recommendations to the company following our visits.

\section{What We Found}

- Production volume increased approximately 70\% between 2012 and 2017 which made direct comparison of sampling results between the two visits difficult. Personal full-shift sampling results exceeded the NIOSH recommended exposure limits for both diacetyl and 2,3-pentanedione in 2012 and 2017.

- In November 2012, area sample diacetyl concentrations were highest in packaging (112.2 parts per billion) and the packaging mezzanine (247.2 parts per billion). In 2017, the flavoring room (372.0 parts per billion) and flavoring mezzanine (251.3 parts per billion) had the highest concentrations.

- In November 2012, one personal sample in the nonproduction offices exceeded the NIOSH recommended exposure limit for diacetyl. Prior to the April 2017 survey, the air handling unit serving the nonproduction offices was replaced resulting in no samples exceeding the exposure limits.

- In November 2012 and April 2017, area 2,3-pentanedione concentrations were highest in the flavoring room (273.1 parts per billion, 2012; 1285.3 parts per billion, 2017) and flavoring mezzanine (206.4 parts per billion, 2012; 2060.3 parts per billion, 2017).

- Source sampling results in November 2012 showed the storage bins on the packaging mezzanine had the highest concentrations of diacetyl and 2,3-pentanedione. As a result, the packaging mezzanine was enclosed and ventilated prior to our April 2017 survey.

- Diacetyl was identified in 11 of 13 bulk flavoring samples. Compared to diacetyl, higher concentrations of 2,3-pentanedione were identified in almost all the flavorings. 2,3-Hexanedione was measured in five samples.

- In November 2012, air samples for dust were below occupational exposure limits. Dust samples were not collected in April 2017.

- Employees used brooms to sweep the production floor, wet or dry wipes on table tops and equipment surfaces, and compressed air to remove coffee bean dust from surfaces and equipment. In response to a NIOSH recommendation after the November 2012 visit, the facility reduced the use of compressed air for cleaning and placed industrial vacuums throughout the production spaces for use in cleaning tasks.

- Ventilated enclosures were installed around all grinders prior to our November 2012 visit. An assessment of those enclosures showed they were largely ineffective. Before our April 
2017 visit, enclosures around two grinders were improved, and the third grinder was completely replaced with a sealed grinder to reduce emissions. The April 2017 survey revealed that additional improvements are needed.

- Peak levels of carbon monoxide inside the flavoring room grinder enclosure exceeded the NIOSH ceiling of 200 parts per million; employees typically do not enter the grinder enclosure during operation.

- In July/August 2012, N95 filtering facepiece respirators were available but not required. In September 2012, flavoring specialists and mixers sometimes wore half-face airpurifying respirators. In November 2012, flavoring employees were required to wear fullface powered air-purifying respirators. In April 2017, half-face air-purifying respirators were required in flavoring, the packaging mezzanine, while feeding roasted coffee into the new corner-seal packaging line, and during rework.

- During the September 2012 medical survey of current employees at the coffee facility:

- Eye and nose symptoms were the most commonly reported symptoms.

- Some participants with mucous membrane irritation of eyes, nose, or sinuses attributed it to green coffee or roasted coffee dust, smoke, pallet dust/debris, heat in the roasting room, or the burlap bags.Shortness of breath was the most commonly reported lower respiratory symptom followed by chest wheezing or whistling, trouble breathing, and cough.

- Of 69 participants with spirometry, five had obstructive abnormalities, two had restrictive abnormalities, and eight had low FEF25-75.

- Current coffee plant employees had a 2.7-fold excess of spirometric obstruction and 1.6-fold excess of shortness of breath (when hurrying on level ground or walking up a slight hill) compared to the U.S. population of the same age, race/ethnicity, sex, and cigarette smoking distribution.

- Spending work time in the roasting room was associated with having trouble with breathing, wheeze, sinus symptoms, and burning eyes in the last 12 months. There were no significant associations between symptoms and currently spending work time in the flavoring room or grinding/packaging room.

- Five of 45 participants who completed the mannitol challenge test had abnormal tests reflecting bronchial hyperactivity. Two of the five reported no respiratory symptoms, excluding the diagnosis of clinical asthma.

- All 60 participants who took the blood test had evidence of being exposed to green coffee beans by their immunoglobulin G levels; 22 participants had high levels of total immunoglobulin E; one participant had specific immunoglobulin E to coffee or green coffee beans, and one participant had specific immunoglobin $\mathrm{E}$ to castor beans.

- Of 13 former employees, five reported physician-diagnosed obliterative bronchiolitis, a serious, often disabling lung disease; all five had abnormal spirometry that was not reversible with bronchodilator. Another former employee had elevated total immunoglobulin $\mathrm{E}$ and specific immunoglobulin $\mathrm{E}$ to green coffee, coffee, and caster bean allergens.

- The company started a medical surveillance program; NIOSH reviewed company spirometry and found it to be of good quality. 
- Of 27 employees tested by NIOSH who also had a company-provided spirometry test, one had a drop in FEV1 greater than 15\% after expected loss due to aging.

- Of 23 employees who did not have NIOSH spirometry testing but had two companyprovided spirometry tests, none had excessive drops in FEV1 or FVC.

\section{What the Employer Can Do}

- Ensure employees understand potential hazards (e.g., diacetyl, 2,3-pentanedione, carbon monoxide, carbon dioxide, green and roasted coffee dust) in the workplace and how to protect themselves.

- Continue working with a qualified ventilation contractor to improve existing local exhaust ventilation systems and install additional systems targeted at specific points along production lines to capture alpha-diketones at their source.

- Increase the amount of outdoor air supplied to areas where local exhaust ventilation is not feasible or cannot reduce concentrations below NIOSH recommended exposure limits. Ensure that outdoor air is supplied from an area free of contamination from existing exhaust systems.

- Modify existing ventilation systems serving the production offices, breakroom and locker rooms to ensure that no air from the production area is recirculated into those areas.

- Conduct follow-up air sampling to verify that any modifications made were effective in reducing exposures to below the recommended exposure limits.

- Eliminate the use of compressed air as much as possible during cleaning. Instead, use a vacuum system with a high-efficiency particle air filter and wet methods whenever possible.

- Until engineering and administrative controls are in place, respiratory protection for diacetyl and 2,3-pentanedione should continue to be used to reduce exposures to alphadiketones. The choice of respirator should be guided by personal exposure sampling for diacetyl and 2,3-pentanedione.

- Ensure employees required to use respiratory protection receive an annual medical evaluation, training, and fit testing, along with all other elements of a written respiratory protection program as required by the Occupational Safety and Health Administration Respiratory Protection Standard (29 Code of Federal Regulations part 1910.134).

- Continue to make N95 disposable filtering facepiece respirators available for voluntary use for protection against dust exposure.

- Encourage employees to report new, worsening, or ongoing respiratory symptoms to their healthcare providers and to a designated individual at the workplace.

- Maintain the medical surveillance program for employees who work in the production area. 


\section{What Employees Can Do}

- Use any local exhaust ventilation as instructed by your employer.

- Use respirators when required according to your employer's written respiratory protection program as required by the Occupational Safety and Health Administration Respiratory Protection Standard (29 Code of Federal Regulations part 1910.134).

- Some employees may wish to use N95 disposable filtering facepiece respirators when emptying burlap bags of green beans into the roaster dump stations, cleaning the roaster exhaust system of chaff, when emptying the chaff containers, or cleaning the green bean storage area.

- Report new, persistent, or worsening respiratory symptoms to your healthcare providers and a designated individual at your workplace.

- Participate in your employer's surveillance program.

- Report new, persistent, or worsening respiratory symptoms to your personal healthcare provider(s) and, as instructed, to a designated individual at your workplace.

- Participate in your employer's medical monitoring program as instructed by your employer. 
This page left intentionally blank 


\section{Abbreviations}

\begin{tabular}{|c|c|}
\hline$\mu \mathrm{m}$ & Micrometer \\
\hline$\mu g$ & Microgram \\
\hline$\mu \mathrm{g} / \mathrm{cc}$ & Microgram per cubic centimeter \\
\hline${ }^{\circ} \mathrm{F}$ & degrees Fahrenheit \\
\hline $\mathrm{ACGIH}^{\circledR}$ & American Conference of Governmental Industrial Hygienists \\
\hline APF & Assigned protection factor \\
\hline BMI & Body mass index \\
\hline $\mathrm{cfm}$ & Cubic feet per minute \\
\hline CFR & Code of Federal Regulations \\
\hline $\mathrm{CO}$ & Carbon monoxide \\
\hline $\mathrm{CO}_{2}$ & Carbon dioxide \\
\hline DLCO & Diffusing capacity of the lung for carbon monoxide \\
\hline FEV1 & 1-second forced expiratory volume \\
\hline FEF25-75 & Forced mid-expiratory flow \\
\hline FID & Flame ionization detector \\
\hline $\mathrm{FVC}$ & Forced vital capacity \\
\hline $\mathrm{GC}$ & Gas chromatograph \\
\hline IDLH & Immediately dangerous to life or health \\
\hline $\operatorname{Ig}$ & Immunoglobulin \\
\hline IOM & Institute of Occupational Medicine \\
\hline $\mathrm{kU} / \mathrm{L}$ & Kilounits per liter \\
\hline $\mathrm{L}$ & Liter \\
\hline LEV & Local exhaust ventilation \\
\hline LPM & Liters per minute \\
\hline LOD & Limit of detection \\
\hline LOQ & Limit of quantitation \\
\hline $\mathrm{mgA} / \mathrm{L}$ & Milligrams of antigen specific-antibodies per liter \\
\hline $\mathrm{mg} / \mathrm{m}^{3}$ & Milligrams per cubic meter of air \\
\hline $\mathrm{mL}$ & Milliliter \\
\hline $\mathrm{mL} / \mathrm{min}$ & Milliliter per minute \\
\hline NHANES & National Health and Nutrition Examination Survey \\
\hline NIOSH & National Institute for Occupational Safety and Health \\
\hline OSHA & Occupational Safety and Health Administration \\
\hline PAPR & Powered air-purifying respirator \\
\hline PEL & Permissible exposure limit \\
\hline ppb & Parts per billion \\
\hline ppm & Parts per million \\
\hline $\mathrm{PVC}$ & Polyvinyl chloride \\
\hline REL & Recommended exposure limit \\
\hline RH & Relative humidity \\
\hline SDS & Safety data sheet \\
\hline SMR & Standardized morbidity ratio \\
\hline STEL & Short-term exposure limit \\
\hline TLV $^{\circledR}$ & Threshold limit value \\
\hline TVOC & Total volatile organic compound \\
\hline TWA & Time-weighted average \\
\hline $\mathrm{VOC}$ & Volatile organic compound \\
\hline
\end{tabular}




\section{Summary}

Physicians at a university medical center diagnosed obliterative bronchiolitis, a serious, often disabling lung disease, in five former employees of the coffee roasting, flavoring, and packaging facility. In April 2012, the National Institute for Occupational Safety and Health's Health Hazard Evaluation Program received a confidential employee request from a coffee roasting, flavoring, and packaging facility with approximately 85 employees. The requestors had concerns about respiratory symptoms, lung disease, and eye irritation related to the manufacturing of coffee products, including ingredients used in the flavoring process. In July/August 2012, we conducted an initial walkthrough site visit at the facility. In September 2012, we conducted a medical survey; we administered a questionnaire, performed breathing tests, and measured antibodies in blood. In November 2012, we conducted an industrial hygiene survey and ventilation assessment at the facility. The industrial hygiene survey consisted of collecting personal breathing zone and area air samples for alpha-diketones (i.e., diacetyl and 2,3-pentanedione) and dust. Bulk samples of whole bean green and roasted coffee, ground roasted coffee, and liquid flavorings were collected to evaluate the potential for emission of diacetyl and 2,3-pentanedione. We used continuous monitoring instruments to measure total volatile organic compounds, carbon monoxide, carbon dioxide, temperature, and relative humidity in specific areas and during tasks.

During the medical survey at the facility, the most commonly reported symptoms were eye and nose symptoms. Shortness of breath was the most commonly reported lower respiratory symptom followed by chest wheezing or whistling, trouble breathing, and cough. Current coffee plant employees had a 2.7-fold excess of spirometric obstruction and 1.6-fold excess of shortness of breath compared to the U.S. population. Spending work time in the roasting room was associated with having trouble with breathing, wheeze, sinus symptoms, and burning eyes in the last 12 months. There were no significant associations between symptoms and currently spending work time in the flavoring room or grinding/packaging room. Five of 45 participants who completed the mannitol challenge test had abnormal tests reflecting bronchial hyperactivity; two of the five reported no respiratory symptoms, excluding a diagnosis of clinical asthma. All 60 participants who took the blood tests had evidence of being exposed to green coffee beans by their immunoglobulin G levels; 22 participants had high levels of total immunoglobulin E; one participant had specific immunoglobulin $\mathrm{E}$ to coffee or green coffee beans, and one participant had specific immunoglobulin $\mathrm{E}$ to castor beans. Of 13 former employees, five reported physician-diagnosed obliterative bronchiolitis; all five had abnormal spirometry. Another former employee had elevated total immunoglobulin E and abnormal specific immunoglobulin E to green coffee, coffee, and caster bean allergens.

During the November 2012 industrial hygiene survey, employees in the grinding/packaging area for unflavored coffee had the highest mean diacetyl exposures, with personal concentrations averaging 93 parts per billion (ppb). This area was under positive pressure with respect to flavored coffee production (mean personal diacetyl levels of $80 \mathrm{ppb}$ ).

The 2,3-pentanedione exposures were highest in the flavoring room with mean personal exposures of $122 \mathrm{ppb}$, followed by exposures in the unflavored coffee grinding/packaging 
area (53 ppb). Peak 15-minute airborne concentrations of 14,300 ppb diacetyl and 13,800 ppb 2,3-pentanedione were measured at a small open hatch in the lid of a hopper containing ground unflavored coffee on the mezzanine over the grinding/packaging area. Three out of the four bulk coffee flavorings tested had at least a factor of two higher 2,3-pentanedione than diacetyl headspace measurements. Six interim reports providing results and recommendations were sent to the company following the 2012 surveys.

To evaluate the process and ventilation changes made by the company in response to NIOSH recommendations, we conducted a second industrial hygiene survey and ventilation assessment in April 2017. We also reviewed the quality of spirometry tests performed by the company's medical surveillance provider and found the spirometry results to be of good quality. The industrial hygiene survey included the collection of general area and personal air and bulk samples for diacetyl, 2,3-pentanedione, and 2,3-hexanedione. We used continuous monitoring instruments to measure total volatile organic compounds, carbon monoxide, and carbon dioxide in specific areas and during specific work tasks. Source sampling results in November 2012 showed the storage bins on the packaging mezzanine had the highest concentrations of diacetyl and 2,3-pentanedione. As a result, the packaging mezzanine was enclosed and ventilated prior to our April 2017 survey. Overall, time-weighted average air concentrations of diacetyl and 2,3-pentanedione were consistently higher during our second industrial hygiene survey. In April 2017, the production volume was approximately $70 \%$ higher than our first visit which likely contributed to the higher concentrations measured in some areas. We identified jobs where some work tasks resulted in higher air concentrations of diacetyl and 2,3-pentanedione than other tasks. Specifically, grinding, weighing and packaging, and flavoring roasted coffee beans were associated with higher diacetyl and 2,3-pentanedione levels.

We recommend installing local exhaust and dilution ventilation and implementing administrative controls such as modification of work practices. Until engineering and administrative controls are in place, we recommend respiratory protection to reduce exposures to alpha-diketones. The choice of respirator should be guided by personal exposure sampling for diacetyl and 2,3-pentanedione. We also recommend continuing the medical surveillance program.

\section{Introduction}

In June 2012, the National Institute for Occupational Safety and Health (NIOSH) received a confidential employee request for a health hazard evaluation at a coffee roasting, flavoring, and packaging facility regarding concerns about respiratory symptoms, lung disease, and eye irritation related to the manufacturing of coffee products, including ingredients used in the flavoring process. In July/August 2012, we conducted a walkthrough visit at the facility. In September 2012, we conducted a medical survey that consisted of a medical and work history questionnaire, spirometry, administration of bronchodilator or mannitol challenge test, tests for carbon monoxide diffusing capacity and alveolar volume, and blood tests for immune responsiveness. In November 2012, we conducted a ventilation assessment and 
industrial hygiene survey. We collected area and personal breathing zone air samples for dust and volatile organic compounds (VOCs), including diacetyl and 2,3-pentanedione. In April 2017, we conducted a second ventilation assessment and industrial hygiene survey. During the 2017 visit, the total daily production volume at the plant was 70\% higher than in 2012 . We collected area and personal breathing zone air samples for VOCs, including diacetyl, 2,3-pentanedione, and 2,3-hexanedione. We also measured carbon monoxide (CO), carbon dioxide $\left(\mathrm{CO}_{2}\right)$, and total VOCs (TVOCs) in air using real-time instruments.

\section{Background}

Physicians at a university medical center diagnosed obliterative bronchiolitis, a serious, often disabling lung disease, in five individuals who had worked at a coffee roasting, grinding, flavoring, and packaging facility. In June 2012, employees at the facility requested a NIOSH health hazard evaluation.

\section{Diacetyl and 2,3-Pentanedione}

Diacetyl (2,3-butanedione) and 2,3-pentanedione (acetyl propionyl) are VOCs known as alpha-diketones that are added as ingredients in food flavorings used in some food products such as microwave popcorn, bakery mixes, and flavored coffee [Kanwal et al. 2006; Martyny et al. 2008; Day et al. 2011; LeBouf et al. 2019; Harvey et al. 2020]. Diacetyl, 2,3-pentanedione, other VOCs, and gases such as $\mathrm{CO}$ and $\mathrm{CO}_{2}$ are naturally produced and released during the coffee roasting process [Raffel and Thompson 2013; Daglia et al. 2007; Nishimura et al. 2003; Newton 2002]. Grinding roasted coffee beans produces a greater surface area for off-gassing (sometimes called degassing) of these compounds [Akiyama et al. 2003]. Often, coffee roasting facilities package newly roasted coffee in permeable bags or in bags fitted with one-way valves to allow the coffee to off-gas after it is packaged. Sometimes, newly roasted coffee is placed in bins or containers and allowed to off-gas before packaging.

NIOSH has recommended exposure limits (RELs) for diacetyl and 2,3-pentanedione in workplace air (Table 1) [NIOSH 2016a]. The NIOSH objective in establishing RELs for diacetyl and 2,3-pentanedione is to reduce the risk of respiratory impairment (decreased lung function) and the severe irreversible lung disease obliterative bronchiolitis associated with occupational exposure to these chemicals. The NIOSH RELs are intended to protect workers exposed to diacetyl or 2,3-pentanedione for a 45-year working lifetime. The REL for diacetyl is based on a quantitative risk assessment which necessarily contains assumptions and some uncertainty. Analytical limitations current at the time were taken into consideration in setting the REL for 2,3-pentanedione. The RELs should be used as a guideline to indicate when steps should be taken to reduce exposures in the workplace.

These exposure limits and the accompanying recommendations for control of exposures were derived from a risk assessment of flavoring-exposed workers. At an exposure equal to the diacetyl REL, the risk of adverse health effects is low. NIOSH estimated that less than 1 in 1,000 workers exposed to diacetyl levels of 5 parts per billion (ppb) as a time-weighted 
average (TWA) for 8 hours a day, 40 hours a week for a 45-year working lifetime would develop reduced lung function (defined as forced expiratory volume in one second [FEV1] below the lower limit of normal) as a result of that exposure. NIOSH predicted that around 1 in 10,000 workers exposed to diacetyl at 5 ppb for a 45-year working lifetime would develop more severe lung function reduction (FEV1 below $60 \%$ predicted, defined as at least moderately severe by the American Thoracic Society [Pellegrino et al. 2005]). Workers exposed for less time would be at lower risk for adverse lung effects.

\section{2,3-Hexanedione}

2,3-Hexanedione is also an alpha-diketone sometimes used as a substitute for diacetyl and is produced naturally during coffee roasting. In a study using animals, there was some evidence that 2,3-hexanedione might also damage the lungs, but it appeared to be less toxic than diacetyl and 2,3-pentanedione [Morgan et al. 2016]. There are no established occupational exposure limits for 2,3-hexanedione.

\section{Carbon Monoxide and Carbon Dioxide}

$\mathrm{CO}$ and $\mathrm{CO}_{2}$ are gases produced by combustion. They are also produced as a result of reactions that take place during coffee roasting. These gases are released during and after roasting and grinding by a process called off-gassing [Anderson et al. 2003; Hawley et al. 2017; LeBouf et al. 2018]. High exposures to $\mathrm{CO}$ and $\mathrm{CO}_{2}$ can cause headache, dizziness, fatigue, nausea, confusion, rapid breathing, impaired consciousness, coma, and death [Newton 2002; Nishimura et al. 2003; Langford 2005; CDC 2018; Raffel and Thompson 2013; Rose et al. 2017]. Occupational exposure limits for $\mathrm{CO}$ and $\mathrm{CO}_{2}$ are listed in Table 1.

\section{Inhalable Dust}

Dust refers to the particles present in air, either from natural forces or from mechanical processes. Inhalable dust includes particles of various sizes. Some of the particles may be too large to enter the deepest areas of the lungs but can enter the nose, mouth, and upper airways during breathing. Occupational exposure limits for inhalable dust are listed in Table 1.

\section{Exposure Limits}

We utilize mandatory (legally enforceable) and recommended occupational exposure limits when evaluating workplace hazards. Occupational exposure limits are developed by federal agencies and safety and health organizations to prevent adverse health effects from workplace exposures.

\section{Occupational Safety and Health Administration (OSHA) [Mandatory]}

The U.S. Department of Labor's OSHA permissible exposure limits (PELs) are legal limits that are enforceable in workplaces covered under the Occupational Safety and Health Act. OSHA PELs represent the legal maximum for a TWA exposure to a physical or chemical agent over a work shift [OSHA 2019]. OSHA short-term exposure limits (STELs) are the legal maximum average exposure for a 15-minute time period. Some chemicals also have an OSHA ceiling value which represent levels that must not be exceeded at any time. Currently, there are no PELs for diacetyl, 2,3-pentanedione, or 2,3-hexanedione. For substances for which an OSHA PEL has not been issued, violation of the OSHA General Duty Clause can be considered using available 
occupational exposure references and recommendations [OSHA 1993; OSHA 2003], such as the American Conference of Governmental Industrial Hygienists $\left(\mathrm{ACGIH}^{\circledR}\right)$ Threshold Limit Values $\left(\mathrm{TLVs}^{\circledR}\right)$ and NIOSH RELs.

American Conference of Governmental Industrial Hygienists (ACGIH) [Recommended] ACGIH is a professional, not-for-profit scientific association that reviews existing published, peer-reviewed scientific literature and publishes recommendations for levels of substances in air based on an 8-hour workday and 40-hour workweek. These recommendations are called TLVs [ACGIH 2019]. ACGIH TLVs are not standards; they are health-based guidelines derived from scientific and toxicological information. ACGIH provides TLV-TWA guidelines that are levels that should not be exceeded during any 8-hour workday of a 40hour workweek. ACGIH also provides TLV-STEL guidelines which are 15-minute exposure levels that should not be exceeded during a workday. Exposures above the TLV-TWA but less than the TLV-STEL should be (1) less than 15 minutes, (2) occur no more than four times a day, and (3) be at least 60 minutes between exposures [ACGIH 2019]. Additionally, ACGIH provides TLV-Ceiling values which are levels that should not be exceeded at any time during a work shift. The ACGIH TLV-TWA for diacetyl is $10 \mathrm{ppb}$. The TLV-STEL for diacetyl is 20 ppb. Currently, there is no TLV-TWA or TLV-STEL for 2,3-pentanedione.

\section{National Institute for Occupational Safety and Health (NIOSH) [Recommended]}

For NIOSH RELs, TWA indicates a time-weighted average concentration for up to a 10-hour workday during a 40-hour workweek

NIOSH provides RELs as TWA concentrations that should not be exceeded over an 8 or 10-hour work shift, during a 40-hour workweek [NIOSH 2016a, 2016b]. RELs are intended to be protective over a 45-year working lifetime. NIOSH also provides STELs which are 15-minute TWA exposures that should not be exceeded at any time during a workday [NIOSH 2016b]. Some chemicals have ceiling values which are concentrations that should not be exceeded at any time [NIOSH 2016b]. For some chemicals, NIOSH has established an Immediately Dangerous to Life or Health (IDLH) value. An IDLH value is a concentration of an air contaminant that can cause death or immediate or delayed permanent adverse health effects, or prevent escape from such an environment. Currently, NIOSH has RELs and STELs for diacetyl and 2,3-pentanedione [NIOSH 2016a]. NIOSH does not have a REL or a STEL for 2,3-hexanedione. NIOSH does not have ceiling limits or IDLH values for diacetyl, 2,3-pentanedione, or 2,3-hexanedione.

For diacetyl and 2,3-pentanedione, the NIOSH RELs are $5.0 \mathrm{ppb}$ and $9.3 \mathrm{ppb}$, respectively, as a TWA for up to an 8-hour workday during a 40-hour workweek (Table 1). The NIOSH STELs are $25 \mathrm{ppb}$ for diacetyl and $31 \mathrm{ppb}$ for 2,3-pentanedione [NIOSH 2016b]. The NIOSH exposure limits do not differentiate between natural and synthetic chemical origin of diacetyl or 2,3-pentanedione. Although the NIOSH exposure limit for 2,3-pentanedione is above that of diacetyl, 2,3-pentanedione has been shown to be as hazardous as diacetyl [Hubbs et al. 2012; Morgan et al. 2012]. The hazard potential probably increases when these chemicals occur in combination with each other; having exposure to chemicals with the same functional alpha-diketone group and effect on the same system or organ (e.g., lungs) can result in 
additive effects [ACGIH 2019]. The NIOSH REL is higher for 2,3-pentanedione than for diacetyl largely because analytic measures were not available in a validated OSHA method to detect 2,3-pentanedione at lower levels. In addition to the REL, NIOSH also recommends an action level for diacetyl of $2.6 \mathrm{ppb}$ to be used with exposure monitoring in an effort to ensure employee exposures are routinely below the diacetyl REL. When exposures exceed the action level, employers should take corrective action (i.e., determine the source of exposure, identify methods for controlling exposure) to ensure that exposures are maintained below the NIOSH REL for diacetyl [NIOSH 2016a].

Table 1. Personal exposure limits for compounds sampled during NIOSH industrial hygiene surveys, November 2012 and April 2017

\begin{tabular}{|l|c|c|c|c|c|c|}
\hline \multirow{2}{*}{ Compound } & OSHA* & \multicolumn{2}{c|}{ ACGIH } & \multicolumn{3}{c|}{ NIOSH } \\
\cline { 2 - 7 } & PEL & TLV & STEL & REL & STEL & IDLH \\
\hline Diacetyl & - & $10 \mathrm{ppb}$ & $20 \mathrm{ppb}$ & $5.0 \mathrm{ppb} \dagger$ & $25 \mathrm{ppb}$ & - \\
\hline 2,3-Pentanedione & - & - & - & $9.3 \mathrm{ppb} \dagger$ & $31 \mathrm{ppb}$ & - \\
\hline 2,3-Hexanedione & - & - & - & - & - & - \\
\hline Inhalable dust & - & $10 \mathrm{mg} / \mathrm{m}^{3}+$ & - & - & - & - \\
\hline Carbon dioxide $\S$ & $5,000 \mathrm{ppm}$ & $5,000 \mathrm{ppm}$ & $30,000 \mathrm{ppm}$ & $5,000 \mathrm{ppm}$ & $30,000 \mathrm{ppm}$ & $40,000 \mathrm{ppm}$ \\
\hline Carbon monoxide $\S$ & $50 \mathrm{ppm}$ & $25 \mathrm{ppm}$ & - & $35 \mathrm{ppm}$ & $\begin{array}{c}200 \mathrm{ppm} \\
\text { (ceiling limit) }\end{array}$ & \begin{tabular}{l}
$1,200 \mathrm{ppm}$ \\
\hline
\end{tabular} \\
\hline
\end{tabular}

Note: OSHA=Occupational Safety and Health Administration; ACGIH=American Conference of Governmental Industrial Hygienists; NIOSH=National Institute for Occupational Safety and Health; PEL=permissible exposure limit; $T L V=$ threshold limit value; $S T E L=$ short-term exposure limit; $R E L=$ recommended exposure limit; IDLH=immediately dangerous to life or health; $\mathbf{m g} / \mathbf{m}^{3}=$ milligram per cubic meter; $\mathbf{p p b}=$ parts per billion; $\mathbf{p p m}=$ parts per million; "_" $=$ no exposure limit available.

*There are no OSHA STELs for the compounds in the table.

$\dagger$ The NIOSH RELs for diacetyl and 2,3-pentanedione are time-weighted averages for up to an 8-hour day, during a 40-hour workweek.

†ACGIH does not have a TLV for inhalable dust but does provide guidelines for total dust; ACGIH guidelines suggests airborne concentrations be kept below $10 \mathrm{mg} / \mathrm{m}^{3}$.

§OSHA and NIOSH limits are designed for occupational exposure measurements in manufacturing and other trades that have potential sources of carbon dioxide or carbon monoxide (e.g., coffee roasting, welding, vehicle exhaust, diesel engine exhaust). Typical levels of carbon monoxide in offices are 0-5 ppm. In office settings, carbon dioxide generally should not be greater than $700 \mathrm{ppm}$ above outdoor carbon dioxide levels; this typically corresponds to indoor concentrations below 1200 ppm.

qThis is the NIOSH ceiling exposure limit for carbon monoxide. A ceiling concentration should not be exceeded at any time.

\section{Obliterative Bronchiolitis}

Obliterative bronchiolitis is a serious, often disabling, lung disease that involves scarring of the very small airways (i.e., bronchioles). Symptoms of this disease may include cough, shortness of breath on exertion, or wheeze, that do not typically improve away from work [NIOSH 2012]. Occupational obliterative bronchiolitis has been identified in flavoring manufacturing workers, microwave popcorn workers, and coffee roasting and packaging workers who worked with flavoring chemicals or butter flavorings [Kreiss 2013; Kim et al. 2010; Kanwal et al. 2006; Harvey et al. 2018, 2020]. Recently, obliterative bronchiolitis was reported in an individual in India who had worked for 20 years in a coffee facility that roasted and ground coffee; he quit after developing respiratory symptoms [Chetambath et al. 2020]. 


\section{Work-related Asthma}

Work-related asthma refers to asthma that is brought on by ("occupational asthma") or made worse by ("work-exacerbated asthma" or "work-aggravated asthma") workplace exposures [NIOSH 2017; Tarlo 2016; Tarlo and Lemiere 2014; OSHA 2014; Henneberger et al. 2011]. Work-related asthma includes asthma due to sensitizers, which cause disease through immune (allergic) mechanisms, and asthma due to irritants, which cause disease through non-immune mechanisms. Symptoms of work-related asthma include episodic shortness of breath, cough, wheeze, and chest tightness. The symptoms may begin early in a work shift, towards the end of a shift, or hours after a shift. They generally, but do not always, improve or remit during periods away from work, such as on weekends or holidays.

Green and roasted coffee dust and castor beans (from cross-contamination of bags used to transport coffee) are known risk factors for occupational asthma [Figley and Rawling 1950; Karr et al. 1978; Zuskin et al. 1979, 1985; Thomas et al. 1991]. Persons who become sensitized (develop an immune reaction) to coffee dust can subsequently react to relatively low concentrations in the air. Others may experience irritant-type symptoms from exposure to coffee dust [Oldenburg et al. 2009].

\section{Facility and Process Description}

\section{Facility and Workforce}

At the time of the initial NIOSH walkthrough in July/August 2012, the plant had approximately 85 employees that produced flavored and unflavored whole bean and ground roasted coffee and packaged some tea, largely for commercial consumers. The roasting facility opened in its current location in May 2003. It consisted of a two-story office space directly attached to a one-story steel industrial-style building that contained the production operations within several rooms. Most production area rooms (warehouse, roasting room, packaging/grinding room, hold room, production support corridor) were not completely isolated, as walls did not always extend to the ceiling, and large curtained openings between the spaces existed to facilitate forklift traffic. The flavoring room was isolated with walls to the ceiling and had a 0.12-gauge polyvinyl chloride (PVC) ribbed strip curtain door separating it from unflavored coffee production. The flavoring room was kept under negative air pressure with respect to the other production areas, to prevent contamination of unflavored coffee with flavorings. The employees worked day and evening shifts that sometimes overlapped, depending on job responsibilities. Most employees worked 8-hour shifts; however, sometimes employees in the flavoring room worked 12-hour shifts, three or four days per week, and others worked overtime hours depending on the orders for that week.

\section{Warehouse}

The warehouse was separated into finished goods and greens (green coffee bean storage) areas by a wall with two breezeways at each end. Loading docks with overhead doors were located on the back wall of the warehouse. Green coffee beans were delivered in burlap bags to the facility by trucks. In April 2017, we were told the production volumes had increased substantially. The amount of green coffee beans stored in the greens warehouse had increased noticeably. 
Employees known as greens unloaders transferred the bags onto pallets, which were then moved and stacked in the greens warehouse via forklifts. When the green coffee beans were needed for processing, material handlers moved the pallets and placed them at the dumping station for each roasting line.

Material handlers also moved palletized finished goods by forklift through PVC ribbed strip curtain doorways from the grinding/packaging room and the flavoring room into the finished goods warehouse. The finished goods warehouse had a small shipping and receiving office in the back corner near the overhead doors where truck drivers took delivery of finished goods. There was also an area where small orders were packaged for mail shipment.

\section{Roasting Room}

Employees known as greens dumpers emptied burlap bags of green coffee beans into hoppers in the floor. The beans were then automatically fed into a perforated cylinder within a large gas-fired coffee roaster. Employees known as roasters stood nearby to monitor the process, including listening for the "first crack" and checking for the proper color and smell of roasted beans. Throughout their shift, roasters took samples of roasted coffee beans to the quality control room. In the quality control room, roasters ground the beans and used an instrument to evaluate the color of the roasted coffee.

When the roasting process was completed, beans were emptied into a large cooling bin to cool; they were automatically stirred and aerated to ensure even cooling. Afterward, the roasted beans were transferred by a bucket elevator system to large hoppers on a mezzanine above the packaging lines in the grinding/packaging room or to hoppers on the mezzanine in the flavoring room. The roasting room was separated from the grinding/packaging room by a PVC ribbed strip curtain doorway. Roasters and dumpers used brooms and compressed air to clean their work areas.

\section{Grinding/Packaging Room - Unflavored Coffee}

The grinding/packaging room consisted of six packaging lines for unflavored coffee, a mezzanine above the lines with hoppers for unflavored whole beans and ground coffee, a tea machine and associated mezzanine, and a hand packing station. Whole coffee beans delivered from the roasting room were stored in the mezzanine bean hoppers until they were ready to be ground or packed on the lines below. For ground coffee, the beans dropped into one of two grinding machines, after which it was sent up to the mezzanine ground coffee hoppers. Ground or whole coffee was placed in bags with exhaust valves to off-gas $\mathrm{CO}_{2}$ and volatiles. Coffee to be packed in non-valved bags required a 12-hour off-gassing period in the mezzanine hoppers prior to packaging.

When ready to be bagged, whole coffee beans or ground coffee dropped to one of the six packaging machines that filled bags and placed them on a conveyer belt. The grinding and packaging machine operators frequently climbed the mezzanine stairs to inspect hopper material levels and dislodge material. Packers and helpers placed cardboard boxes at the end of the conveyer belt to place bagged coffee in boxes. A material handler transported the pallets using a forklift to the finished goods warehouse. 
A tea machine operator ran the equipment that filled bags with tea, and then boxed them. The tea arrived fully-processed at the plant, where it was essentially repackaged from large sacks to smaller bags for customers.

At the hand packing station, employees known as hand packers completed small batch orders, such as those from small coffee shops or online customers, by manually filling and labeling bags. The hand packers also worked alongside the packaging lines to perform rework, where coffee with faulty packaging was manually redirected into the packaging process to be packed correctly, including reloading it into the hoppers on the mezzanine. Besides unflavored coffee, these employees handled some flavored coffee at the hand packing station in the grinding/packaging room or in the adjacent hold room for rework.

In April 2017, the grinding/packaging room was largely the same as in 2012 with six packaging lines and two grinders; however, a corner-seal packaging line had been installed in the hold room and a Super Sack filling station was installed in the main packaging area near the entrance to the finished good warehouse. Additionally, an enclosed grinder feeding two lines had been replaced with a new unenclosed, sealed grinder that fed those packaging lines and the Super Sack filling station. The most significant modification made to the facility since November 2012 was the enclosure of the entire mezzanine level of the grinding/packaging room; it was separate from the other production spaces. Two new supply air ducts were added along the south wall; each duct had two openings, one high and one low. Two exhaust fans for the space were located in the roof near the northern end of the space.

\section{Flavored Coffee Production Room}

During our initial walkthrough in July/August 2012, flavoring occurred in small batches. Initially, freshly roasted coffee beans sat overnight to off-gas. The next day a mixer or flavor specialist scooped whole roasted coffee beans from a hopper into a bin on wheels and transported it to one of two flavor mixing stations. A mixer ran a flavoring station used to make hazelnut coffee, and a flavor specialist ran the other mixing station which made smaller batches of flavored coffee including cinnamon twist, cinnamon bun, cinnamon almond macaroon, blueberry cobbler, butter pecan, butterscotch, butter toffee, coconut cream, Swiss chocolate almond, white chocolate mousse, eggnog, gingerbread snap, hazelnut, French caramel cream, French vanilla, Irish cream, praline \& cream, pumpkin, spiced butter rum, and others.

At each mixing station, the mixer or flavor specialist scooped roasted coffee beans into open barrels mounted on a rotating rack. The mixer or flavor specialist then weighed the liquid flavoring on a small scale on an open bench top. Some flavorings were stored in the flavoring room in large barrels and pumped into one-gallon containers. Most flavorings were stored in three to five-gallon containers.

After a flavoring was weighed, the mixer or flavor specialist carried the open container to a mixing station and poured the flavoring into one of the rotating barrels of roasted coffee beans and repeated this process until all coffee beans were flavored. The employee stood nearby to monitor the process, break up clumps of coffee, and make sure the flavoring was 
evenly distributed. When mixing was complete, they manually emptied the barrels into large storage containers on wheels. The employee repeated this process until the ordered amount of flavored coffee had been completed; for the larger orders, this process was repeated for the duration of the shift. After the coffee beans were flavored, they were manually dumped into an opening in the floor to be transported via an enclosed bucket elevator to a hopper on the flavoring mezzanine for a 12-hour off-gassing period before grinding or packaging. After the beans were ground, they were transported back up to a hopper on the mezzanine for an additional 12-hour off-gassing before packaging.

When ready to be bagged, the flavored whole bean or ground coffee dropped to one of two packaging machines in the flavoring room that filled bags and placed them on a conveyer belt. Flavored coffee was packaged in non-valved bags so that the flavoring did not contaminate other coffee. Packers and helpers placed cardboard boxes at the end of the packaging lines to catch bags from the conveyer belt. Once full, they taped the cardboard box tops and stacked the boxes on pallets. Using a forklift, a material handler transported the pallets to the finished products warehouse. Occasionally, hand packers manually packed small orders of flavored coffee and performed re-works where coffee with faulty packaging was manually redirected into the packaging process.

In August 2012, the company changed the layout of the flavoring room. Small batches of flavored coffee continued to be prepared as previously described, while processing of larger batches of hazelnut coffee became more automated. In this new process, the coffee was roasted and ground with no off-gas periods afterwards, and then the ground coffee was flavored in a large batch automated mixer that pumped the flavoring from a carboy next to the machine and injected it directly onto the ground coffee. The flavored coffee was then transported up to the mezzanine via an enclosed bucket elevator to a hopper for a 12-hour off-gassing prior to packaging. The manual tasks included dumping the beans into an opening in the floor to be ground and filling the carboy with the appropriate flavoring.

In April 2017, the layout of the flavoring room and the associated local exhaust ventilation systems were fundamentally the same as in November 2012.

\section{Quality Control Room}

Quality control technicians performed quality checks on the coffee during all steps of the production process. The quality control room equipment included a sieve shaker, scales, small grinders, stovetop, small roasting machine, coffee brewers, water tank, and a machine to test bags for valve integrity. Throughout their shift, quality control technicians intermittently left the quality control room for minutes at a time to go to other parts of the plant (such as the greens warehouse, grinding/packaging room, and flavoring room) to retrieve samples of coffee for quality checks. Throughout the day, quality control technicians performed a procedure called cupping. Cupping is a systematic method for investigating the nature of green coffee beans and includes smelling and inspecting the green coffee beans, roasting and grinding samples, smelling during the roasting and grinding, testing the aroma, and tasting the coffee. 
For flavored coffee, quality control technicians performed some quality checks, including opening flavored coffee bags, weighing the coffee on a scale, and brewing and tasting the coffee. These activities were done in the break room (located in the production support office area) instead of the quality control room, to prevent contaminating the non-flavored coffee.

\section{Maintenance Rooms}

Adjacent to the roasting room and separated by a 3/4-height wall was a maintenance shop where mechanical and welding work was performed. Additionally, a small maintenance room was located behind the maintenance supervisor's office in the production support office area.

\section{Offices}

The non-production offices were located in a two-story section of the building near the reception entrance to the plant. Several production support offices were located within the larger production area, adjacent to the grinding and packaging operation for unflavored coffee. The production support offices were typical room height while the grinding/packaging room averaged over 30 feet tall. Between the quality control room and reception area was a room used to train staff and demonstrate coffee brewing equipment and company coffee products to customers.

\section{Worker Mobility}

Many employees did not spend all their time in their company-designated department (e.g., nonproduction offices, production support offices, warehouse, roasting room, grinding/ packaging room, flavoring room, quality control room) since their job duties entailed spending time in various areas of the plant. For example, the plant manager, production supervisors, and maintenance staff often entered multiple areas of the plant. Material handling and inventory staff entered the production areas to move things or check inventory. The housekeeper cleaned nonproduction offices, the production support areas, and the warehouse office. Quality control technicians obtained samples in the warehouse, grinding/ packaging room, and flavoring room or dealt with paperwork in different areas of the plant. Some nonproduction office employees reported giving tours of the entire plant or entering the different production or production support areas to check paperwork or get questions answered. Some participants reported helping in other departments, for example, with reworks or hand packing in the flavoring room or operating the packaging machines in the grinding/packaging room or flavoring room.

\section{Cleaning Activities}

In November 2012, various cleaning techniques were used throughout the production areas. Employees used brooms to sweep the production floor, wet or dry wipes on table tops and equipment surfaces, and compressed air to remove coffee bean dust from surfaces and equipment. The facility had a wash station equipped with a commercial dishwasher that washed buckets and containers for reuse. In response to a NIOSH recommendation after the 2012 visit, the facility reduced the use of compressed air for cleaning and placed industrial vacuums throughout the production spaces for use in cleaning tasks. 
In April 2017, wet/dry vacuum cleaners (Dayton Model 135020) were stationed along beams throughout the production area for cleaning to limit the use of compressed air. Despite the addition of the vacuums, many cleaning tasks were still observed to be completed using brooms, dust mops, or compressed air.

\section{Personal Protective Equipment}

Employees in the production areas wore steel toe shoes, safety glasses/goggles, companyprovided uniforms, hair covers, and beard covers (if applicable). Hearing protection (foam ear plugs) was available but not required. Mixers and flavor specialists wore rubber aprons, gloves and face shields when measuring or pouring flavorings. They also wore face shields at the time of the NIOSH walkthrough and medical survey.

At the NIOSH initial walkthrough in July/August 2012, N95 filtering facepiece respirators were available but not required. At the NIOSH medical survey in September 2012, the flavoring specialists and mixers sometimes wore half-mask respirators with organic vapor/particulate cartridges in the flavoring room. N95 filtering facepiece respirators (for particulates but not organic vapors) were available but not required for other staff. At the time of the NIOSH industrial hygiene survey in November 2012, individuals who worked in the flavoring room or entered the flavoring room wore full-face powered air-purifying respirators (PAPRs) with an assigned protection factor (APF) of 1000 and NIOSH-certified organic vapor/particulate cartridges. N95 filtering facepiece respirators were available but not required in other production areas.

During our April 2017 visit, employees were required to wear a half-face air-purifying respirators with NIOSH-certified organic vapor/particulate cartridges in the flavoring room, packaging room mezzanine, while filling the hopper on the corner-seal packaging machine, when working inside grinder enclosures, and when doing rework activities.

\section{Methods}

We conducted an initial walkthrough at the coffee roasting, flavoring, and packaging facility in July/August 2012. We returned for a medical survey in September 2012. In November 2012 and April 2017, we conducted industrial hygiene surveys and ventilation assessments. We had the following objectives for the health hazard evaluation:

1. Measure employees' exposure to diacetyl, 2,3-pentanedione, and 2,3-hexanedione during coffee processing;

2. Identify process areas or work tasks associated with emissions of diacetyl, 2,3-pentanedione, and 2,3-hexanedione;

3. Measure levels of TVOCs, $\mathrm{CO}, \mathrm{CO}_{2}$, and inhalable dust throughout the facility;

4. Assess ventilation systems and their effect on exposure levels;

5. Determine if employees had mucous membrane, respiratory, or systemic symptoms and the proportion of those symptoms that were work-related or aggravated by work; 
6. Determine if employees had abnormal lung function;

7. Determine total and specific Immunoglobulin $\mathrm{E}$ and $\mathrm{G}$;

8. Compare employees' prevalence of lower respiratory symptoms and healthcare provider-diagnosed asthma to expected levels based on general population values.

9. Evaluate company-provided spirometry and assess changes in lung function over time.

We provided seven interim reports with recommendations to the company following our visits.

\section{Initial Walkthrough}

We held an opening and closing meeting with management and employees, toured the facility, collected bulk samples of flavorings and evacuated canister air samples, and had informal interviews with employees.

\section{Industrial Hygiene Surveys}

\section{Sampling Times for Alpha-Diketones}

We designed the sampling strategy to assess full-shift exposures and to identify tasks and processes that were the greatest contributors to employee exposure to alpha-diketones. For diacetyl, 2,3-pentanedione, and 2,3-hexanedione, air samples were collected over seconds, minutes, and hours. Samples collected over hours can help determine average concentrations that can be compared to the NIOSH RELs for diacetyl and 2,3-pentanedione. These average concentrations might not tell us about short-term peak exposures that could be relevant to respiratory health, particularly when tasks are repeated multiple times per day. Therefore, during certain tasks, we collected air samples over several minutes. We also conducted instantaneous sampling over seconds to help identify point sources of alpha-diketones.

\section{Air Sampling and Analysis Using Modified Occupational Safety and Health Administration (OSHA) Methods}

There are three validated OSHA Analytical Methods used to analyze samples for alphadiketones in air. OSHA Method 1013 is used for determining low parts per million (ppm) concentrations of diacetyl [OSHA 2008a]. In response to the need for longer sampling time periods with a lower limit of detection or reliable quantitation limit, OSHA Method 1012 was validated for parts per billion (ppb) concentrations of diacetyl [OSHA 2008b]. OSHA Method 1016 is used to measure 2,3-pentanedione concentrations [OSHA 2010].

We collected personal and area air samples for diacetyl and 2,3-pentanedione on silica gel sorbent tubes during both industrial hygiene surveys over multiple days. April 2017 samples were also analyzed for 2,3-hexanedione. The samples were collected and analyzed according to modified OSHA Methods 1013/1016 [OSHA 2008a; OSHA 2010; LeBouf and Simmons 2017]. In accordance with the two methods, two glass silica gel sorbent tubes were connected by a piece of tubing and inserted into a protective, light-blocking cover. The tubes were 
connected in series to a sampling pump pulling air through the tubes at a flow rate of 50 milliliters per minute ( $\mathrm{mL} / \mathrm{min})$. The sampling setup was attached to an employee's breathing zone or placed in an area basket in locations throughout the facility. For full-shift sampling, we collected two consecutive 3-hour samples and calculated the TWA concentration from the two samples, assuming that the total 6-hour monitoring results reflected a full work shift (8hour) TWA exposure. This is a more conservative approach than the alternative assumption of no exposure during the last two hours of the shift. We refer to these samples as "full-shift samples" throughout this report. We also collected short-term, task-based samples in the same manner with a sampling pump flow rate of $200 \mathrm{~mL} / \mathrm{min}$, as detailed in OSHA Methods 1013/1016 [OSHA 2008a; 2010].

Samples from the first industrial hygiene survey (November 2012) were analyzed by Bureau Veritas North America (BVNA; Novi, MI). The samples were chemically desorbed using two milliliters $(\mathrm{mL})$ of $95 \%$ ethanol:5\% water (ACS spectrophotometric grade), shaken for 60 minutes, and subsequently analyzed using an HP 5890 gas chromatograph with a flame ionization detector (GC/FID) (Agilent Technologies, Inc.). The sample extracts were subsequently derivatized according to a modified OSHA Method 1012 to increase sensitivity [OSHA 2008b]. The derivatized extracts were analyzed using an HP 5890 GC with an electron capture detector (GC/ECD) (Agilent Technologies, Inc.). For the November 2012 visit, we reported results from the validated method with the greatest sensitivity: OSHA Method 1012 for diacetyl and OSHA Method 1016 for 2,3-pentanedione.

Samples from the second industrial hygiene survey (April 2017) were analyzed in the NIOSH Respiratory Health Division's Organics Laboratory. The samples were extracted in 95\% ethanol:5\% water containing 3-pentanone as an internal standard, shaken for 60 minutes, and subsequently analyzed using an Agilent 7890/7001 GC/mass spectrometer (GC/MS) system. The mass spectrometer operated in selected ion monitoring mode for increased sensitivity compared to the traditional FID used in OSHA Methods 1013/1016 [LeBouf and Simmons 2017].

A limit of detection (LOD) is the lowest mass that an instrument can detect above background and is a criteria used to determine whether to report a result from a sample. The LODs decreased between the first and second visit. The LODs for the first industrial hygiene survey were 0.05 micrograms per sample ( $\mu \mathrm{g} /$ sample) for diacetyl (OSHA Method 1012) and $0.20 \mu \mathrm{g} / \mathrm{sample}$ for 2,3-pentanedione (OSHA Method 1016). These equate to $1.6 \mathrm{ppb}$ for diacetyl and $5.4 \mathrm{ppb}$ for 2,3-pentanedione for a typical full-shift TWA air sample but will vary depending on the volume of air collected during the sampling period.

The limit of quantitation (LOQ) is the lowest mass that can be reported with acceptable precision, and there is greater confidence in the reported result if it is above the LOQ. The LOQs for the first industrial hygiene survey were 0.18 micrograms per sample ( $\mu \mathrm{g} / \mathrm{sample})$ for diacetyl (OSHA Method 1012) and $0.63 \mu \mathrm{g} /$ sample for 2,3-pentanedione (OSHA Method 1016). These equate to $5.7 \mathrm{ppb}$ for diacetyl and $17.1 \mathrm{ppb}$ for 2,3-pentanedione for a typical full-shift TWA air sample but will vary depending on the volume of air collected during the sampling period. 
The LODs for the second industrial hygiene visit in April 2017 were $0.01 \mu \mathrm{g} / \mathrm{sample}$ for diacetyl, 2,3-pentanedione, and 2,3-hexanedione. These equate to $0.32 \mathrm{ppb}$ for diacetyl, 0.27 $\mathrm{ppb}$ for 2,3-pentanedione, and $0.24 \mathrm{ppb}$ for 2,3-hexanedione for a typical full-shift TWA air sample. The LOQs were $1.1 \mathrm{ppb}$ for diacetyl, 0.90 for 2,3-pentanedione, and $0.79 \mathrm{ppb}$ for 2,3-hexanedione.

The LODs for task samples are generally higher than typical LOD values for full-shift samples since the air volumes collected during task samples were lower. When the values presented in the report were from samples below the LOD they are denoted by a " $<$ " symbol.

\section{Air Sampling and Analysis Using Evacuated Canisters}

We collected personal and area air samples and instantaneous task-based and source air samples for VOCs, including diacetyl and 2,3-pentanedione using evacuated canisters during the walkthrough. In November 2012, full-shift personal and area samples were collected and analyzed for diacetyl and 2,3-pentanedione. In April 2017, we collected instantaneous air samples before and after the work shift to determine if air concentrations of alpha-diketones (diacetyl, 2,3-pentanedione, and 2,3-hexanedione) changed over the course of a work shift. The evacuated canister sampling setup consisted of a $450-\mathrm{mL}$ evacuated canister equipped with either a restricted flow controller set at a 15-minute, 6-hour, or 9-hour duration, or an instantaneous flow controller designed for a short sampling duration (less than 30 seconds). Instantaneous samples were taken by opening the evacuated canister to grab a sample of air to help identify point sources of alpha-diketones. For task-based air samples, a NIOSH employee placed the inlet of the flow controller in an employee's personal breathing zone as they performed their work task to replicate exposure. For source air samples, a NIOSH employee placed the inlet of the flow controller directly at the source of interest.

The canister air samples were analyzed using a pre-concentrator/GC/MS [LeBouf et al. 2012; NIOSH 2018]. For the walkthrough and first industrial hygiene visit, the typical LODs were $2.7 \mathrm{ppb}$ for diacetyl, and $3.3 \mathrm{ppb}$ for 2,3-pentanedione, but LODs for individual samples were dependent on the pressure inside each canister after the samples have been collected, and they may be higher or lower than these typical values. The typical LOQs were $8.9 \mathrm{ppb}$ and $10.9 \mathrm{ppb}$ for diacetyl and 23-pentanedione, respectively. For the second industrial hygiene survey in April 2017, typical LODs were $0.78 \mathrm{ppb}$ for diacetyl, $1.1 \mathrm{ppb}$ for 2,3-pentanedione, and $1.9 \mathrm{ppb}$ for 2,3-hexanedione. The typical LOQs were $2.6 \mathrm{ppb}, 3.6 \mathrm{ppb}$, and $6.3 \mathrm{ppb}$ for diacetyl, 2,3-pentanedione, and 2,3-hexanedione, respectively.

\section{Inhalable Dust Sampling (November 2012 Only)}

We collected personal and area air samples for inhalable dust using the Institute of Occupational Medicine (IOM) sampler (SKC Inc., Eighty Four, PA) loaded with a preweighed $25-\mathrm{mm}$ polyvinyl chloride filter with air pulled through the filter at a flow rate of 2.0 liters per minute for a minimum of 6 hours to achieve a TWA sample. Inhalable dust samples were collected and weighed following NIOSH Method 0500 [NIOSH 1994]. The LOD for the gravimetric method was 200 micrograms per sample ( $\mu \mathrm{g} / \mathrm{sample}$ ), which corresponds to approximately 0.3 milligrams per cubic meter $\left(\mathrm{mg} / \mathrm{m}^{3}\right)$ for typical samples. The actual LOD for individual samples varies, depending on actual sampling duration. 


\section{Bulk Sampling and Headspace Analysis}

We used 50-mL sterile polypropylene centrifuge tubes to collect four liquid flavoring samples during the initial walkthrough. Bulk samples of nine liquid flavorings were collected during the second industrial hygiene survey. For headspace analysis of alpha-diketones, we transferred $1 \mathrm{~mL}$ of liquid bulk material into a sealed $40-\mathrm{mL}$ amber volatile organic analysis vial and let it rest for 24 hours at room temperature $\left(70^{\circ} \mathrm{F}\right)$ in the laboratory. Then $2 \mathrm{~mL}$ of headspace air was transferred to a clean $450-\mathrm{mL}$ canister and pressurized to approximately 1.5 times atmospheric pressure. Using the canister analysis system, the concentrations were calculated in ppb of analytes in the headspace as an indicator of emission potential.

\section{Real-time Air Sampling}

We collected real-time area samples for TVOCs and total dust concentrations throughout the facility during November 5-8, 2012. The real-time TVOC data were collected using RAE Systems ppbRAE monitors (models 3000 and 7240, RAE Systems Inc., San Jose, CA) which contain photoionization detectors with 10.6 electron volt lamps. They are a non-specific detector that will efficiently respond to any VOC with an ionization potential less than 10.6 electron volts. The ppbRAE monitors were calibrated with isobutylene, so all reported results are isobutylene-equivalents. Real-time total dust measurements were collected using TSI DustTrak DRX aerosol monitors (model 8533, TSI Inc., Shoreview, MN). Since we had a limited number of real-time instruments, we rotated them in the area sampling baskets distributed throughout the facility. We occasionally removed the TVOC monitors from the area baskets to more closely monitor a process or task.

During April 11-13, 2017, we used RAE Systems (San Jose, CA) ppbRAE 3000 monitors or Tiger VOC detector monitors (ION Science, Stafford, TX) to measure concentrations of TVOCs in the air during both visits. Both instruments use non-specific photoionization detectors that respond to chemicals with ionization potentials below the energy of the lamp. These monitors were used to identify areas where coffee could be releasing VOCs. Areas where higher concentrations of TVOCs were measured may benefit from further sampling to characterize specific exposures to alpha-diketones.

During both visits we also collected real-time measurements of temperature and relative humidity (RH) using TSI Incorporated (Shoreview, MN) VelociCalc Model 9555-X MultiFunction Ventilation Meters equipped with Model 982 IAQ probes. In April 2017, we also collected real-time measurements of $\mathrm{CO}_{2}$ and $\mathrm{CO}$ using the same equipment.

\section{Ventilation Assessments}

In November 2012, we collected physical measurements of all ducts, ventilation openings and rooms with a standard tape measure or a Zircon (Campbell, CA) LaserVision DM 200 laser tape measure. Air flow measurements of supply vents and exhaust outlets were taken using an Accubalance Plus Model 8373 Air Capture Hood (TSI Incorporated, Shoreview, MN) or a TSI VelociCalc Plus Model 8324 Rotating Vane Anemometer, depending on which was most appropriate for the ventilation component being measured. The complete set of ventilation measurements allowed the estimation of volumetric flow rates in cubic feet per 
minute $(\mathrm{cfm})$ into and out of each area. A Ventilation Smoke Tube Kit, Catalog \#458481 (MSA, Pittsburgh, PA), was used to visualize airflow patterns in the plant, particularly in and around local exhaust ventilation hoods, to investigate whether contaminant sources were effectively captured and removed by the ventilation system. Differential pressure measurements between adjacent spaces were taken under various ventilation scenarios using an Energy Conservatory DG-500 Pressure Gauge (Minneapolis, MN).

In August 2017, the ventilation assessment was repeated using an Alnor (TSI Incorporated, Shoreview, MN) Model RVA501 Air Velocity Meter in place of the Accubalance Plus Model 8373 Air Capture Hood and TSI VelociCalc Plus Model 8324 Rotating Vane Anemometer.

\section{Informal Interviews during Walkthrough Visit}

A NIOSH medical officer conducted voluntary, private individual interviews with 22 employees about their work history and health concerns. A NIOSH staff member fluent in Spanish assisted during the interviews, as needed.

\section{NIOSH Medical Survey}

\section{Participants}

We invited all current employees to participate in the medical survey at the workplace on September 10-13, 2012, including on-site temporary workers. Thirteen former workers, including the five who were diagnosed with obliterative bronchiolitis, participated in the medical survey at the local health department on September 14, 2012. Participation was voluntary; written informed consent approved by the NIOSH Institutional Review Board was obtained from each individual at the time of testing. The survey included a medical and work history questionnaire, spirometry, administration of bronchodilator or mannitol challenge test, tests for carbon monoxide diffusing capacity and alveolar volume, and blood tests for immune responsiveness.

\section{Questionnaire}

We used an interviewer-administered computerized questionnaire to ascertain symptoms and diagnoses, work history with this company and other coffee or flavoring companies, and cigarette smoking history. Questions on respiratory health were derived from three standardized questionnaires, the European Community Respiratory Health Survey (ECRHS) [Burney et al. 1994; ECRHS 2014], the American Thoracic Society (ATS) adult respiratory questionnaire (ATS-DLD-78) [Ferris 1978], and the Third National Health and Nutrition Examination Survey (NHANES III) questionnaire [CDC 1996], and were supplemented with respiratory, dermatological, and systemic symptom questions. We had four bilingual interpreters that assisted with Spanish translation of consent, questionnaires, and instructions during medical testing.

\section{Spirometry}

The purpose of the spirometry test was to determine a person's ability to move air out of their lungs. Test results were compared to expected normal values. The test included three measurements or calculations: 1) forced vital capacity (FVC) (total amount of air the participant can forcefully blow out after taking a deep breath), 2) FEV1 (amount of air the 
participant can blow out in the first second of exhaling), 3) mid-expiratory flow (FEF25-75) (forced expiratory flow between $25 \%$ and $75 \%$ of exhaled volume), and 4 ) ratio of FEV1 to FVC. We used ATS criteria for acceptability and repeatability [Miller et al. 2005].

We used a volume spirometer (dry rolling seal spirometer) to measure exhaled air volume and flow rates. We used equations for predicted values and lower limits of normal derived from NHANES III data to define abnormal spirometry [Hankinson et al. 1999]. We defined obstruction as an FEV1/ FVC ratio less than the lower limit of normal with FEV1 less than the lower limit of normal; restriction as a normal FEV1/FVC ratio with FVC less than the lower limit of normal; and mixed obstruction and restriction as having FEV1, FVC, and FEV1/FVC ratio all less than the lower limit of normal. We used the FEV1 percent predicted to categorize such abnormalities as mild, moderate, moderately severe, severe, or very severe [Pellegrino et al. 2005]. We defined a low FEF25-75 as less than the lower limit of normal.

\section{Bronchodilator Reversibility Testing for Spirometry}

If a participant had abnormal spirometry, we repeated the test after the participant received a bronchodilator inhaler medication (i.e., albuterol), which can open the airways in some individuals (e.g., asthmatics). We defined reversibility (improvement) as increases of at least $12 \%$ and $200 \mathrm{~mL}$ for either FEV1 or FVC after bronchodilator administration.

\section{Diffusing Capacity and Alveolar Volume (DLCO)}

The purpose of DLCO test is to determine how well a person's lungs transfer oxygen. Diffusing capacity is decreased in persons with emphysema and in persons with scarring or inflammatory diseases of the air sacs of the lung. The purpose of the alveolar volume test is to estimate the amount of air in a person's lungs after taking a deep breath. We measured DLCO using the single breath technique with helium as the tracer gas. We used the ATS criteria for acceptability and repeatability [MacIntyre et al. 2005]. We compared the alveolar volume to reference values generated from a stratified random sample of the general population of an entire state [Miller et al. 1983]. We defined DLCO below the lower limit of normal as low diffusing capacity. From the same test, we estimated total lung capacity using the calculated alveolar volume.

\section{Mannitol Challenge Test for Bronchial Hyperresponsiveness}

We used mannitol challenge testing to examine bronchial hyperresponsiveness in employees with normal spirometry. This is a test that is frequently abnormal in persons with uncontrolled asthma, who may have normal lung function between asthma attacks but whose airways are sensitive and can narrow in reaction to irritants and allergens. We measured the FEV1 following successive doses of mannitol (0, 5, 10, 20, 40, 80, 160, 160, 160 milligrams (mg). We asked subjects to exhale completely before taking a controlled deep inspiration from the device, to hold their breath for 5 seconds, and then to exhale through the mouth. Sixty seconds after inhalation of the $0 \mathrm{mg}$ capsule, the FEV1 was measured in duplicate. The highest of these values was taken as the baseline FEV1 and used to calculate the target FEV1 value that indicated a $15 \%$ fall in response to the mannitol challenge. The interpolated provocative dose causing a 15\% fall in FEV1 was expressed as a PD15 [Pharmaxis, Inc. 2012]. The procedure outlined for the $0 \mathrm{mg}$ capsule was repeated for each dose step until a 
$15 \%$ fall in FEV1 was achieved (or a 10\% fall between consecutive doses), or the cumulative dose of $635 \mathrm{mg}$ had been administered. A value above $635 \mathrm{mg}$ was considered normal. A value from $156 \mathrm{mg}$ to $635 \mathrm{mg}$ was considered mildly increased airway sensitivity. A value from $36 \mathrm{mg}$ to $155 \mathrm{mg}$ was considered moderately increased airway sensitivity. A value of $35 \mathrm{mg}$ or less was considered severely increased airway sensitivity [Anderson and Brannan 2003; Pharmaxis, Inc. 2012].

\section{Determination of Total and Specific Immunoglobulin $G$ and $E$}

We tested participants' blood to determine if they had antibodies that reacted to coffee, green coffee beans, or castor beans. There are different classes of antibodies including immunoglobulin $\mathrm{G}$ (IgG) and immunoglobulin E (IgE). The presence of IgG antibodies specific to coffee, green coffee bean, or castor bean antigens is a marker of exposure to that specific antigen. The level of specific IgG usually reflects the amount of exposure to that antigen. IgE is considered the allergic antibody. Adults who have allergies tend to have an elevated total IgE blood level, but this does not provide information as to the specific allergen that a person may be allergic to. We examined whether or not participants had $\operatorname{IgE}$ antibodies in the blood that reacted to coffee, green coffee bean, or castor bean allergens.

We collected $20 \mathrm{~mL}$ of blood by venipuncture from each participant. The serum was separated for quantitative measurement of total $\operatorname{IgE}$, specific IgE, and specific IgG antibodies. Samples were analysed for total $\operatorname{IgE}$ and specific $\operatorname{IgG}$ and $\operatorname{IgE}$ by fluoroenzymeimmunoassay using the ImmunoCAP100 (Phadia AB, Uppsala, Sweden). Total IgE serum levels equal to or greater than 100 kilounits per liter $(\mathrm{kU} / \mathrm{L})$ indicate an atopic status (tendency to develop allergic diseases such as atopic dermatitis, hay fever, and asthma); total IgE serum levels less than 100kU/L indicate a non-atopic status. Specific IgE and specific-IgG were measured using green coffee (k70), coffee (Rf221), and castor bean (k71) allergens/antigens covalently coupled to ImmunoCAPs (Phadia AB). Sensitivity to a specific allergen was considered positive when IgE titers exceeded $0.35 \mathrm{kUA} / \mathrm{L}$. (The "A" represents the amount of specific $\mathrm{IgE}$ antibody present in the blood.) Antibody level to antigen-specific IgG was measured as milligrams of antigen specific-antibodies per liter $(\mathrm{mgA} / \mathrm{L})$.

\section{Index of Suspicion for Possible Lung Disease}

We developed an index of suspicion for possible obliterative bronchiolitis using questionnaire data and medical test results. In participants who reported ever going into the grinding/ packaging room or the flavoring room, indications for possible obliterative bronchiolitis were the following: shortness of breath on exertion (a report of shortness of breath walking with people of his/her own age on level ground; of having to stop for breath when walking at his or her own pace on level ground; or having to stop for breath after walking about 100 yards or after a few minutes), cough, chest wheeze/whistling, regular trouble with breathing, abnormal spirometry, decreased diffusing capacity, or decreased alveolar volume. We included these symptoms and abnormalities because medical literature documents that spirometry, diffusing capacity, and lung volumes can be insensitive for biopsy-confirmed obliterative bronchiolitis, and many cases have normal spirometry or have abnormalities in any pattern [Ghanei et al. 2008; King et al. 2011; Markopoulou et al. 2002]. In addition, 
pulmonary function abnormalities in flavoring-exposed workers may not be accompanied by reported symptoms [Kreiss et al. 2002].

For an index of suspicion for possible work-related asthma (including occupational asthma and work-exacerbated asthma), we considered both asthma arising during employment and pre-employment asthma with exacerbation related to work. Indications for possible asthma were the following: awoken by an attack of shortness of breath in the past 12 months; awoken with a feeling of tightness in the chest in the past 12 months; cough; chest wheeze/ whistling in the past 12 months; regular trouble breathing; obstruction on spirometry with a bronchodilator response and the presence of asthma-like symptoms; or positive response to mannitol with the presence of asthma-like symptoms. Prior physician diagnoses of respiratory disorders were also taken into consideration. If an asthma indication was present, a positive IgE response to coffee, green coffee beans, or castor beans was considered evidence for occupational asthma associated with any of these antigens.

\section{Coffee Facility Occupational Health Provider Spirometry}

The coffee roasting, flavoring, and packaging facility contracted an occupational health provider to perform spirometry as part of their medical surveillance program. We assessed the occupational health provider spirometry data collected in October 2014 and October 2015 for quality and excessive declines in FEV1 or FVC between tests for employees who completed more than one spirometry test, including NIOSH spirometry data from the September 2012 medical survey.

We classified the spirometry tests using a grading scheme based on the acceptability and repeatability criteria recommended by the American Thoracic Society [Miller et al. 2005]. Trials were considered to have acceptable quality for measurement of FEV1 if they were free of technical errors at the start of the trial (including large extrapolated volume and cough in the first second), and there was evidence of adequate inspiration. For measurement of FVC, trials also were required to show evidence of adequate expiration and that end-of-test criteria were satisfied to be considered of acceptable quality.

Each test received a separate quality grade for FEV1 and FVC. Any trial deemed not technically acceptable was not considered when grading the quality of the test session. We assigned FEV1 quality grade $\mathrm{A}$ if a test session contained at least three acceptable trials, and the highest two values were repeatable within $100 \mathrm{~mL}$. FEV1 grade B was assigned if the session contained at least two acceptable trials, and the highest two values were repeatable within $150 \mathrm{~mL}$. FEV1 grade $\mathrm{C}$ was assigned if the session contained at least two acceptable trials, and the highest two values were within $250 \mathrm{~mL}$. Similarly, we assigned FVC quality grade $\mathrm{A}$ if a test session contained at least three trials, and the highest two values were repeatable within $100 \mathrm{~mL}$. FVC grade B was assigned if the session contained at least two acceptable trials, and the highest two values were repeatable within $150 \mathrm{~mL}$. FVC grade C was assigned if the session contained at least two acceptable trials, and the highest two values were repeatable within $250 \mathrm{~mL}$. Only tests with A, B or C quality grades in both FEV1 and FVC were interpreted. 


\section{Longitudinal Changes in Spirometry}

For medical survey participants that had company-provided spirometry results, we compared the results of NIOSH spirometry tests performed and the most recent company-provided spirometry test to assess their change in FVC and FEV1. Excessive decline in FEV1 or FVC was defined as a $15 \%$ or more decrease in FEV1 or FVC, after accounting for the expected loss due to aging, between two spirometry tests [Pellegrino et al. 2005; Townsend and Occupational and Environmental Lung Disorders Committee 2011]. We mailed health hazard evaluation participants letters (in English and Spanish, if applicable) regarding their change in FVC and FEV1 from the NIOSH spirometry testing and the most current companyprovided spirometry testing. We recommended participants provide that information to their physicians. Of the employees that did not have NIOSH spirometry testing but had two company-provided spirometry tests, we compared the results between the two companyprovided spirometry tests to evaluate for excessive declines in FEV1 or FVC.

\section{Statistical Analysis}

Industrial Hygiene Survey and Ventilation Assessment

We performed analyses using Excel (Microsoft ${ }^{\circledR}$, Redmond, WA) and SAS version 9.4 (SAS Institute Inc., Cary, NC). We created summary statistics by work area location, job title, and task. When the values presented in the report are from samples below the LOD they are denoted by a "<" symbol.

\section{Medical Survey}

Based on the participants' questionnaire responses, we determined the job title and department they were primarily assigned to at the time of the survey and during past jobs at the facility. Worker mobility suggested that classifying employees into similar exposure groups based on job title or company-designated department would result in substantial misclassification of exposure and make evaluation of potential exposure-response relationships difficult. Since we had questionnaire data regarding whether employees spent time in the grinding/packaging room or flavoring room during their current or past jobs at the coffee roasting, flavoring, and packaging facility, we used that index of exposure for analyses. We also created exposure variables using assignment to the roasting room combined with reports of entering the roasting room for the current and past jobs.

We compared participants' prevalences of symptoms and spirometric obstructive and restrictive abnormalities and abnormal FEF25-75 to expected prevalences of a sample of the general population reflected in the NHANES III, adjusting for gender, race, age (age $\leq 39$ and $\geq 40$ ), and smoking categories (ever/never). For restrictive pattern on spirometry, we also adjusted for body mass index (BMI).

We conducted analyses using SAS version 9.3 and 9.4 (SAS Institute, Cary, North Carolina). We ran linear regressions using the GLM procedure on percent predicted FEV1, FVC, FEF25-75, DLCO, and alveolar volume, and on the FEV1/FVC ratio in relation to currently and ever having any work time in the grinding/packaging room and flavoring room, as well as for currently and ever having any work time in the roasting room. We used logistic regression models to evaluate prevalence of upper and lower respiratory symptoms, 
sinus symptoms, and eye irritation in relation to currently having worked in the grinding/ packaging room and/or flavoring room, and currently having worked in the roasting room. The comparison group for working in grinding/packaging room and/or flavoring room was composed of participants who worked in neither. The models for symptoms and the FEV1/ FVC ratio were adjusted for age and smoking pack-years, while the percent predicted lung function parameter models were adjusted for smoking pack-years. We chose a probability of less than or equal to 0.05 as a criterion for statistical significance. In view of the small size of the worker population and the curtailed distribution of exposure indices, we report a probability between greater than 0.05 and less than or equal to 0.1 as marginally significant.

\section{Results}

All results tables are in Appendix A.

\section{Walkthrough Visit - July/August 2012}

Headspace analyses of flavorings collected during the walkthrough showed that 2,3-pentanedione existed in higher concentrations than diacetyl in three of the four samples (Table A1).

Canister sample results from the walkthrough are shown in Table A2. We collected 14 evacuated canister samples; eight personal samples and six area samples. All personal samples were collected on flavoring room employees. Three-hour TWA personal sample concentrations in the flavoring room ranged from $160 \mathrm{ppb}$ to $260 \mathrm{ppb}$ diacetyl and $110 \mathrm{ppb}$ to $570 \mathrm{ppb}$ 2,3-pentanedione, and $13 \mathrm{ppb}$ to $90 \mathrm{ppb}$ 2,3-hexanedione. An instantaneous sample collected near a worker's breathing zone immediately after addition of flavoring to beans in a tumbler measured $400 \mathrm{ppb}$ diacetyl and 2,000 ppb 2,3-pentanedione. Concentrations of diacetyl and 2,3-pentanedione were lowest in the 15-minute samples collected in the greens warehouse and roasting room. A 4.5-hour sample collected in the unflavored coffee grinding/ packaging room (just outside flavoring room entrance) measured $170 \mathrm{ppb}$ diacetyl and 120 ppb 2,3-pentanedione.

\section{Industrial Hygiene Surveys}

Personal and Area Full-shift Air Sampling Results

Modified Occupational Safety and Health Administration (OSHA) Methods

Table A3 presents the personal and area full-shift air sampling results from our first industrial hygiene visit in November 2012. We collected 59 personal and 111 area full-shift air samples over four days. Fifty-eight personal air samples (98\%) were above the NIOSH REL for diacetyl of $5.0 \mathrm{ppb}$ and 42 (71\%) were above the NIOSH REL for 2,3-pentanedione of 9.3 ppb.

Overall, employees in packaging had the highest personal exposures to diacetyl ranging from $75.4 \mathrm{ppb}$ to $166.0 \mathrm{ppb}$. Packaging employee exposures exceeded the NIOSH REL for diacetyl by as much as 33 times. Employees in the production area offices had the second highest 
maximum personal exposure to diacetyl of $139.5 \mathrm{ppb}$ (range: $39.7 \mathrm{ppb}-139.5 \mathrm{ppb}$ ), closely followed by employees in flavoring with a maximum concentration of $96.3 \mathrm{ppb}$ (range: $52.6 \mathrm{ppb}-96.3 \mathrm{ppb}$ ). Employees in the flavoring room were required to wear respirators. Diacetyl concentrations measured in five samples taken on employees working all over the facility and in one sample from an employee working in all offices ranged from $49.2 \mathrm{ppb}$ to $80.1 \mathrm{ppb}$. Personal diacetyl concentrations in roasting ranged from $15.1 \mathrm{ppb}-40.1 \mathrm{ppb}$ and concentrations in the quality control room ranged from $11.7 \mathrm{ppb}-31.3 \mathrm{ppb}$. Concentrations in the downstairs non-production offices, finished good warehouse, and greens warehouse were all below $11.7 \mathrm{ppb}$, with all but one exceeding the NIOSH REL for diacetyl of $5.0 \mathrm{ppb}$.

Employees in flavoring had the highest personal exposures to 2,3-pentanedione ranging from $79.6 \mathrm{ppb}$ to $199.0 \mathrm{ppb}$. Flavoring room employee exposures exceeded the NIOSH REL for 2,3-pentanedione by as much as 21 times. Employees in packaging had the second highest average personal exposure to 2,3-pentanedione ranging from $17.9 \mathrm{ppb}$ to 133.6 $\mathrm{ppb}$, followed by employees who worked all over the facility with exposures ranging from $31.7 \mathrm{ppb}$ to $45.0 \mathrm{ppb}$. Concentrations of 2,3-pentanedione measured in three samples taken on employees working in the production area offices ranged from $9.5 \mathrm{ppb}$ to $44.8 \mathrm{ppb}$. Personal 2,3-pentanedione concentrations in roasting ranged from $<6.0 \mathrm{ppb}$ to $15.8 \mathrm{ppb}$ and concentrations in the quality control room ranged from $<5.4 \mathrm{ppb}$ to $15.8 \mathrm{ppb}$. Concentrations in the downstairs non-production offices, finished good warehouse, and greens warehouse were all below the LOD.

Area sample concentrations for diacetyl inside the facility were highest in packaging and on the packaging mezzanine with concentrations ranging from 67.9 to $247.2 \mathrm{ppb}$ diacetyl. The second highest concentration was found in flavoring and the flavoring mezzanine, ranging from $44.0 \mathrm{ppb}$ to $144.0 \mathrm{ppb}$ diacetyl. Concentrations in production area offices ranged from $33.8 \mathrm{ppb}$ to $93.4 \mathrm{ppb}$, followed by roasting and the roasting mezzanine with a range of 9.5 to $50.6 \mathrm{ppb}$ diacetyl.

Area sample concentrations for 2,3-pentanedione inside the facility were highest in flavoring (including the mezzanine), where the range was $48.7 \mathrm{ppb}$ to $273.1 \mathrm{ppb}$. Second highest area sample concentrations were in packaging and the packaging mezzanine with results ranging from $23.0 \mathrm{ppb}$ to $190.6 \mathrm{ppb}$ ). Production area offices showed a range of $9.9 \mathrm{ppb}$ to $46.2 \mathrm{ppb}$ 2,3-pentanedione, followed by roasting and the roasting mezzanine showing ae range of $>$ $5.3 \mathrm{ppb}-26.8 \mathrm{ppb}$.

Table A4 presents the personal and area full-shift air sampling results from our second industrial hygiene visit in April 2017. We collected 29 personal and 147 area full-shift air samples over three days. Twenty-eight of the 29 personal air samples (97\%) exceeded the NIOSH REL for diacetyl of $5.0 \mathrm{ppb}$ and the NIOSH REL for 2,3-pentanedione of $9.3 \mathrm{ppb}$.

Overall, the seven flavoring employees had the highest measured personal exposure to diacetyl, ranging from $100.3 \mathrm{ppb}$ to $163.8 \mathrm{ppb}$. Employees in the flavoring room were required to wear respirators, so their true exposures were lower. Employees in packaging had the second highest exposures with concentrations ranging from $47.2 \mathrm{ppb}$ to $129.3 \mathrm{ppb}$ diacetyl. A sample on a production office employee followed with a concentration of 52.4 
$\mathrm{ppb}$, then three samples on employees who worked all over the facility showed a range of $30.6 \mathrm{ppb}$ to $45.2 \mathrm{ppb}$.

Employees in flavoring also had the highest personal exposure to 2,3-pentanedione. The seven flavoring employee measurements ranged from $182.7 \mathrm{ppb}$ to $899.9 \mathrm{ppb}$. Employees in the flavoring room were required to wear respirators, so their true exposures were lower. Employees in the packaging room had the second highest exposures with a range of $20.5 \mathrm{ppb}$ to $161.6 \mathrm{ppb} 2,3$-pentanedione. A sample on a production office employee followed with a concentration of $23.9 \mathrm{ppb}$, then three samples on employees who worked all over the facility showed a range of $15.8 \mathrm{ppb}$ to $21.4 \mathrm{ppb}$.

Area sampling showed flavoring and the flavoring mezzanine had the highest air concentrations of diacetyl, with 24 total samples ranging from $93.2 \mathrm{ppb}$ to $372.0 \mathrm{ppb}$. The packaging mezzanine, packaging room and new packaging line (old hold room) had 48 samples with diacetyl concentrations ranging from $32.9 \mathrm{ppb}$ to $176.2 \mathrm{ppb}$. Respirator use was required for any employee entering the packaging mezzanine area. Fifteen samples from offices in the production area showed concentrations ranging from $16.2 \mathrm{ppb}$ to $128.9 \mathrm{ppb}$ diacetyl.

Area samples in flavoring and the flavoring mezzanine also had the highest air concentrations of 2.3-pentanedione, with 24 total samples ranging from $224.2 \mathrm{ppb}-2060.3 \mathrm{ppb}$ and an average concentration of $636.1 \mathrm{ppb}$ on the lower level and $1553.0 \mathrm{ppb}$ on the mezzanine. The packaging mezzanine, packaging and new packaging line (old hold room) had 48 samples with 2,3-pentanedione concentrations ranging from $23.0 \mathrm{ppb}-124.1 \mathrm{ppb}$. Average area sample concentrations in those areas showed the packaging mezzanine with the highest $(77.0 \mathrm{ppb})$ followed by packaging $(67.0 \mathrm{ppb})$, then the new packaging line (old hold room) with 63.1 ppb 2.3-pentanedione. Fifteen samples from offices in the production area showed concentrations ranging from $8.0 \mathrm{ppb}-98.1 \mathrm{ppb}$ with an average of $40.8 \mathrm{ppb}$ 2.3-pentanedione.

Nineteen of the 29 personal air samples were above the LOD for 2,3-hexanedione; of those above LOD, flavoring room employees had the highest concentrations, ranging from below LOD to $15.7 \mathrm{ppb}$. The flavoring and flavoring mezzanine area samples also showed the highest concentrations with a 24 sample range of $2.5 \mathrm{ppb}$ to $53.3 \mathrm{ppb}$. All other area samples in the facility were below $6.0 \mathrm{ppb}$ for 2,3-hexanedione.

Tables A5 and A6 compare the diacetyl and 2,3-pentanedione concentrations for area samples collected in the same location during the first (November 2012) and second (April 2017) industrial hygiene surveys. Area sample concentrations of diacetyl (Table A5) were higher in the finished goods warehouse, flavoring room, flavoring room mezzanine, and greens warehouse in April 2017. Diacetyl concentrations were lower in the maintenance shop, nonproduction offices (both downstairs and upstairs), packaging mezzanine, quality control room, reception area, and roasting mezzanine. Area sample concentrations of 2,3-pentanedione (Table A6) were higher in the finished goods warehouse, flavoring room, flavoring room mezzanine, greens warehouse, quality control room, roasting, and the roasting mezzanine April 2017. 


\section{Full-shift Evacuated Canisters}

During our first industrial hygiene visit in November 2012, personal evacuated canister sample concentrations were highest for employees in the flavoring room with a range of $110.5 \mathrm{ppb}$ to $323.6 \mathrm{ppb}$ for diacetyl, and $56.0 \mathrm{ppb}$ to $310.0 \mathrm{ppb}$ for 2,3-pentanedione (Table A7). Concentrations in packaging ranged from $67.1 \mathrm{ppb}$ to $142.1 \mathrm{ppb}$ for diacetyl and 16.0 ppb to $96.0 \mathrm{ppb}$ for 2,3-pentanedione. A single sample from a production office employee measured 86.8 ppb diacetyl and 54.0 ppb 2,3-pentanedione. Employees who worked all over the plant were exposed to concentrations ranging from $67.1 \mathrm{ppb}$ to $86.8 \mathrm{ppb}$ diacetyl and $42.0 \mathrm{ppb}$ to $56.0 \mathrm{ppb} 2,3$-pentanedione, followed by quality control room employees $(8.7 \mathrm{ppb}$ $-30.8 \mathrm{ppb}$ diacetyl, $<3.2 \mathrm{ppb}-20.0 \mathrm{ppb} 2,3$-pentanedione), and roasting workers (7.9 ppb 20.5 ppb diacetyl, <3.8 ppb - 11.0 ppb 2,3-pentanedione).

Area evacuated canister sample concentrations for diacetyl and 2,3-pentanedione were highest in the flavoring (126.3 ppb - 323.6 ppb diacetyl, 69.0 ppb-240.0 ppb 2,3-pentanedione) and packaging (86.8 ppb - 292.0 ppb diacetyl, $17.0 \mathrm{ppb}-220.0 \mathrm{ppb}$ 2,3-pentanedione). Two samples in the production area offices gave $41.8 \mathrm{ppb}$ and 69.5 ppb diacetyl, and $25.0 \mathrm{ppb}$ and $44.0 \mathrm{ppb}$ 2,3-pentanedione. Results from samples collected outside flavoring room exhaust were $13.4 \mathrm{ppb}$ and $25.3 \mathrm{ppb}$ diacetyl and $15.0 \mathrm{ppb}$ and 76.0 ppb 2,3-pentanedione.

No full-shift evacuated canister samples were taken as part of the second industrial hygiene survey in April 2017.

\section{$\underline{\text { Area/Personal Inhalable Dust Samples }}$}

We collected 25 personal and 106 area samples for inhalable dust (Table A8) during our November 2012 industrial hygiene survey. Of the 106 area samples collected, 67 (63\%) were below the LOD. The maximum concentration measured inside the facility was $1.2 \mathrm{mg} /$ $\mathrm{m}^{3}$ in the roasting room. Samples collected in all other areas ranged from below the LOD to $0.7 \mathrm{mg} / \mathrm{m}^{3}$. One area sample collected outside the loading dock showed an inhalable dust concentration of $232.5 \mathrm{mg} / \mathrm{m}^{3}$ on a day where many delivery trucks entered and exited the plant.

Of the 25 personal inhalable dust samples collected, only four (16\%) were below the LOD. The maximum personal inhalable dust concentrations on two employees unloading green beans from a delivery truck were $14.9 \mathrm{mg} / \mathrm{m}^{3}$ and $14.8 \mathrm{mg} / \mathrm{m}^{3}$, measured on the same day. All other personal inhalable dust results ranged from below LOD to $2.7 \mathrm{mg} / \mathrm{m}^{3}$.

No inhalable dust samples were collected during the second industrial hygiene visit in April 2017.

\section{Task-based Air Sampling Results}

\section{Evacuated Canisters}

We collected three 15-minute task-based canister samples, one each in roasting, packaging, and the quality control room, during our first industrial hygiene visit in November 2012. The packaging sample results showed 249 ppb diacetyl and 175 ppb 2,3-pentanedione during 
grinding of unflavored roasted coffee beans. Concentrations in the roasting sample were 16 ppb diacetyl and 8 ppb 2,3-pentanedione while green coffee beans were roasted and cooled. The quality control room followed with sample concentrations of $11 \mathrm{ppb}$ diacetyl and $6 \mathrm{ppb}$ 2,3-pentanedione while sample roasting and grinding were performed.

We collected two instantaneous canister samples with a sample duration of approximately 30 seconds. One sample by the grinder in the quality control room during grinding of unflavored coffee beans showed $87 \mathrm{ppb}$ diacetyl and $78 \mathrm{ppb}$ 2,3-pentanedione. The second sample, collected in the break room while a quality control technician emptied a packet of French vanilla flavored coffee onto a filter on a scale, showed $50 \mathrm{ppb}$ diacetyl and $64 \mathrm{ppb}$ 2,3-pentanedione. These instantaneous results should not be compared to the 15-minute STELS.

No task-based evacuated canister samples were taken as part of the second industrial hygiene survey in April 2017.

\section{Source Air Sampling Results}

Modified Occupational Safety and Health Administration (OSHA) Methods

During the November 2012 industrial hygiene survey, a 15-minute source air sample collected at the open hatch of a hopper on the packaging mezzanine containing ground coffee had concentrations of 14,300 ppb diacetyl and 13,800 ppb 2,3-pentanedione. A 15-minute sample at the open hatch of an adjacent empty hopper on the packaging mezzanine had 628 ppb diacetyl and $475 \mathrm{ppb}$ 2,3-pentanedione. Source air samples were not collected as part of the April 2017 industrial hygiene visit.

\section{Background Pre- and Post-Shift Diacetyl and 2,3-Pentanedione Canister Results}

No background pre- and post-shift evacuated canister samples were taken during the first industrial hygiene visit in November 2012. Table A9 presents the instantaneous evacuated canister pre- and post-shift background air sampling results from our second industrial hygiene visit (April 2017) collected in various locations throughout the facility. Diacetyl and 2,3-pentanedione air concentrations either decreased or remained constant over the course of the work day for the three days sampled. Pre and post-shift concentrations were highest in flavoring and packaging, followed by the warehouses, roasting, and quality control room.

\section{Bulk Samples and Headspace Results}

Results from the analyses of the bulk flavoring samples collected during the second industrial hygiene survey are provided in Table A10. Diacetyl was identified in seven of nine bulk flavoring samples, and 2,3-pentanedione was identified in almost all the flavorings in higher concentrations than diacetyl. 2,3-Hexanedione was measured in only one sample.

\section{Real-time Monitoring: Total Volatile Organic Compounds (TVOCs), Dust, Carbon Monoxide (CO) and Carbon Dioxide $\left(\mathrm{CO}_{2}\right)$}

\section{TVOC concentrations}

During the first industrial hygiene survey, the lowest TVOC concentrations were found in the nonproduction offices and warehouses (Table A11). The next lowest concentrations 
were found in roasting with most peaks below 1,000 ppb. There were a few peaks above $1,000 \mathrm{ppb}$ associated with cleaning tasks. The quality control room showed slightly higher concentrations with peaks over 4,000 ppb during roasting and grinding of coffee. The breakroom showed higher overall TVOC concentrations with a peak over 10,000 ppb during the weighing of flavored coffee. Background TVOC concentrations near the grinders in packaging were between $1,000 \mathrm{ppb}$ and 2,000 ppb with some peaks over 50,000 ppb and multiple peaks over $10,000 \mathrm{ppb}$ on the mezzanine over the line 7 packaging machine. The flavoring room showed the highest background TVOC concentrations with consistent readings over 2,000 ppb and peaks over 9,000 ppb on the mezzanine above the hoppers. The flavoring room had its own exhaust ventilation to the outside of the building. Measured TVOC concentrations outside the flavoring room exhaust ranged from 4,000 ppb to 10,000 $\mathrm{ppb}$ and were reflective of the concentration profiles of the flavoring room area.

Table A12 shows TVOC measurements taken throughout the facility during our second industrial hygiene visit in April 2017. Overall, TVOC concentrations were highest in flavoring. The highest mean TVOC concentration was found inside the flavoring room grinder enclosure on line $4(17,737 \mathrm{ppb})$ with peak reading of $342,500 \mathrm{ppb}$. The second highest mean TVOC concentration of $12,488 \mathrm{ppb}$ was measured at the small batch barrel flavoring station, however that location showed the highest peak value observed at 165,900 ppb. Outside of flavoring, packaging showed the next highest mean and peak concentrations. The maximum TVOC concentration in packaging was inside the enclosed mezzanine $(28,556$ $\mathrm{ppb}$ ). TVOC mean concentrations were lowest in the production manager's office and in roasting.

Dust

Table A13 shows real-time total dust measurements taken throughout the facility during our first industrial hygiene visit in November 2012. The highest average concentrations were measured in roasting and ranged from 0.16 to 1.59 milligrams per cubic meter $\left(\mathrm{mg} / \mathrm{m}^{3}\right)$. Peak dust concentrations in roasting were observed up to $9.36 \mathrm{mg} / \mathrm{m}^{3}$. The greens warehouse showed the second highest concentrations of total dust which was due to unloading of the green coffee bean bags from the box truck; some peak concentrations were as high as 3.77 $\mathrm{mg} / \mathrm{m}^{3}$. The QC room showed peaks of up to $2.05 \mathrm{mg} / \mathrm{m}^{3}$ during the roasting and grinding of coffee, but overall the concentrations were low. Packaging and flavoring both showed low concentrations of total dust ranging from $0.04 \mathrm{mg} / \mathrm{m}^{3}$ to $0.15 \mathrm{mg} / \mathrm{m}^{3}$.

No real-time dust sampling measurements were taken during the second industrial hygiene visit in April 2017.

\section{Carbon Monoxide and Carbon Dioxide}

No $\mathrm{CO}$ or $\mathrm{CO}_{2}$ real-time measurements were taken during the first industrial hygiene visit in November 2012.

Table A14 shows real-time $\mathrm{CO}$ and $\mathrm{CO}_{2}$ measurements collected in April 2017. In flavoring, average $\mathrm{CO}$ concentrations ranged from $1.1 \mathrm{ppm}$ at the small batch barrel flavoring station to 
$59.6 \mathrm{ppm}$ inside the flavoring room grinder enclosure. The highest peak measurement of CO was observed in the flavoring room grinder enclosure $(\geq 500 \mathrm{ppm}$, the highest concentration measured by the instrument), followed by the packaging area grinder enclosure (148.2 ppm). Average $\mathrm{CO}_{2}$ concentrations ranged from $431.2 \mathrm{ppm}$ at roaster 1 operator's desk to 1,183 ppm inside the flavoring room grinder enclosure. The highest peak measurement of $\mathrm{CO}_{2}$ was observed in the flavoring room grinder enclosure $(4,636 \mathrm{ppm})$; all other observed values were below 1,819 ppm (flavoring room ribbon elevator).

\section{Ventilation Assessments}

During our initial walkthrough in July/August 2012, flavoring had two local exhaust ventilation systems, each with an exhaust fan on the outside wall. On one system, a local exhaust ventilation canopy hood was located approximately 24 inches above the station where flavoring was pumped out of a large barrel into smaller one-gallon jugs. The onegallon containers were stored in negative pressure ventilated cabinets above and below the bench used for weighing flavorings. Local exhaust ventilation ducts in the cabinets maintained the negative pressure. An open-ended ventilation duct was located approximately 18 inches from the scale used to weigh out the liquid flavorings, and the barrel flavoring station had a capture hood located just below the rolling barrels. The other local exhaust ventilation system served the hazelnut coffee mixing station scale and rotating barrels in a similar configuration. Two additional fans in the wall exhausted air directly from the room. Cool air was provided to the room through two air-conditioning units: one that recirculated the room air and the other that introduced fresh air from outside. We were told that the flavoring room was designed to be at negative pressure to the rest of the plant via the ventilation system to prevent the flavorings from contaminating unflavored coffee.

Local exhaust ventilation was not present for any equipment in packaging. Roasting had two wall fans that exhausted plant air over the roof of the warehouses, and air from the roasters was directly exhausted through an afterburner system and then out of stacks on the roof above. Four make-up air units along the roasting room and adjacent maintenance shop outside wall provided supplemental makeup air. The production offices had air-conditioning units that fully recirculated air from the production space, while the non-production offices had a dedicated heating, ventilating, and air-conditioning system.

Prior to the first industrial hygiene visit in November 2012, the grinders in packaging had been enclosed in sheet metal shrouds (or hoods), with access doors and plastic viewing windows, that were vented via ductwork from the tops of the hoods to an exhaust fan located adjacent to the roasting room wall fans. At the small batch mixing station in flavoring, the open-ended ventilation duct had been moved closer to the flavoring scale, and the capture hood beneath the rotating barrels had been relocated above the barrels. The other local exhaust ventilation system in flavoring had been modified to meet the requirements of the newly-renovated hazelnut coffee process line. The system included a grinder ventilation hood enclosure similar to those in packaging, ductwork to the new enclosed ventilated automated mixer, and a canopy hood above its flavoring carboy.

Table A15 presents the individual measurements obtained from the ventilation system in the plant in November 2012. They were collected with an airflow hood or a rotating vane 
anemometer and represent a snapshot of the overall production area ventilation profile at the time of the sampling. No holes were drilled in the ductwork and pitot-tubes were not used as would be done in a full ventilation assessment. Any changes in ventilation system operation or performance, production operations, doors opening or closing, or pressure differentials between adjacent spaces could significantly affect results. Also, we were unable to measure airflow through the afterburners in the roasting room or determine the sources of the combustion air. We made no attempt to control the use of afterburners as we collected our ventilation measurements, but instead allowed the afterburners to operate as normal. Thus, we do not understand how afterburner operation and performance may have affected the results presented in Table A15.

The most significant modification made to the facility between our first and second industrial hygiene visits was the enclosure of the entire mezzanine level above the packaging lines; it was now separate from the other production spaces. Two new supply air ducts within the mezzanine enclosure were added along the south wall; each duct had two openings, one high and one low. Two exhaust fans from the space were located in the roof near the northern end of the space.

Both the mezzanine supply air and exhaust fans were controlled by separate variable frequency drive (VFD) motors. These drives vary the fan speed by varying the frequency of the motor. The maximum fan speed and air flow would be achieved at a reading 60 Hertz $(\mathrm{Hz})$, and the fan speed and air flow would both be zero at a reading of $0 \mathrm{~Hz}$. During our visit, the supply and exhaust fans were both originally set to $42 \mathrm{~Hz}$. At that setting, the supply air flow was estimated to be $8,900 \mathrm{cfm}$. Ventilation smoke released at openings in the floor showed that the mezzanine space was neutral to packaging. Working with the maintenance manager, different VFD settings were tested according to Table A16. In the end, the VFDs were set to $30 \mathrm{~Hz}$ for the supply fans and $60 \mathrm{~Hz}$ for the exhaust fans late morning on April 13,2017 to properly maintain the mezzanine under negative pressure compared to the grinding/packaging space.

Gaps observed in the enclosure around the grinder feeding lines 7 and 8 during the November 2012 industrial hygiene visit were sealed with spray foam before our April 2017 visit, and a differential pressure gauge was added to help monitor the enclosure performance. However, there was still no skirting around the bottom of the enclosure. The exhaust flow from this enclosed grinder was now the only exhaust point served by the connected exhaust fan; previously the fan also served the grinder enclosure for the old grinder on lines 5 and 6 , but that opening had been capped. The 12-inch exhaust duct opening leading from the top of the grinder enclosure was equipped with a damper to help regulate flow. The damper was roughly $50 \%$ open during our visit, and the exhaust flow from the enclosure was estimated to be 400 cubic feet per minute ( $\mathrm{cm})$. Ventilation smoke released at the base of the enclosure showed that the enclosure was neutral to only weakly negative, depending on where the smoke was released (closer to the exhaust end was more likely to be negative).

The layout of the flavoring room and the associated LEV systems were fundamentally the same during both industrial hygiene surveys. The exhaust system was comprised of two exhaust fans/circuits. One fan (Exhaust Fan 1) served eight local exhaust hoods, which 
included the barrel mixing station, the flavor mixing duct hood, the flavor storage cabinets, a general exhaust grille behind the flavoring storage rack and a flavor pump station hood. There were also three exhaust grilles in the duct behind the flavoring barrel storage rack. This LEV system was designed as a common negative pressure plenum with takeoffs from the main plenum to each hood. The four exhaust intakes associated with the barrel mixing station had individual dampers to help control the air flow, while the four intakes further downstream did not have dampers. The result of this design was that hoods closest to the fan (i.e., those associated with the barrel mixing station) generally had higher flow rates than those downstream. The exhaust hood over the flavor pumping station did not have any measurable exhaust flow. Furthermore, the exhaust duct downstream of the flavor bench and storage cabinets was in poor condition with the tape on the duct seams peeling off.

The second exhaust fan (Exhaust Fan 2) served the flavoring pump station for the ribbon blender, the ribbon blender hood, and the grinder enclosure. There was no measurable exhaust in the canopy hood over the flavorings carboy, but it may not have been necessary since it appeared to be sealed and was pumped to a closed ribbon blender. Estimated flow rates for the exhaust hoods are shown in Table A17, along with the values measured in November 2012, for comparison.

In April 2017, gaps in the enclosure for the flavoring room grinder, observed in November 2012, were sealed with spray foam and a differential pressure gauge was installed in the duct leading from the enclosure, but there was still no skirting around the bottom of the enclosure. The damper in the exhaust duct for the grinder enclosure was almost completely closed. Qualitative tests with ventilation smoke tubes showed that the grinder enclosure was neutral to only weakly negative.

The quality control room appeared the same during both industrial hygiene visits. Smoke testing on the large range hood located over the sample roasters showed good capture on that side of the hood, while there was poor capture on the side of the hood over the stove burners.

All air supply in production offices was recirculated from the production area. There were two ceiling level air returns, one located in the locker room and one in the maintenance manager's office. Most production offices and break room doors were open throughout the day shift during both industrial hygiene visits. However, the doors between the locker room and quality control room were kept closed (to the production area) during the day.

\section{Informal Employee Interviews during Walkthrough Visit}

Twenty-two of 26 onsite employees were interviewed individually. Some employees noted symptoms that they attributed to work: occasional sneezing due to odors, sinus problems due to green coffee dust, and skin issues due to cardboard or roasted coffee beans. Diagnoses reported among interviewed employees included seasonal allergies, asthma, and COPD. Approximately half noted they were current or past smokers. Some employees in production noted that once they completed the tasks for their primary job title, they often helped with other production tasks, or sometimes, they would fill-in if someone was absent for the day. On any given day, some supervisors also helped, as needed, with production tasks (e.g., roasting, grinding, weighing, or packaging). Some office employees started at the company in 
coffee processing jobs before moving to office positions. Some employees reported working at another coffee roasting and packaging facility before working at this facility. Multiple employees noted that hearing protection was available for voluntarily use when roasting.

\section{Medical Survey Results (September 2012)}

\section{NIOSH Medical Survey}

Of approximately 85 current employees at the coffee roasting facility during our medical survey, 75 (88\%) participated in one or more components of the medical survey (Table A18). The majority of employees were male (68\%) and Hispanic (69\%), with an average age of 35 years (median age 34, range 18-67 years).

The average duration of employment at the current facility was 2.9 years; the median duration was 1.3 years, and the range was 0.04-9.3 years. Among the participants, 31 (41\%) worked at the current facility one year or less; 28 (38\%) worked at the facility between one and five years, and 16 (21\%) worked there five or more years. Of the 75 employees, 12 had also worked at the old facility before the new facility opened in 2003. Mean years employed at the current and old facility was 4.3 years and range from months to 25.0 years (Table A18).

At the time of the survey, $67 \%$ of the 75 participants reported currently working in or spending time in the grinding/packaging room $(\mathrm{n}=50)$ or the flavoring room $(\mathrm{n}=50)$ (Table A19). The number currently spending time in either area was $63(84 \%)$. The number working or spending time in both areas was 37 (49\%). During their tenure at the current facility, 58 (77\%) participants had ever worked or spent time in the grinding/packaging room, and 54 $(72 \%)$ had ever worked or spent time in the flavoring room, with $66(88 \%)$ having ever spent time in one or the other high alpha-diketone exposure areas.

\section{Symptoms and Diagnoses}

At the time of the survey, 36 (48\%) participants reported one or more lower respiratory symptoms in the past 12 months: regular trouble breathing, woken by shortness of breath, woken with chest tightness, usual cough, wheeze or whistling in chest, asthma attack, or troubled by shortness of breath when hurrying on level ground or walking up a slight hill. Of the 75 participants, 21 (28\%) reported shortness of breath hurrying on level ground or walking up a slight hill (Table A20). Of these 21 participants, nine reported being short of breath walking with people of his or her own age on level ground, and five reported having to stop for breath after walking about 100 yards or after a few minutes on level ground. Nine persons did not provide the start date or give enough information on the start date, precluding a determination of whether they had pre-existing shortness of breath before employment. Six persons reported their shortness of breath started before their hire date, and five reported their shortness of breath started after their hire date at the plant, while one reported shortness of breath onset started within one month of hire.

The prevalences of other symptoms over the last year and last four weeks are listed in Table A20. Some participants with mucous membrane irritation of eyes, nose, or sinuses attributed it to green coffee or roasted coffee dust, smoke, pallet dust/debris, heat in the roasting room, 
or the burlap bags. Three participants noted that coffee dust caused or aggravated their asthma type symptoms (e.g., cough, wheeze, awakening with chest tightness or shortness of breath). At the time of the survey, 26\% (20/75) of participants reported one or more of the following asthma-type symptoms in the past 12 months: wheezing or whistling in their chest, waking up with chest tightness, or awakening by an attack of shortness of breath. Of the 20, one reported current asthma, and one reported a past physician diagnosis of asthma. Prevalences of self-reported physician diagnoses are reported in Table A21. No current worker participants reported a diagnosis of emphysema, bronchiolitis obliterans, interstitial lung disease, hypersensitivity pneumonitis, or chemical pneumonitis. No current employee participants reported having changed job duties because of breathing difficulties.

Thirty-three (44\%) participants reported ever wearing a disposable respirator at the plant. (Participants were shown pictures of disposable dust respirators when asked if they had ever worn a disposable respirator at the facility.) Table A22 summarizes tasks participants performed while wearing the disposable respirators. Four participants reported wearing half-face respirators in the flavoring room. Sixteen (21\%) participants reported ever wearing hearing protection at the plant.

\section{NHANES III Comparison of Symptoms and Diagnoses}

In comparison to expected numbers from the NHANES III survey [CDC 1996], participants had a 1.6-fold significantly higher prevalence of shortness of breath on exertion in response to the question of shortness of breath on level ground or walking up a slight hill [SMR 1.6 (95\% CI:1.0-2.4] (Table A23). This degree of shortness of breath is less than those degrees used in our index of suspicion for obliterative bronchiolitis, but persons with higher degrees of shortness of breath respond affirmatively to this question as well. The other symptom that approached statistical significance was wheeze in the last 12 months, with a SMR of 1.5 (95\% CI: 0.9-2.5). No statistically significant excesses of physician-diagnosed asthma, chronic bronchitis, cough, phlegm, sinus problems, or eye and nasal symptoms, existed in comparison to the national sample.

\section{Medical Tests}

Table A24 summarizes the lung function testing results for current workers. Of 69 participants with spirometry results, five had obstructive abnormalities, two had restrictive abnormalities, and eight had low FEF25-75. Of the five workers with airways obstruction, four had mild obstruction, and one had moderate obstruction. We administered bronchodilator to three participants with mild obstruction, of whom one met the definition of reversibility. All five participants with obstruction had normal diffusing capacity and alveolar volumes. The two with a restrictive pattern on spirometry had a low DLCO or alveolar volume. Four other participants with low DLCO or alveolar volume had normal spirometry.

Of the 45 participants who completed the mannitol challenge test, five had abnormal tests, reflecting bronchial hyperactivity. Three had mildly increased sensitivity and one moderate sensitivity of the airways. All five had normal spirometry, diffusing capacity, and alveolar volume. Two of those with abnormal mannitol tests reported no respiratory symptoms, which is inconsistent with a diagnosis of clinical asthma. Four of the five with an abnormal 
mannitol challenge test participated in the blood draw, and three had elevated total IgE reflecting atopy, but none had detectable levels of specific IgE to allergens from green coffee beans, coffee, or castor bean.

Of 60 current employee participants who took the ImmunoCAP blood tests, all had evidence of having been exposed to green coffee beans by their IgG levels (mean 1.54 milligrams per liter $(\mathrm{mg} / \mathrm{L})$. The great majority also had evidence of exposure to coffee $(n=57,95 \%$, mean $0.95 \mathrm{mg} / \mathrm{L})$ and castor beans $(\mathrm{n}=52,87 \%$, mean $0.60 \mathrm{mg} / \mathrm{L})$. Of the 60 participants, $22(36.6 \%)$ had high levels of total IgE; no participants who underwent testing had specific IgE to coffee or green coffee beans. One participant had specific IgE to castor beans. This participant reported no physician diagnosed asthma, but at the time of the medical survey, reported waking up with chest tightness in the past 12 months but not in the previous four weeks. The participant's spirometry was normal; the participant did not complete the mannitol challenge test.

\section{Lung Function Comparison to National Rates (NHANES III)}

Of the 69 participants in the NIOSH spirometry survey five had obstructive spirometric abnormalities (Table A25). This represented a statistically significant 2.7 -fold excess (95\% confidence interval $(\mathrm{CI})=1.2-6.4)$ in comparison to the general U.S. population sample studied in NHANES III, adjusted for age distribution, race, sex, and smoking history. The SMRs for abnormal restrictive spirometry $(0.4 ; \mathrm{CI}=0.1-1.6)$ and FEF25-75 $(1.1 ; \mathrm{CI}=0.6-$ 2.2) were not elevated.

\section{Lung Function by Work Area}

The statistical models that assessed spirometry outcome related to work area contained the 69 participants who underwent spirometry. Participants who reported currently spending work time in both the grinding/packaging room and flavoring room had significantly lower FEV1/ FVC ratios (expressed as a percent) compared to participants who reported not currently spending time in either of the areas $(77 \%$ vs. $83 \% \mathrm{p}=0.01)$. This analysis controlled for age and pack-years of smoking. Participants who reported currently spending work time in either the grinding/packaging room or the flavoring room had a marginally significantly lower mean FEV1/FVC ratio compared to participants who currently did not spend work time in either area $(80 \%$ vs. $83 \% \mathrm{p}=0.08)$. Participants who reported currently spending time in both high exposure areas had significantly lower percent predicted FEF25-75 than those who reported not currently spend time in both areas $(83 \%$ vs. $104 \%, \mathrm{P}=0.002)$. A logistic regression of abnormal FEF25-75 indicated a marginally significant effect of currently spending time in both high exposure areas $(\mathrm{OR} 8.8, \mathrm{CI}=0.98-79.7, \mathrm{P}=0.052)$.

The mean FEV1/FVC ratio for ever spending time in both the grinding/packaging room and flavoring room compared to never in either area was marginally significantly different (78\% vs. $82 \%, \mathrm{p}=0.1$ ). The mean FEV1/FVC ratio for ever spending time in either the grinding/ packaging room or flavoring room compared to never in either area was not statistically different $(80 \%$ vs. $83 \%, p=0.3)$, but the smaller size of the comparison group $(n=9)$ who had never worked in the areas lowered the statistical power. Current or ever major work area alone (without including time spent in the same area) was not associated with FEV1/ 
FVC ratio. No other lung function parameter was associated with major work area or with time spent in these two high alpha-diketone exposure areas. No lung function parameter was associated with spending work time (either currently or ever) in the roasting room.

\section{Symptoms by Work Area}

Currently spending work time in the roasting room was significantly associated with having trouble with breathing in the last 12 months (OR 3.8, CI $=1.0-14.0, \mathrm{p}=0.044$ ); wheeze in the last 12 months (OR 3.39, $\mathrm{CI}=1.0-11.3, \mathrm{p}=0.047)$; sinus symptoms in the last 12 months (OR 4.2, $\mathrm{CI}=1.2-14.6, \mathrm{p}=0.025)$; and burning eyes in the last 12 months (OR $4.37, \mathrm{CI}=1.3-15.2, \mathrm{p}=0.020)$. There were no significant associations between symptoms and currently spending work time in the flavoring and/or grinding and packaging rooms.

\section{Possible Work-related Lung Disease}

Current workers meeting index of suspicion for possible obliterative bronchiolitis There were six participants among the current employees for whom we had the highest suspicion of possible obliterative bronchiolitis using the criteria described in the methods section. Five of the six met the shortness of breath on exertion criteria, and at some time during their tenure had the flavoring room or the grinding/packaging room as their major department assignment or spent some time in these areas. Three of the five reported post-hire onset of the shortness of breath, and two did not give a date of onset. Four of the six reported other lower respiratory symptoms. Three of the six had lung function abnormalities. Four of the six had never smoked, and two had a minor smoking history of less than one pack-year. One of the six reported a diagnosis of walking pneumonia that did not respond to antibiotics, and one had a post-hire diagnosis of asthma but did not report current asthma.

\section{Current workers meeting index of suspicion for possible work-related asthma}

We had suspicion that five other employees had work-related asthma, which includes both occupational asthma where exposures at work cause onset of asthma and workexacerbated asthma where exposures at work exacerbate but did not cause onset of the asthma. In examining the medical survey results of the current employees, we noted two participants with highest suspicion of possible occupational asthma. One participant had a positive antibody test for castor beans. The second participant had mild obstruction, a posthire diagnosis of asthma, and asthma medication use. (The participant noted in the above section with post-hire asthma may also possibly have occupational asthma.) We noted three participants with highest suspicion of possible work-exacerbated asthma. All three reported asthma-type symptoms that improved away from work. One had pre-hire onset of symptoms. Two were mannitol sensitive and had elevated total IgE.

In summary, the eleven employees for whom we had the highest suspicion of occupational lung disease, either obliterative bronchiolitis or work-related asthma, had abnormalities or symptoms that merited follow up and clinical referral.

\section{Former Workers}

We tested 13 former workers, of whom five reported physician-diagnosed obliterative 
bronchiolitis. At the time of our testing, they ranged in age from 25 to 42 years. All five reported post-hire onset of lower respiratory symptoms and abnormal spirometry (FEV1 range: $22.4 \%-41.9 \%$ of predicted; FVC range: $73.1 \%-88.3 \%$ of predicted; FEV1/FVC ratio range: $25.9 \%-43.6 \%$; FEF $25-75$ range: $6.1 \%-12.3 \%$ of predicted). Two had obstructive abnormalities with reduction in FEV1, and three had mixed abnormalities with reduction in FEV1/FVC ratio and FVC. None had reversibility with bronchodilator. The two participants with the lowest percent predicted FEV1s (22.4\% and 31.9\%) had low alveolar volumes.

All five former workers, who were diagnosed with obliterative bronchiolitis, reported working in the flavoring room (as a mixer, flavor specialist, hand packer/helper, packaging machine operator, and/or grinder); four reported working in the grinding/packaging room (as a helper, packaging machine operator, and/or grinder). Some reported that in addition to their primary job, they sometimes had secondary duties helping out in other areas including grinding coffee or performing re-works in the flavoring room. Two of the five had high levels of total IgE; none of the five had specific IgE to coffee, green coffee beans, or castor beans. Only one of five had ever smoked, although the age less than 40 years likely precluded smoking as an etiology for the severe spirometric abnormality.

Of the remaining eight former workers tested, ages ranged from 22 to 51 years. All eight reported chest symptoms. One had mild restriction on spirometry without bronchodilator response. The remainder had normal spirometry and other lung function tests. One had abnormal specific IgE to green coffee, coffee, and castor bean allergens as well as an elevated total IgE. Two others also had high total IgE.

\section{Company-provided Spirometry}

The company provided NIOSH with 145 pdf copies of spirometry reports from testing in October 2014 (for 80 employees) and October 2015 (for 65 employees). In 2014, the companycontracted reviewing physician reported 23 (29\%) of 80 employees reported one or more respiratory symptoms (cough, wheezing, or shortness of breath on any degree of exertion) and the 23 had a mean FEV1 \% predicted of $93 \%$ and FVC \% predicted of $94 \%$. Of the $23,43 \%$ were current smokers. The smoking prevalence for all 80 employees was not noted. In 2015, the company-contracted reviewing physician reported 17 (26\%) of 65 employees reported having one or more respiratory symptoms (cough, wheezing, or shortness of breath on any degree of exertion) with $41 \%$ being current smokers. The overall smoking prevalence of tested employees was reported to be $30 \%$. The physician noted no significant differences in spirometry values between employees with and without respiratory symptoms. He also reported that review and comparison of employees with spirometry tests in 2014 and 2015 did not reveal significant or unusual trends.

We excluded two of the spirometry reports from 2015 because the resolution of the plots was not good enough for NIOSH to definitively identify the usable trials. Of the 104 employees with company-provided spirometry reports, 39 (37.5\%) had tests in both 2014 and 2015, and the remaining 65 had been tested in only one of those years. Overall, we found the company's spirometry testing to be of good quality with 140 having an A, B, or C quality grade for both FVC and FEV1. Of the 143 tests reviewed, 141 (98.6\%) had an FVC quality grade of A (69.9\%), B (20.3\%), or C (8.4\%), and 140 (97.9\%) had a FEV1 quality grade of A (73.4\%), B 
$(16.8 \%)$, or C $(7.7 \%)$.

Overall, NIOSH interpretations were similar to those of the company-contracted reviewing physician. The reviewing physician appeared to use the same ATS interpretative strategies for lung function tests as NIOSH [Pellegrino et al. 2005]. We noted a few differences between NIOSH and the reviewing physician when it came to grading the severity level of spirometric restriction. This might be explained if the reviewing physician used the value of the percent predicted FVC rather the value of the percent predicted FEV1 to grade the severity of spirometric restriction. We used the FEV1 percent predicted to categorize the severity (e.g., mild, moderate, severe) of restrictive and obstructive abnormalities [Pellegrino et al. 2005].

Of the 69 employees that completed spirometry during the health hazard evaluation, 27 had additional tests collected during the company's medical surveillance; the 2014 and 2015 company-provided reports included results on 77 workers that NIOSH had not previously tested with spirometry.

\section{Longitudinal Changes in Spirometry}

Of the 27 employees tested by NIOSH who also had a company-provided spirometry test result, one employee had a drop in FEV1 greater than 15\%, after accounting for expected loss due to aging, between the NIOSH test and the most recent company provided test. The employee's FVC declined less than 15\%. This employee's NIOSH spirometry test showed normal spirometry. Two years later, the company-provided spirometry test showed a mild abnormality.

Of the 23 employees that did not have NIOSH spirometry testing but had two companyprovided spirometry tests, none had drops in FEV1 or FVC greater than $15 \%$, after accounting for expected loss due to aging.

\section{Discussion}

Diacetyl, 2,3-pentanedione, 2,3-hexanedione, other VOCs, and other chemicals such as CO and $\mathrm{CO}_{2}$ are naturally produced when coffee beans are roasted, and grinding roasted coffee beans produces greater surface area for the off-gassing of these chemicals [Anderson et al. 2003; Akiyama et al. 2003; Daglia et al. 2007; Newton 2002; Nishimura et al. 2003; Raffel and Thompson 2013]. Occupational exposure to diacetyl and 2,3-pentanedione can cause loss of lung function and the lung disease obliterative bronchiolitis [NIOSH 2016a]. Exposure to green and roasted coffee dust is a risk factor for work-related asthma [Harvey et al. 2020].

\section{Alpha-Diketones}

\section{Personal Air Sampling}

Evacuated canister samples collected during the walkthrough visit in July/August 2012 were collected over three-hour periods. Direct comparison to the 8-hour NIOSH REL is not applicable because the evacuated canister method is not validated for personal sampling. However, these samples provided initial important information on alpha-diketone concentrations in the facility and were used to develop the sampling strategies for the future 
industrial hygiene surveys.

In November 2012, all personal air sample concentrations were above the NIOSH REL for diacetyl except for one in the finished goods warehouse. The highest full-shift personal diacetyl concentration was measured on a packaging room employee sample (166 ppb). During the second visit in April 2017, all personal air sample concentrations were above the NIOSH REL for diacetyl except one sample on an employee working in the upstairs nonproduction offices. The highest measured personal exposure in April 2017 was $163.8 \mathrm{ppb}$ on an employee working in the flavoring room. As noted earlier, the REL should be used as a guideline to indicate when steps should be taken to reduce exposures in the workplace. The risks associated with the measured levels are higher than NIOSH recommends.

As described in the quantitative risk assessment from the NIOSH Criteria Document (Tables 5-27 and 5-29) [NIOSH 2016a], after a 45-year working lifetime exposure to $100 \mathrm{ppb}$ (a concentration lower than the highest concentration (166 ppb) measured at this facility), NIOSH estimated that 25.7 in 1,000 workers would develop reduced lung function (FEV1 below the lower limit of normal). NIOSH predicted that around 2.7 in 1000 workers exposed to diacetyl at $100 \mathrm{ppb}$ would develop more severe lung function reduction (FEV1 below 60\% predicted, defined as at least moderately severe by the American Thoracic Society [Pellegrino et al. 2005]). After a 45-year working lifetime exposure to $200 \mathrm{ppb}$ (a concentration higher than the highest concentration measured at this facility), NIOSH estimated that 58.7 in 1,000 workers would develop reduced lung function (FEV1 below the lower limit of normal). NIOSH predicted that 6.4 in 1000 workers exposed to diacetyl at $200 \mathrm{ppb}$ would develop more severe lung function reduction. The effects of a working lifetime exposure at $166 \mathrm{ppb}$ is closer to $200 \mathrm{ppb}$ than $100 \mathrm{ppb}$. NIOSH recommends keeping diacetyl concentrations below $5 \mathrm{ppb}$ because at this level, the risk of reduced lung function after a working lifetime of exposure is below 1 in 1000 workers. NIOSH recommends taking steps to reduce diacetyl exposures to below the REL of 5 ppb whenever possible.

The highest full-shift personal sample results of 2,3-pentanedione observed during both visits were measured on employees working in the flavoring room with a maximum concentration of $199.0 \mathrm{ppb}$ in 2012 and $899.6 \mathrm{ppb}$ in 2017. Higher sample concentrations of 2,3-pentanedione than diacetyl in the flavoring room is consistent with the historical substitution of 2,3-pentanedione for diacetyl in the flavorings added to whole bean and ground coffee and was reflected in the headspace results for the nine bulk flavoring samples collected in April 2017. Although this substitution was intended to lower the risk of diacetylrelated lung disease, animal experiments have shown that 2,3-pentanedione is as hazardous to animal tissue as diacetyl [Morgan et al. 2012, 2016; Hubbs et al. 2012].

With the exception of samples in the flavoring room, results generally showed personal exposures to diacetyl and 2,3-pentanedione were higher during our first visit (November 2012) compared to our second visit (April 2017). Alpha-diketone emissions of diacetyl and 2,3-pentanedione into workplace air are directly related to the amount of roasted coffee being produced. During the second visit, the company had added additional packaging equipment and was roasting, flavoring, and packaging approximately $70 \%$ more coffee. Increased 
production volume would be anticipated to result in higher personal exposures. However, the facility had undergone renovations to its ventilation and processing systems, enclosed the packaging mezzanine, and improved its grinder enclosures since our first visit. These changes were effective at limiting the anticipated increase in alpha-diketone exposures throughout the facility associated with the increased production volume. Overall, the majority of personal sample diacetyl concentrations in 2017 were lower than those observed in 2012 (Tables A4 and A5). The notable exceptions were higher diacetyl and 2,3-pentanedione personal sample concentrations measured in the flavoring room in 2017. However, these sample concentrations do not take into account the required respiratory protection, which if used properly, significantly reduces actual employee exposures.

\section{Area Air Sampling}

Air samples in production areas from both industrial hygiene surveys showed levels of diacetyl and 2,3-pentanedione over the NIOSH RELs of $5 \mathrm{ppb}$ and $9.3 \mathrm{ppb}$. However, these results cannot be compared directly to exposure limits but could result in over-exposure to employees working in these areas without respiratory protection.

In contrast to personal sample results, the area samples in production/storage areas, (flavoring, packaging and warehouses) showed higher results during the second visit. The increased volume of coffee being produced and stored during our second visit could result in the larger values due to more off-gassing of diacetyl and 2,3-pentanedione.

\section{Bulk Samples}

Diacetyl and 2,3-pentanedione are known respiratory hazards; however, in some flavoring formulations, they might not be listed as ingredients on safety data sheets (SDSs) when they are present [LebBouf et al. 2019]. This might be because diacetyl or 2,3-pentanedione are part of a proprietary mixture deemed trade secret, or diacetyl or 2,3-pentanedione may not be listed on SDSs if they are present at less than 1\% composition [OSHA 2012]. Diacetyl and 2,3-pentanedione also may be present in starter distillates which have a generally recognized as safe (GRAS) designation by U.S. Food and Drug Administration for ingestion by consumers [FDA 2008]. The GRAS designation does not take into account potential workplace exposures due to emissions from bulk flavorings. Diacetyl and 2,3-pentanedione as volatile constituents in headspace analysis have been identified in liquid flavorings; however, the alpha-diketones were not listed on flavorings' SDSs [LeBouf et al. 2019].

This coffee roasting, flavoring, and packaging facility requested that its flavoring suppliers eliminate diacetyl from the flavorings; however, our analyses of head space samples from bulk samples showed that they continued to contain some diacetyl and other alpha-diketones (2,3-pentanedione, 2,3-hexanedione) that were being used as diacetyl substitutes. Headspace analysis from the July/August visit in 2012 showed that for three of the flavorings tested, 2,3-pentanedione concentrations were one to two orders higher than diacetyl. Analyses of bulk flavoring samples collected during the April 2017 industrial hygiene survey identified 2,3-pentanedione in all nine samples and diacetyl in seven of the nine samples. 
2,3-Hexanedione was measured in only one sample.

\section{Dust}

During our visits, we noticed that the roasting room was hot and smoky at times, and coffee dust was aerosolized when compressed air was used to clean. The high dust concentrations in these areas may have caused irritation and respiratory symptoms among some employees. Spending time in the roasting room was significantly associated with sinus trouble, burning eyes, wheezing, having trouble with breathing in the last 12 months at the time of the medical survey.

The majority of dust sample results in 2012 were at or below the limit of detection, except in roasting and the greens warehouse. From the real-time dust sampling, we observed high concentrations in the greens warehouse (during the unloading of burlap bags of green coffee beans) and in the roasting room.

Although area inhalable dust concentrations were below OSHA and ACGIH occupational exposure limits, coffee dust, even at low concentrations, is known to cause respiratory symptoms [Zuskin et al. 1993; Sakwari et al. 2013]. Green and roasted coffee dust and castor beans (from cross-contamination of bags used to transport coffee) are known risk factors for occupational asthma [Figley and Rawling 1950; Karr et al. 1978; Zuskin et al. 1979, 1985; Thomas et al. 1991]. People who become sensitized (develop an immune reaction) to coffee dust can subsequently react to relatively low concentrations in the air. Others may experience irritant-type symptoms from exposure to coffee dust [Oldenburg et al. 2009].

\section{Real-time Sampling for $\mathrm{CO}, \mathrm{CO}_{2}$, and TVOCs}

Our real-time monitoring found that the highest overall levels of total $\mathrm{CO}, \mathrm{CO}_{2}$, and TVOCs were observed in flavoring and packaging.

Measurements of CO in April 2017, collected beside the new grinder for lines $5 \& 6$ and near the grinder enclosure for lines $7 \& 8$ in packaging and inside the flavoring room grinder enclosure, exceeded the NIOSH REL of $35 \mathrm{ppm}$. Only one measurement inside the flavoring room grinder enclosure exceeded the OSHA PEL (50 ppm). Also, peak levels of $\mathrm{CO}$ exceeded the NIOSH ceiling of $200 \mathrm{ppm}$ inside the flavoring room grinder enclosure. The NIOSH ceiling limit should not be exceeded at any time; however, employees do not typically enter the grinder enclosure during operation. The highest average $\mathrm{CO}_{2}$ concentrations were observed in the flavoring room with a range of $893.4 \mathrm{ppm}$ to $1,183.0$ ppm, which was below the NIOSH REL (5,000 ppm) and OSHA PEL (5,000 ppm).

Interpreting real-time sampling results in a complex industrial setting is often difficult. Variations in TVOCs, $\mathrm{CO}_{2}$, or $\mathrm{CO}$ may be the result of nearby work tasks, tasks in adjacent areas of the facility, or a combination of both. Efforts were made to minimize instrument variability (e.g., daily calibration and maintenance), but variations occur between instruments. The Tiger TVOC monitors were used only in flavoring during the 2017 visit and were not used in 2012. All other TVOC measurements were taken with the RAE Systems, 
ppbRAE 3000 monitors.

There is no standard for TVOC concentrations, however they can be used as a guideline tool for investigation of emissions and efficacy of controls. The TVOC background concentrations ranged from 1,000 $\mathrm{ppb}-2,000 \mathrm{ppb}$ with some brief peaks over 52,000 ppb and several others over $10,000 \mathrm{ppb}$ in the grinding/packaging room. The real-time instruments used are unable to distinguish between compounds in the TVOC readings. Thus, it is not possible to estimate the contribution of diacetyl and 2,3-pentandeione to the TVOC values, but the readings are useful in identifying areas and processes that release the highest concentrations of TVOCs. Furthermore, NIOSH sampling results for alpha-diketones have indicated their presence in relatively high concentrations in areas that correspond to the real-time TVOC results. The flavoring and grinding/packaging rooms consistently showed the highest background concentrations in the facility. In the grinding/packaging room, we observed high TVOC concentrations above the grinders and hoppers of roasted coffee. We know from published studies that diacetyl and 2,3-pentanedione are produced during the coffee roasting process [Daglia et al. 2007] and are released during grinding [Akiyama et al. 2003]. In the break room, we recorded TVOC concentration readings as high as 10,873 ppb while a QC technician weighed ground, flavored coffee. As we have recommended in previous interim letters, quality control checks of flavored coffee should not be performed in the break room.

\section{Respiratory Protection}

The respirator protection requirements for employees at this facility varied over time. In July/August 2012, N95 filtering facepiece respirators were available but not required. In September 2012, flavoring specialists and mixers sometimes wore half-face air-purifying respirators. In November 2012, flavoring employees were required to wear full-face powered air-purifying respirators (with an APF of 1000). In April 2017, half-face air-purifying respirators were required in flavoring, the packaging mezzanine, while feeding roasted coffee into the new corner-seal packaging line, and during rework.

Until engineering and administrative controls are in place, we recommend respiratory protection to reduce exposures to alpha-diketones. The choice of respirator should be guided by personal exposure sampling for diacetyl and 2,3-pentanedione. Information on respirators can be found in Chapter 8 of the NIOSH Criteria Document [NIOSH 2016a] and in the NIOSH Respirator Selection Logic [NIOSH 2004]. The selection of a specific respirator depends on the particular situation and should be made only by qualified personnel [NIOSH 2016a].

\section{Ventilation}

The most significant modification made to the facility following the November 2012 industrial hygiene visit was the enclosure of the entire mezzanine level above packaging. During our April 2017 industrial hygiene visit, it was separate from all other production spaces. Two new air ducts to supply air to the enclosed mezzanine were added along the south wall, and each duct had two supply openings, one high and one low. Two exhaust fans were located in the roof near the northern end of the space. The air-handling unit serving the 
nonproduction office areas had also been replaced since 2012.

While the changes made since 2012 should have resulted in noticeable reductions in airborne concentrations of diacetyl and 2,3-pentanedione in some areas of the facility, demonstrating those reductions in 2017 was complicated by a 70\% increase in total production since 2012. Enclosing the packaging mezzanine and ventilating it separately would be expected to have the most noticeable reductions in alpha-diketone concentrations in the enclosed mezzanine and the remainder of packaging. As shown in Table A3, the alpha-diketone concentrations were generally lower in the packaging mezzanine, which can be directly attributed to the additional ventilation added to the enclosure. The concentrations in the rest of packaging remained relatively stable between 2012 and 2017. Given the production volume increase, this indicates the mezzanine enclosure and added ventilation had the intended effect.

In 2017, as in 2012, the production offices were served by air-handling units that pulled their supply air from packaging. All air supply in production offices was recirculated from the production area. There were two ceiling level air returns, one located in the locker room and one in the maintenance manager's office. Most production offices and break room doors were open throughout the day shift. However, the doors between the locker room and QC area were kept closed to the production area during the day. In general, this ventilation configuration resulted in production offices having similar airborne concentrations of alphadiketones as the adjacent packaging area.

\section{Medical Survey}

This coffee plant had five cases of physician-diagnosed obliterative bronchiolitis among employees who have left employment. The question addressed by the NIOSH medical survey was whether these cases were a sentinel for disease or subclinical findings in current or other former employees that might reflect past or continuing disease risk. Several findings among the current workforce studied in 2012 suggested that occupational lung disease risk was present and required follow up: (1) A statistically significant 2.7-fold excess of measured spirometric obstruction and a 1.6-fold excess of shortness of breath on exertion existed in the coffee plant employees compared to the U.S. noninstitutionalized population of the same age, race/ethnic, sex, and cigarette smoking distribution. (2) Several employees reported a severe degree of shortness of breath, which is unusual in working populations. (3) Employees that spent time in both of the high alpha-diketone exposure areas (grinding/ packaging and flavoring rooms) had a statistically significant decrease in mean FEV1/FVC ratio in comparison to employees that had not worked in either of these areas, adjusted for the usual correlates of such ratios. (4) Employees that currently spent time in both of the high alpha-diketone exposure areas had a mean FEF25-75\% predicted that was 21 percentage points lower than employees without such exposure. (5) We identified six employees who had production area alpha-diketone exposures and reported shortness of breath or had abnormalities on the battery of medical tests, which were concerning and unlikely to be explained by cigarette smoking. In addition, we identified five current employees with suspect work-related asthma, of whom two had likely occupational asthma.

The current employee participants had a 2.7-fold excess prevalence of obstructive spirometry. 
The five former employees with physician-diagnosed obliterative bronchiolitis had marked obstructive or mixed obstructive and restrictive spirometric abnormalities on our spirometry testing. We found no current employees with that degree of impairment on spirometry, although four had comparable degrees of severe shortness of breath with exertion. We found that employees assigned to or spending time in both grinding and flavoring areas with high exposure to diacetyl and 2,3-pentanedione had a 6.0 percentage points lower average FEV1/ FVC ratio, compared to employees working in neither area. This finding suggested there may have been a subclinical effect on spirometry in this group, which accounted for nearly half of the plant population. Our finding of a 21 percentage point difference in the mean FEF25-75\% predicted in the high exposure group compared to all other employees is consistent with a small airways effect in employees who spent time in both high exposure areas (grinding/ packaging and flavoring rooms), as was striking in the sentinel former worker obliterative bronchiolitis cases whose FEF25-75 measurements were all less than $12.4 \%$ predicted.

One purpose of spirometric measurement was to identify employees with mild or moderate impairment so they could be prevented from developing severe impairment like the former employees who were diagnosed with obliterative bronchiolitis, which precluded their continued employment and many activities of daily living. Of the seven current employees that had spirometric abnormalities during the NIOSH testing, five with obstruction and two with restrictive pattern on spirometry, four either reported no industrial exposures to alphadiketones, were of an age that smoking habit might explain their abnormality (although smokers are not precluded from developing obliterative bronchiolitis), or their symptoms started pre-hire and did not appear to be work-exacerbated. The remaining three, two with obstruction and one with restrictive pattern on spirometry, reported working or spending time in high exposure areas, had no smoking history, and either reported work-related symptoms, or there was no clear-cut explanation for their symptoms. We included employees with restrictive abnormalities as needing further diagnostic evaluation because the pathologic presence of obliterative bronchiolitis can be accompanied by restrictive spirometric abnormalities or even normal spirometry. This has been shown in case series of obliterative bronchiolitis found on surgical biopsy but accompanied with either normal or abnormal spirometry [Ghanei et al. 2008, Markopoulou et al. 2002, King et al. 2011]. For that reason, we place emphasis on a cardinal symptom of pathologic obliterative bronchiolitis, shortness of breath.

The 1.6-fold excess of exertional shortness of breath compared to the U.S. population was concerning, given that persons can have this hallmark symptom of obliterative bronchiolitis but have normal spirometry [Ghanei et al. 2008; King et al. 2011]. The rapid progression of obliterative bronchiolitis within months in some worker populations [Kreiss et al. 2002; NIOSH 2008; Kanwal et al. 2011], and the prevalence of abnormalities in this plant with short median tenure of work supported institution of medical surveillance, as we advised in December 2012. Comparison of spirometry over time can allow identification of excessive decline in spirometry, if it exists, even within the normal range of spirometry. Early identification of such employees allows prevention of occupational lung disease such as obliterative bronchiolitis and asthma by counseling regarding risks, implementing engineering interventions to lower exposure, possibly reassigning employees to lower 
exposure jobs, and motivating employees to achieve better adherence to respiratory protection.

Twenty participants in the medical survey had asthma-like symptoms (wheezing or whistling in their chest, waking up with chest tightness, or awakening by an attack of shortness of breath), but only five reported a physician diagnosis of asthma. Asthma-like symptoms have been reported among persons diagnosed with obliterative bronchiolitis [Akpinar-Elci 2004; Modi et al. 2008; Cavalcanti et al. 2012]; however, respiratory health concerns are not limited to obliterative bronchiolitis or the use of flavorings [Harvey et al. 2020]. The coffee industry has a known risk of occupational asthma in relation to green and roasted coffee dusts and castor bean dusts from contaminated shipping bags [Figley and Rawling 1950; Thomas et al. 1991]. Plant management reported that only new burlap bags were used; however, a majority of employees had IgG evidence of past exposure to castor bean allergen. It is possible the burlap bags became contaminated with castor bean dust in shipping containers or somewhere else during the transport of the green coffee beans to the coffee roasting, flavoring, and grinding facility. We found one employee with a history of asthma symptoms and specific allergy to castor bean dust, consistent with having occupational asthma which may be active when castor bean allergens are present in the facility. One former employee had specific allergy to green coffee, coffee, and castor bean, and may have occupational asthma based on his reported symptoms during and after employment.

Mucous membrane symptoms, specifically eye, nose, and sinus symptoms, were commonly reported symptoms. Some participants with eyes, nose, or sinuses irritation attributed it to the burlap bags, green or roasted coffee dust, smoke, pallet dust/debris, or roasting room heat. Upper respiratory disease such as allergic rhinitis (hay fever, nasal allergies) and sinusitis are sometimes associated with lower respiratory symptoms and asthma and might precede the diagnosis of asthma [Shaaban et al. 2008; EAACI Task Force on Occupational Rhinitis et al. 2008; Rondón et al. 2012, 2017; Sahay et al. 2016]. Upper respiratory involvement (e.g., rhinitis, sinusitis) can result in suboptimal control of asthma. Green coffee dust is thought to be a more potent allergen than roasted coffee dust because roasting destroys some of the allergenic activity [Lehrer et al. 1978]. As discussed in the recommendations section, one way to prevent symptoms related to green coffee dust is to continue to make N-95 disposable filtering-face piece respirators available for voluntary use when emptying burlap bags of green coffee beans into storage silos or containers or when emptying the chaff containers or cleaning the green bean storage area.

In October 2014, the company instituted a medical surveillance program in response to our evaluation as a means of early identification of employees who might be developing lung disease (e.g., asthma, obliterative bronchiolitis) and to help prioritize interventions to prevent occupational lung disease. We reviewed company-provided spirometry conducted in October 2014 and October 2015. Most (98\%) tests were graded A, B, or C and could therefore be interpreted with confidence. One employee had at least a $15 \%$ decline in FEV1 or FVC between spirometry conducted during the NIOSH medical survey and subsequent contracted medical surveillance program spirometry. FEV1 and FVC are expected to decline by approximately $30 \mathrm{~mL}$ each year in the average non-smoking adult [OSHA 2013]. A 
$15 \%$ decline in FEV1 or FVC, after accounting for expected loss due to aging, is more than expected [Pellegrino et al. 2005; Townsend MC and Occupational and Environmental Lung Disorders Committee 2011]. Excessive decline in FEV1 or FVC could be due to work-related lung disease, or other factors such as the spirometry equipment, test subject or technician technique, or non-work-related illness affecting results. It is important to monitor the change in lung function and symptoms over time in employees participating in the medical surveillance program, and for the employee's healthcare provider to investigate progressive symptoms or excessive decline in FEV1 or FVC to address the possibility of work-related lung disease and rule out work-related lung disease or remove that employee from exposure to potential respiratory hazards at work. The systematic analysis of aggregate medical tests and symptoms over time help prioritize interventions to prevent work-related lung diseases in employees.

This health hazard evaluation had several limitations. The first is the workforce was small, and there was not an optimal internal control group with which we could compare the alphadiketone exposed workers. Only nine participants with spirometric measurements had never had any exposures in either the grinding/packaging room or the flavoring room. We had initially thought that we could compare flavoring employees with other production workers. However, the environmental data collected by NIOSH showed that the sum of diacetyl and 2,3-pentanedione exposures were similar for employees in the flavoring room and employees in the grinding and packaging area of unflavored coffee. The human body cannot differentiate between chemicals that are created by roasting unflavored coffee and released by grinding and the same chemicals that are present in chemical flavors added to coffee. Both diacetyl and 2,3-pentanedione have comparable toxicity to the airway epithelium in animals exposed to the chemicals [Morgan et al. 2012; Hubbs et al. 2012]. Apart from the adverse effect of working in the two high apha-diketone exposure areas on FEV1/FVC ratio and percent predicted FEF25-75, our inability to show other exposure-response relationships for alphadiketone exposure associated with adverse respiratory outcomes is likely explained by most employees (including those in production offices adjacent to the grinding/packaging room) having similar exposures at some time during their work weeks. With little range in exposures, it was possible that nearly the entire workforce had exposures sufficient to have affected them to some degree. For that reason, we had to rely on comparisons of shortness of breath and obstructive abnormalities to national data. These comparisons showed that the workforce as a whole had excess abnormalities in obstruction and shortness of breath.

A second limitation was that our environmental measurements in November 2012 were unlikely to reflect diacetyl and 2,3-pentanedione levels that existed in the past when the five sentinel cases became ill enough to seek medical attention. One change that may have affected chemical exposures in the flavoring room was the substitution of diacetyl-containing flavorings with flavorings containing 2,3-pentanedione. However, since 2,3-pentanedione is not safer than diacetyl, this change was unlikely to have lowered risk to employees. Another change that may have lowered average levels of exposure to flavoring chemicals was the engineering controls introduced in the flavoring room, including exhaust hoods, ventilated storage cabinets, and changes in the process of flavoring coffee. Respiratory protection for volatile chemicals was not introduced until after our initial visit and increased in the 
flavoring room after the NIOSH medical survey. Even PAPRs with an APF of 1000 might have been inadequate to lower the peak exposure risk of many thousands of ppb diacetyl or 2,3-pentanedione for a few seconds that were measured on the mezzanine over bins of unflavored ground coffee stored for off-gassing. Peak exposures appeared to be risk factors for obstructive spirometry in the microwave popcorn industry [Kreiss et al. 2002; Kanwal et al 2006]. Enclosing the entire mezzanine level of packaging was the most significant modification made to the facility since November 2012.

A third limitation was our inability to distinguish between relative risk in flavored coffee production and unflavored coffee production. All five sentinel cases of obliterative bronchiolitis had worked in the flavoring room and were attributed to flavoring chemicals. However, a majority of employees in the facility had spent time in the flavoring room, with only 21 of 75 NIOSH medical survey participants reported not working in the flavoring room or entering the flavoring room as part of their job.

A fourth limitation is that some participants did not complete all components of the voluntary medical survey. For example, two participants with an obstructive pattern on spirometry did not perform the bronchodilator test; thus, we do not know if the obstruction was reversible or not. Some participants with normal spirometry who reported lower respiratory symptoms did not perform or complete the mannitol challenge test to evaluate for asthma, and a few participants with lower respiratory symptoms did not perform any of the breathing tests. Additionally, some participants who entered high alpha-diketone exposure areas (e.g., maintenance staff and production supervisors) did not participate in the medical survey.

A fifth limitation was the insensitivity of our medical testing methods for obliterative bronchiolitis. Although the mainstay of medical surveillance recommendations is serial spirometry to identify abnormal declines within the normal range, we now recognize that many patients with exposure-related obliterative bronchiolitis on biopsy have normal spirometry and normal high-resolution computed tomography scanning of the chest. The symptom of exertional shortness of breath is what triggered medical evaluation in those subsequently found to have histological changes on lung biopsy. However, few pulmonary physicians would consider advising lung biopsy for patients with normal spirometry and radiology studies. Employees should be educated to understand the limitations of the medical tests and to consider the risks of further exposure if they develop shortness of breath that is progressive and severe in degree.

A final limitation is the healthy worker effect. Workers who become ill from occupational lung disease leave the workforce or the area in which they become ill if they cannot perform the required exertion. The five former employees with obliterative bronchiolitis reflect this healthy worker effect. Their former colleagues continued to work and thus appear healthier than the entire workforce that has been exposed to alpha-diketones, some of whom have left due to illness. Of the other eight former employees that we tested, at least two more had abnormalities that may have been related to occupational lung disease. Thus, the healthy worker effect in current workers usually results in an underestimation of work-related disease. As in other workforces with former employee sentinel cases, current employees 
usually have a burden of subclinical disease [Kreiss et al. 2002, Kim et al. 2010, Kreiss et al. 2012]. Our findings of abnormal prevalence of shortness of breath, severity of shortness of breath, and excess spirometric obstruction were consistent with an additional burden of occupational lung disease in current workers, despite the healthy worker effect.

In spite of the limitations, our evaluation has strengths. These include a high participation rate among employees, which lessens bias from testing participants who may not be representative of the entire current workforce. We had high quality spirometry measurements and offered confidentiality of results so that employees did not fear that their participation would threaten their employment. Additionally, we had an extensive characterization of average exposures by job and area. A medical surveillance program with serial spirometry and questionnaires can ascertain whether there is any indication of excessive declines that might predict which employees may be developing impairment. Serial environmental measurements can help evaluate whether exposures are lower with the interventions the company has made.

\section{Conclusions}

During both industrial hygiene visits, we identified specific work areas where personal fullshift and task-based exposures to diacetyl and 2,3-pentanedione exceeded their respective NIOSH REL and STEL. Additional efforts to reduce concentrations need to be made such as the installation of local exhaust ventilation or the introduction of more outdoor air. The changes made to the facility prior to our second visit in 2017 did not reduce personal exposures below the RELs. However, those changes did reduce general area air concentration levels below those observed during the first visit, despite the increased production volume. Work areas where grinding, packaging, or flavoring of roasted coffee beans occurred were associated with the highest observed personal sample diacetyl levels. Most full-shift area air sample concentrations of diacetyl were higher during our first industrial hygiene survey in November 2012, except in flavoring and packaging which showed an increase during our April 2017 visit. The packaging and flavoring areas had higher levels of diacetyl, 2,3-pentanedione, 2,3-hexanedione, TVOCs, $\mathrm{CO}$, and $\mathrm{CO}_{2}$ compared to other areas of the facility. We observed the highest levels of TVOCs, $\mathrm{CO}$, and $\mathrm{CO}_{2}$ in the flavoring room. CO levels exceeded the NIOSH ceiling limit of $200 \mathrm{ppm}$ inside the flavoring room grinder enclosure where employees should not be during operation. Measured dust concentrations in 2012 were below OSHA and ACGIH occupational exposure limits.

Enclosing the entire mezzanine level of packaging was the most significant modification made to the facility since November 2012. The alpha-diketone concentrations were generally lower in the packaging mezzanine, which can be directly attributed to the additional ventilation added to the enclosure. Given the production volume increase of $70 \%$ since 2012 , the mezzanine enclosure and added ventilation had the intended effect. However, the production volume increases and installation of additional packaging equipment made it difficult to discern the full impact of the mezzanine enclosure and ventilation on the rest of the production area. For instance, the concentrations in the rest of packaging remained relatively stable between 2012 and 2017. The production offices were served by air-handling units that pulled their supply air from packaging. This ventilation configuration results in production offices having similar airborne concentrations of alpha-diketones as the adjacent packaging area. 
Employees had occupational lung morbidity associated with high diacetyl and 2,3-pentanedione exposures, which were not limited to the flavoring room. Continuation of the medical surveillance program that includes health questionnaires and breathing tests (e.g., spirometry) is important to screen for respiratory symptoms or abnormalities in employees. Also, the systematic analysis of aggregate medical tests and symptoms over time is important to look for trends and possible risk factors for disease that can help prioritize interventions to prevent work-related lung diseases in employees.

\section{Recommendations}

On the basis of our findings, we recommend the actions listed below. We encourage this coffee roasting, flavoring, packaging facility to use a labor-management health and safety committee or working group to discuss our recommendations and develop an action plan. Our recommendations are based on an approach known as the hierarchy of controls. This approach groups actions by their likely effectiveness in reducing or removing hazards. In most cases, the preferred approach is to eliminate hazardous materials or processes and install engineering controls to reduce exposure or shield employees. Until such controls are in place, or if they are not effective or feasible, administrative measures and personal protective equipment might be needed.

\section{Engineering Controls}

Engineering controls reduce employees' exposures by removing the hazard from the process or by placing a barrier between the hazard and the employee. Engineering controls protect employees effectively without placing primary responsibility of implementation on the employee.

1. Continue working with a qualified ventilation contractor to improve existing LEV systems and install additional systems throughout the production space. Any new LEV systems should be targeted at specific points along production lines to capture alpha-diketones at their source.

a. In flavoring, add dampers to the LEV system attached to Exhaust Fan 1 in the flavoring room to allow for better balancing of air flows. Consider closing off the exhaust registers behind the flavoring barrel storage to allow for some (or more) exhaust flow at the flavor pumping station. Add curtains or clear plastic panels around the barrel mixing station in the flavoring room to better enclose the process and improve the capture effectiveness. Consider adding a ventilated enclosure on the bench where the flavorings are weighed and connect it to the Exhaust Fan 1 local exhaust system in the flavoring room. Also, continue working to tighten the grinder enclosure, including the addition of flexible skirting around the bottom and ensure the door remains closed.

b. In packaging, enclose the new grinder serving lines 5 and 6 . Tighten the existing grinder enclosure, including the addition of flexible skirting around the bottom. Ensure that the doors on both grinder enclosures always remain closed. Install 
LEV in areas where rework is done and investigate product lines to determine other areas where LEV may be appropriate.

2. Add dilution ventilation through the addition of outdoor air in areas where LEV is not feasible or cannot reduce concentrations below NIOSH RELs. Ensure that outdoor air is supplied from an area free of contamination from existing exhaust systems.

3. Add markings on the flavoring room and grinding/packaging area grinder enclosure static pressure (magnehelic) gauges to indicate the range of acceptable readings. Consider moving the gauges further down into the enclosures to better indicate enclosure performance. A lower level would also prevent the operator from needing a ladder to accurately read the gauge.

4. Continue to operate the grinding/packaging mezzanine variable frequency drives (VFDs) at $30 \mathrm{~Hz}$ for the supply fans and $60 \mathrm{~Hz}$ for the exhaust fans, as we left them on April 13, 2017. These new settings should properly maintain the mezzanine under negative pressure compared to the grinding/packaging space. These VFD settings may need to be evaluated and readjusted as additional ventilation changes are made.

5. Modify existing ventilation systems serving the production offices, breakroom, and locker rooms so that supply air originates from outside the plant. Ensure that no air from the production area is recirculated into those areas.

6. Conduct follow-up air sampling to verify that the modifications have been effective in reducing alpha-diketone exposures below the NIOSH RELs. If diacetyl and 2,3-pentanedione concentrations are not maintained below the RELs, additional engineering controls may be necessary.

\section{Administrative Controls}

Administrative controls are employer-dictated work practices and policies implemented to reduce or prevent hazardous exposures. Their effectiveness depends on employer commitment and employee acceptance. Regular monitoring and reinforcement are necessary to ensure that policies and procedures are followed consistently.

1. Periodically clean the roasters' exhausts in accordance with manufacturer instructions to remove chaff build up to reduce a fire hazard and to improve the efficiency, energy usage, and roaster performance.

2. Include roaster exhaust checks and any future local exhaust systems in a preventive maintenance schedule to ensure they operate appropriately.

3. Eliminate the use of compressed air and dry sweeping as much as possible during cleaning. Instead, use a vacuum system with a high-efficiency particle air filter and wet methods whenever possible.

4. Ensure employees understand potential hazards (e.g., diacetyl, 2,3-pentanedione, $\mathrm{CO}, \mathrm{CO}_{2}$, dust) in the workplace and how to protect themselves. OSHA's Hazard Communication Standard, also known as the "Right to Know Law" [29 CFR 
1910.1200] requires that employees are informed and trained on potential work hazards and associated safe practices, procedures, and protective measures.

5. Ensure employees are educated to consider the risks of further exposure if they develop lower respiratory symptoms (e.g., cough, shortness of breath, wheezing) that are progressive and severe in degree. Employees should report new, persistent, or worsening symptoms to their personal healthcare providers and to a designated individual at this workplace. Employees with new, persistent, or worsening symptoms should share this report with their healthcare providers.

\section{Personal Protective Equipment}

The effectiveness of personal protective equipment in the form of respiratory protection in controlling respiratory exposures depends on avoiding breakdowns in implementation that result in insufficient protection. Proper use of respiratory protection (respirators) requires a comprehensive respiratory protection program and a high level of employee and management involvement and commitment to assure that the right type of respirator is chosen for each hazard, respirators fit users and are maintained in good working order, and respirators are worn when they are needed. Supporting programs such as training, change-out schedules, and medical assessment might be necessary. Respirators should not be the sole method for controlling hazardous inhalation exposures. Rather, respirators should be used until effective engineering and administrative controls are in place.

1. Until engineering and administrative controls are in place, respiratory protection for diacetyl and 2,3-pentanedione should continue to be used to reduce exposures to alphadiketones. The choice of respirator should be guided by personal exposure sampling for diacetyl and 2,3-pentanedione. Respirators have assigned protection factors (APFs). APF refers to the highest level of protection a properly selected respirator can provide. For instance, air-purifying half-face respirators have an of 10, and airpurifying full-face respirators have an APF of 50. Powered-air purifying respirators have APFs of 25, 50, or 1,000. The OSHA APFs can be found in Table 1 of OSHA Respiratory Protection Standard at https:/www.osha.gov/laws-regs/regulations/ standardnumber/1910/1910.134

Based on a REL for diacetyl of 5 ppb:

- a properly fit-tested half-face respirator with an APF of 10 and organic vapor cartridges would be protective for a diacetyl concentration up to $50 \mathrm{ppb}$ (10 APF x 5 $\mathrm{ppb}=50 \mathrm{ppb})$

- a properly fit-tested half-face respirator with an APF of 50 and organic vapor cartridges would be protective for a diacetyl concentration up to $250 \mathrm{ppb}$ of diacetyl $(50$ APF x 5 ppb $=250 \mathrm{ppb})$

- a properly fit-tested PAPR with an APF of 1000 and organic vapor cartridges would be protective for a diacetyl concentrating up to $5000 \mathrm{ppb}$ of diacetyl (1000 APF x 5 $\mathrm{ppb}=5000 \mathrm{ppb})$ 
Based on a REL for 2,3-pentanedione of $9.3 \mathrm{ppb}$ :

- a properly fit-tested half-face respirator with an APF of 10 and NIOSH-certified organic vapor cartridges would be protective for a 2,3-pentanedione concentration up to $93 \mathrm{ppb}(10 \mathrm{APF} \times 9.3 \mathrm{ppb}=93 \mathrm{ppb})$

- a properly fit-tested half-face respirator with an APF of 50 and NIOSH-certified organic vapor cartridges would be protective for a 2,3-pentanedione concentration up to $465 \mathrm{ppb}$ of 2,3-pentanedione (50 APF x $9.3 \mathrm{ppb}=465 \mathrm{ppb}$ )

- a properly fit-tested PAPR with an APF of 1000 and NIOSH-certified organic vapor cartridges would be protective for a 2,3-pentanedione concentration up to 9,300 ppb of 2,3-pentanedione (1000 APF x $9.3 \mathrm{ppb}=9,300 \mathrm{ppb})$

Information on respirators can be found in Chapter 8 of the NIOSH Criteria Document [NIOSH 2016a] and in the NIOSH Respirator Selection Logic [NIOSH 2004]. The selection of a specific respirator depends on the particular situation and should be made only by qualified personnel [NIOSH 2016a].

2. Continue to implement a written respiratory protection program as required by OSHA Respiratory Protection Standard (29 CFR 1910.134), including medical evaluation, training, fit testing, maintenance, and use requirements for all employees who use respiratory protection.

3. Continue to make N95 disposable filtering-face piece respirators available for voluntary use for protection against green or roasted coffee dust exposure such as during emptying burlap bags of green beans into the storage silos, cleaning the roaster exhaust system of chaff, emptying the chaff containers, or cleaning the green bean storage area. N95 respirators should be available in various sizes, and each potential N95 user should receive a copy of Appendix D of the OSHA Respiratory Protection Standardabout Appendix D and voluntary use of respirators can be found on the OSHA website at https://www.osha.gov/laws-regs/regulations/standardnumber/1910/1910.134AppD

Please be aware N95s are not protective against alpha-diketones (diacetyl, 2,3-pentanedione, or 2,3-hexanedione). In cases of dual exposure to dust and alphadiketones, NIOSH-certified organic vapor cartridges (for the alpha-diketones) and particulate cartridges/filters (for the dust) would be warranted.

4. We did not formally assess noise during our visits. A noise survey would be necessary to determine the need for hearing protection and inclusion in a hearing conservation program. In the interim, continue to offer hearing protection for voluntary use at each roaster as well as other production areas

\section{Medical Surveillance}

The purpose of a medical surveillance program is to help assure the health of employees who have workplace exposures (e.g., diacetyl, 2,3-pentanedione, green coffee beans/dust) known to pose risk for potentially serious health conditions such as asthma or obliterative bronchiolitis. 
1. Continue your medical surveillance program for employees who work or assist in the production area. As detailed in the NIOSH Criteria Document [NIOSH 2016a], a medical surveillance program is recommended for all employees who work in the production areas or enter production areas for a total of 40 hours or more per year. According to the NIOSH Criteria Document, employees should have baseline medical evaluations before they are allowed to work in or enter areas where they might be exposed to diacetyl, 2,3-pentanedione, or similar flavoring compounds. The NIOSH Criteria Document recommends employees in the medical surveillance program be evaluated with a questionnaire (to obtain health and work task information) and spirometry (to assess lung function) every six months.

2. If an employee is identified as likely having lung disease from exposure to diacetyl, 2,3-pentanedione, or a similar flavoring compound, it should be viewed as a sentinel event indicating that there was a breakdown in exposure controls, and there is potential risk for co-workers. Should this occur, the source of exposure should be identified and brought under control. In addition, increased intensity of medical surveillance would be required for all employees performing similar job tasks or having similar or greater potential for exposure. The NIOSH Criteria Document provides detailed guidance on responses to such sentinel events [NIOSH 2016a].

\section{Smoking Cessation Program}

In a workplace with risk of occupational lung disease, prevention of smoking-related lung disease is important and makes the detection of work-related adverse effects easier. We recommend implementing a smoking cessation program to assist employees to stop smoking. The Centers for Disease Control and Prevention offers tools and resources for setting up a smoking cessation program [CDC 2019]. 


\section{Appendix A: Tables}

Table A1. Alpha-diketone concentrations in headspace of bulk samples of flavorings used during the NIOSH walkthrough visit, July/August 2012

\begin{tabular}{|c|c|c|c|c|c|c|c|c|}
\hline & \multicolumn{2}{|c|}{ Flavor A } & \multicolumn{2}{c|}{ Flavor B } & \multicolumn{2}{c|}{ Flavor C } & \multicolumn{2}{c|}{ Flavor D } \\
\hline \multicolumn{1}{|c|}{ Analyte } & $\mathrm{ppb}$ & $\begin{array}{c}\boldsymbol{\mu g} / \mathbf{c c} \\
\text { bulk }\end{array}$ & $\mathrm{ppb}$ & $\begin{array}{c}\boldsymbol{\mu g} / \mathbf{c c} \\
\text { bulk }\end{array}$ & $\mathrm{ppb}$ & $\begin{array}{c}\boldsymbol{\mu g} / \mathbf{c c} \\
\text { bulk }\end{array}$ & $\mathrm{ppb}$ & $\begin{array}{c}\boldsymbol{\mu g} / \mathbf{c c} \\
\text { bulk }\end{array}$ \\
\hline Diacetyl & 119,700 & 1.3 & 2,620 & 0.18 & 59,000 & 4.0 & 10,500 & 0.70 \\
\hline 2,3-Pentanedione & $1,040,000$ & 83 & ND & ND & 529,000 & 42 & 506,000 & 41 \\
\hline 2,3-Hexanedione & 82,000 & 7.5 & ND & ND & 42,500 & 3.9 & 55,500 & 5.1 \\
\hline
\end{tabular}

Note: NIOSH=National Institute for Occupational Safety and Health; $\mathrm{ppb}=$ parts per billion; $\mu \mathrm{g}$ / $c c=$ microgram per cubic centimeter; $\mathrm{ND}=$ not detected. 
Table A2. Alpha-diketone concentrations measured with evacuated canisters in parts per billion, NIOSH walkthrough visit, July/August 2012

\begin{tabular}{|c|c|c|c|c|}
\hline Analyte & $\begin{array}{c}\text { Sample } \\
\text { Type }\end{array}$ & Location & Date & $\begin{array}{c}\text { Concentration } \\
(\mathrm{ppb})\end{array}$ \\
\hline \multirow{8}{*}{$\begin{array}{l}\text { Diacetyl } \\
\text { Diacetyl } \\
\text { Diacetyl } \\
\text { Diacetyl } \\
\text { Diacetyl } \\
\text { Diacetyl } \\
\text { Diacetyl } \\
\text { Diacetyl } \\
\end{array}$} & Personal & Flavoring Specialist & \multirow[t]{3}{*}{$8 / 1 / 2012$} & 160 \\
\hline & Personal & Flavoring Mixer & & 160 \\
\hline & Personal & Flavoring Grinder/Packer Operator & & 130 \\
\hline & Personal & Flavoring Specialist & \multirow[t]{5}{*}{$8 / 2 / 2012$} & 260 \\
\hline & Personal & Flavoring Mixer & & 260 \\
\hline & Personal & Flavoring Grinder/Packer Operator & & 170 \\
\hline & Personal & Flavoring Packer Helper & & 130 \\
\hline & Personal & Flavoring Packer Helper & & 230 \\
\hline \multirow[b]{2}{*}{$\begin{array}{l}\text { Diacetyl } \\
\text { Diacetyl } \\
\text { Diacetyl } \\
\text { Diacetyl } \\
\text { Diacetyl } \\
\text { Diacetyl } \\
\end{array}$} & \multirow{2}{*}{$\begin{array}{l}\text { Area } \\
\text { Area } \\
\text { Area } \\
\text { Area } \\
\text { Area } \\
\text { Area } \\
\end{array}$} & Flavoring Grinder & $8 / 1 / 2012$ & 210 \\
\hline & & $\begin{array}{l}\text { Flavoring Mixing } \\
\text { Flavoring Room Mezzanine } \\
\text { Outside Flavoring Room Entrance } \\
\text { Roaster \#2 } \\
\text { Green Beans Warehouse }\end{array}$ & $8 / 2 / 2012$ & $\begin{array}{c}400 \\
310 \\
170 \\
14 \\
18\end{array}$ \\
\hline \multirow{8}{*}{$\begin{array}{l}\text { 2,3-Pentanedione } \\
\text { 2,3-Pentanedione } \\
\text { 2,3-Pentanedione } \\
\text { 2,3-Pentanedione } \\
\text { 2,3-Pentanedione } \\
\text { 2,3-Pentanedione } \\
\text { 2,3-Pentanedione } \\
\text { 2,3-Pentanedione }\end{array}$} & Personal & Flavoring Specialist & \multirow[t]{3}{*}{$8 / 1 / 2012$} & 530 \\
\hline & Personal & Flavoring Mixer & & 460 \\
\hline & Personal & Flavoring Grinder/Packer Operator & & 180 \\
\hline & Personal & Flavoring Specialist & \multirow[t]{5}{*}{$8 / 2 / 2012$} & 280 \\
\hline & Personal & Flavoring Mixer & & 570 \\
\hline & Personal & Flavoring Grinder/Packer Operator & & 140 \\
\hline & Personal & Flavoring Packer Helper & & 110 \\
\hline & Personal & Flavoring Packer Helper & & 180 \\
\hline \multirow{6}{*}{$\begin{array}{l}\text { 2,3-Pentanedione } \\
\text { 2,3-Pentanedione } \\
\text { 2,3-Pentanedione } \\
\text { 2,3-Pentanedione } \\
\text { 2,3-Pentanedione } \\
\text { 2,3-Pentanedione }\end{array}$} & Area & Flavoring Grinder & $8 / 1 / 2012$ & 650 \\
\hline & Area & Flavoring Mixing & \multirow[t]{5}{*}{$8 / 2 / 2012$} & 2000 \\
\hline & Area & Flavoring Room Mezzanine & & 650 \\
\hline & Area & Outside Flavoring Room Entrance & & 120 \\
\hline & Area & Roaster \#2 & & 12 \\
\hline & Area & Green Beans Warehouse & & 11 \\
\hline
\end{tabular}

Note: $\mathrm{NIOSH}=$ National Institute for Occupational Safety and Health; ppb=parts per billion. 
Table A3. Full-shift personal and area air sampling results by location using OSHA sampling and analytical methods, NIOSH industrial hygiene survey, November 2012

\begin{tabular}{|c|c|c|c|c|c|c|c|}
\hline Analyte & $\begin{array}{c}\text { Sample } \\
\text { Type }\end{array}$ & Location & $\mathbf{N}$ & $\begin{array}{c}\text { Above LOD } \\
\mathrm{N}(\%)\end{array}$ & $\begin{array}{c}\text { Minimum } \\
\text { Concentration } \\
(\mathrm{ppb})\end{array}$ & $\begin{array}{c}\text { Maximum } \\
\text { Concentration } \\
(\mathrm{ppb})\end{array}$ & $\begin{array}{c}\text { Above REL } \\
\text { N (\%) }\end{array}$ \\
\hline Diacetyl & Personal & All Over & 5 & $5(100 \%)$ & 49.2 & 80.1 & $5(100 \%)$ \\
\hline Diacetyl & Personal & Finished Goods Warehouse & 5 & $5(100 \%)$ & 4.3 & 11.7 & $4(80 \%)$ \\
\hline Diacetyl & Personal & Flavoring Room & 12 & $12(100 \%)$ & 52.6 & 96.3 & $12(100 \%)$ \\
\hline Diacetyl & Personal & Greens Warehouse & 4 & $4(100 \%)$ & 8.1 & 9.1 & $4(100 \%)$ \\
\hline Diacetyl & Personal & Offices-All & 1 & $1(100 \%)$ & 54.1 & 54.1 & $1(100 \%)$ \\
\hline Diacetyl & Personal & Offices-Nonproduction Downstairs & 1 & $1(100 \%)$ & 7.2 & 7.2 & $1(100 \%)$ \\
\hline Diacetyl & Personal & Offices-Production Area & 3 & $3(100 \%)$ & 39.7 & 139.5 & $3(100 \%)$ \\
\hline Diacetyl & Personal & Packaging & 16 & $16(100 \%)$ & 75.4 & 166.0 & $16(100 \%)$ \\
\hline Diacetyl & Personal & Quality Control Room & 3 & $3(100 \%)$ & 11.7 & 31.3 & $3(100 \%)$ \\
\hline Diacetyl & Personal & Roasting & 9 & $9(100 \%)$ & 15.1 & 40.1 & $9(100 \%)$ \\
\hline Diacetyl & Area & Finished Goods Warehouse & 9 & $9(100 \%)$ & 4.8 & 16.6 & N/A \\
\hline Diacetyl & Area & Flavoring & 16 & $16(100 \%)$ & 44.0 & 144.0 & $\mathrm{~N} / \mathrm{A}$ \\
\hline Diacetyl & Area & Flavoring-Mezzanine & 4 & $4(100 \%)$ & 82.7 & 124.4 & N/A \\
\hline Diacetyl & Area & Greens Warehouse & 11 & $11(100 \%)$ & 5.2 & 16.4 & $\mathrm{~N} / \mathrm{A}$ \\
\hline Diacetyl & Area & Maintenance Shop & 2 & $2(100 \%)$ & 3.5 & 10.2 & $\mathrm{~N} / \mathrm{A}$ \\
\hline Diacetyl & Area & Offices-Nonproduction Downstairs & 2 & $2(100 \%)$ & 3.1 & 4.4 & $\mathrm{~N} / \mathrm{A}$ \\
\hline Diacetyl & Area & Offices-Nonproduction Upstairs & 3 & $3(100 \%)$ & 4.0 & 4.9 & $\mathrm{~N} / \mathrm{A}$ \\
\hline Diacetyl & Area & Offices-Production Area & 8 & $8(100 \%)$ & 33.8 & 93.4 & $\mathrm{~N} / \mathrm{A}$ \\
\hline Diacetyl & Area & Outside & 4 & $4(100 \%)$ & 1.9 & 4.8 & $\mathrm{~N} / \mathrm{A}$ \\
\hline Diacetyl & Area & Outside of Flavoring Room & 4 & $4(100 \%)$ & 7.2 & 46.5 & N/A \\
\hline Diacetyl & Area & Packaging & 16 & $16(100 \%)$ & 67.9 & 112.2 & $\mathrm{~N} / \mathrm{A}$ \\
\hline Diacetyl & Area & Packaging-Mezzanine & 5 & $5(100 \%)$ & 102.9 & 247.2 & $\mathrm{~N} / \mathrm{A}$ \\
\hline Diacetyl & Area & Quality Control Room & 4 & $4(100 \%)$ & 5.5 & 9.5 & N/A \\
\hline Diacetyl & Area & Reception & 1 & $1(100 \%)$ & 2.6 & 2.6 & $\mathrm{~N} / \mathrm{A}$ \\
\hline Diacetyl & Area & Roasting & 18 & $18(100 \%)$ & 9.5 & 50.6 & $\mathrm{~N} / \mathrm{A}$ \\
\hline Diacetyl & Area & Roasting-Mezzanine & 4 & $4(100 \%)$ & 10.9 & 25.3 & $\mathrm{~N} / \mathrm{A}$ \\
\hline 2,3-Pentanedione & Personal & All Over & 5 & $5(100 \%)$ & 31.7 & 45.0 & $5(100 \%)$ \\
\hline 2,3-Pentanedione & Personal & Finished Goods Warehouse & 5 & $0(0 \%)$ & $<5.2$ & $<5.9$ & $0(0 \%)$ \\
\hline 2,3-Pentanedione & Personal & Flavoring & 12 & $12(100 \%)$ & 79.6 & 199.0 & $12(100 \%)$ \\
\hline 2,3-Pentanedione & Personal & Greens Warehouse & 4 & $0(0 \%)$ & $<5.2$ & $<5.6$ & $0(0 \%)$ \\
\hline 2,3-Pentanedione & Personal & Offices-All & 1 & $1(100 \%)$ & 18.0 & 18.0 & $1(100 \%)$ \\
\hline 2,3-Pentanedione & Personal & Offices-Nonproduction Downstairs & 1 & $0(0 \%)$ & $<5.6$ & $<5.6$ & $0(0 \%)$ \\
\hline 2,3-Pentanedione & Personal & Offices-Production Area & 3 & $3(100 \%)$ & 9.5 & 44.8 & $3(100 \%)$ \\
\hline 2,3-Pentanedione & Personal & Packaging & 16 & $16(100 \%)$ & 17.9 & 133.6 & $16(100 \%)$ \\
\hline 2,3-Pentanedione & Personal & Quality Control Room & 3 & $2(67 \%)$ & $<5.4$ & 15.8 & $2(67 \%)$ \\
\hline 2,3-Pentanedione & Personal & Roasting & 9 & $3(33 \%)$ & $<6.0$ & 15.8 & $3(33 \%)$ \\
\hline 2,3-Pentanedione & Area & Finished Goods Warehouse & 9 & $0(0 \%)$ & $<5.1$ & $<5.6$ & $\mathrm{~N} / \mathrm{A}$ \\
\hline 2,3-Pentanedione & Area & Flavoring & 16 & $16(100 \%)$ & 48.7 & 273.1 & $\mathrm{~N} / \mathrm{A}$ \\
\hline 2,3-Pentanedione & Area & Flavoring-Mezzanine & 4 & $4(100 \%)$ & 150.6 & 206.4 & $\mathrm{~N} / \mathrm{A}$ \\
\hline 2,3-Pentanedione & Area & Greens Warehouse & 11 & $1(9 \%)$ & $<5.0$ & 6.0 & $\mathrm{~N} / \mathrm{A}$ \\
\hline 2,3-Pentanedione & Area & Maintenance Shop & 2 & $0(0 \%)$ & $<5.2$ & $<5.2$ & N/A \\
\hline 2,3-Pentanedione & Area & Offices-Nonproduction Downstairs & 2 & $0(0 \%)$ & $<5.4$ & $<5.6$ & $\mathrm{~N} / \mathrm{A}$ \\
\hline 2,3-Pentanedione & Area & Offices-Nonproduction Upstairs & 3 & $0(0 \%)$ & $<5.3$ & $<5.5$ & $\mathrm{~N} / \mathrm{A}$ \\
\hline 2,3-Pentanedione & Area & Offices-Production Area & 8 & $8(100 \%)$ & 9.9 & 46.2 & $\mathrm{~N} / \mathrm{A}$ \\
\hline 2,3-Pentanedione & Area & Outside & 4 & $0(0 \%)$ & $<4.9$ & $<5.5$ & $\mathrm{~N} / \mathrm{A}$ \\
\hline 2,3-Pentanedione & Area & Outside of Flavoring Room & 4 & $4(100 \%)$ & 14.5 & 254.1 & $\mathrm{~N} / \mathrm{A}$ \\
\hline 2,3-Pentanedione & Area & Packaging & 16 & $16(100 \%)$ & 23.0 & 78.3 & $\mathrm{~N} / \mathrm{A}$ \\
\hline 2,3-Pentanedione & Area & Packaging-Mezzanine & 5 & $5(100 \%)$ & 28.4 & 190.6 & $\mathrm{~N} / \mathrm{A}$ \\
\hline 2,3-Pentanedione & Area & Quality Control Room & 4 & $0(0 \%)$ & $<4.9$ & $<7.0$ & N/A \\
\hline 2,3-Pentanedione & Area & Reception & 1 & $0(0 \%)$ & $<5.3$ & $<5.3$ & $\mathrm{~N} / \mathrm{A}$ \\
\hline 2,3-Pentanedione & Area & Roasting & 18 & $9(50 \%)$ & $<5.3$ & 26.8 & $\mathrm{~N} / \mathrm{A}$ \\
\hline 2,3-Pentanedione & Area & Roasting-Mezzanine & 4 & $2(50 \%)$ & $<5.3$ & 8.6 & $\mathrm{~N} / \mathrm{A}$ \\
\hline
\end{tabular}

Note: OSHA=Occupational Safety and Health Administration; NIOSH=National Institute for Occupational Safety and Health; N=number of samples; Above LOD N (\%) =number and percentage of samples above the limit of detection (LOD); Above REL N $(\%)=$ number and percentage above the NIOSH recommended exposure limit (REL); ppb=parts per billion; N/A=NIOSH RELs are specified for personal air samples and area air samples cannot be used for comparison; "All Over" location includes employees that were cross-trained and performed tasks at different areas; < indicates below the LOD. 


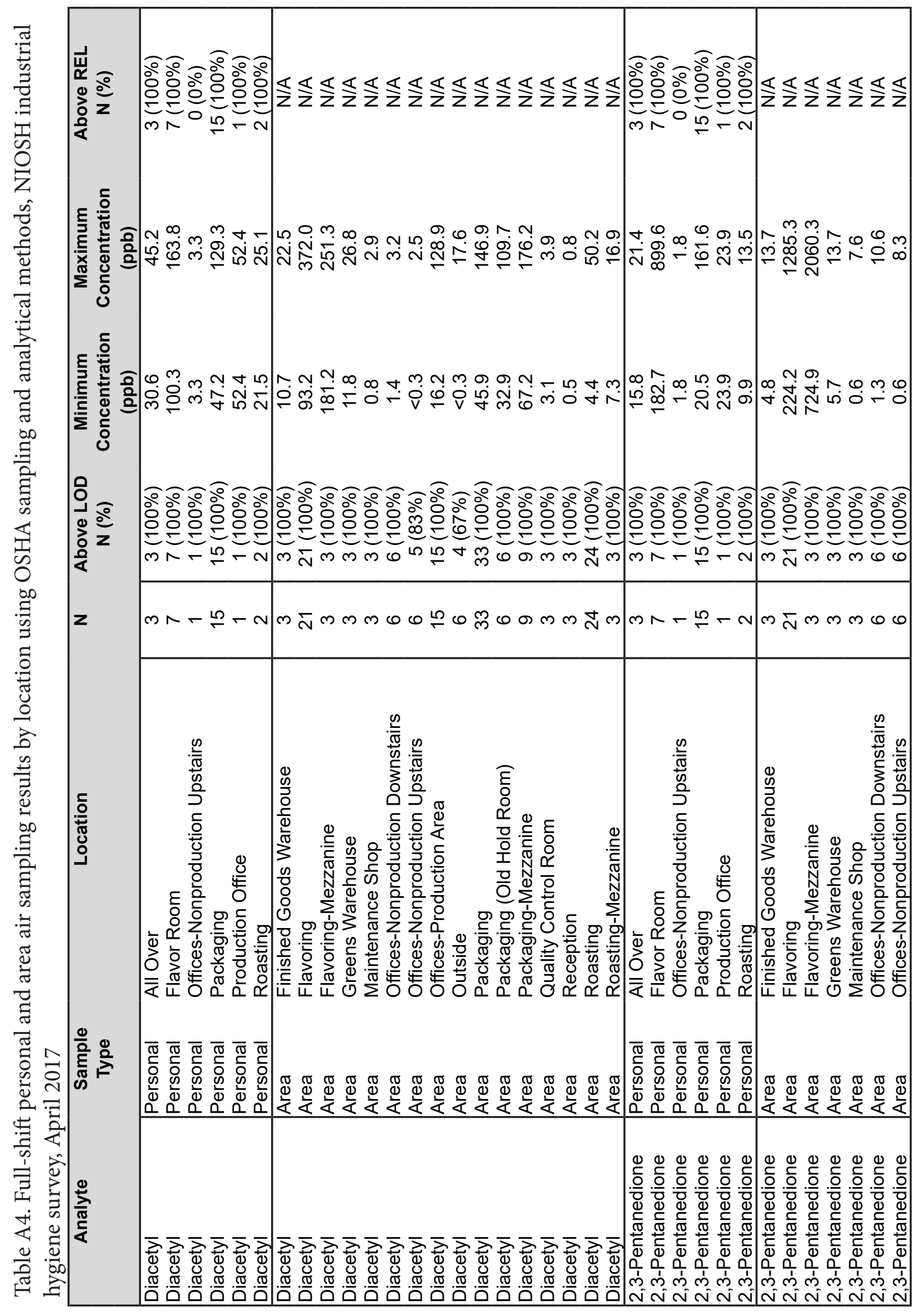




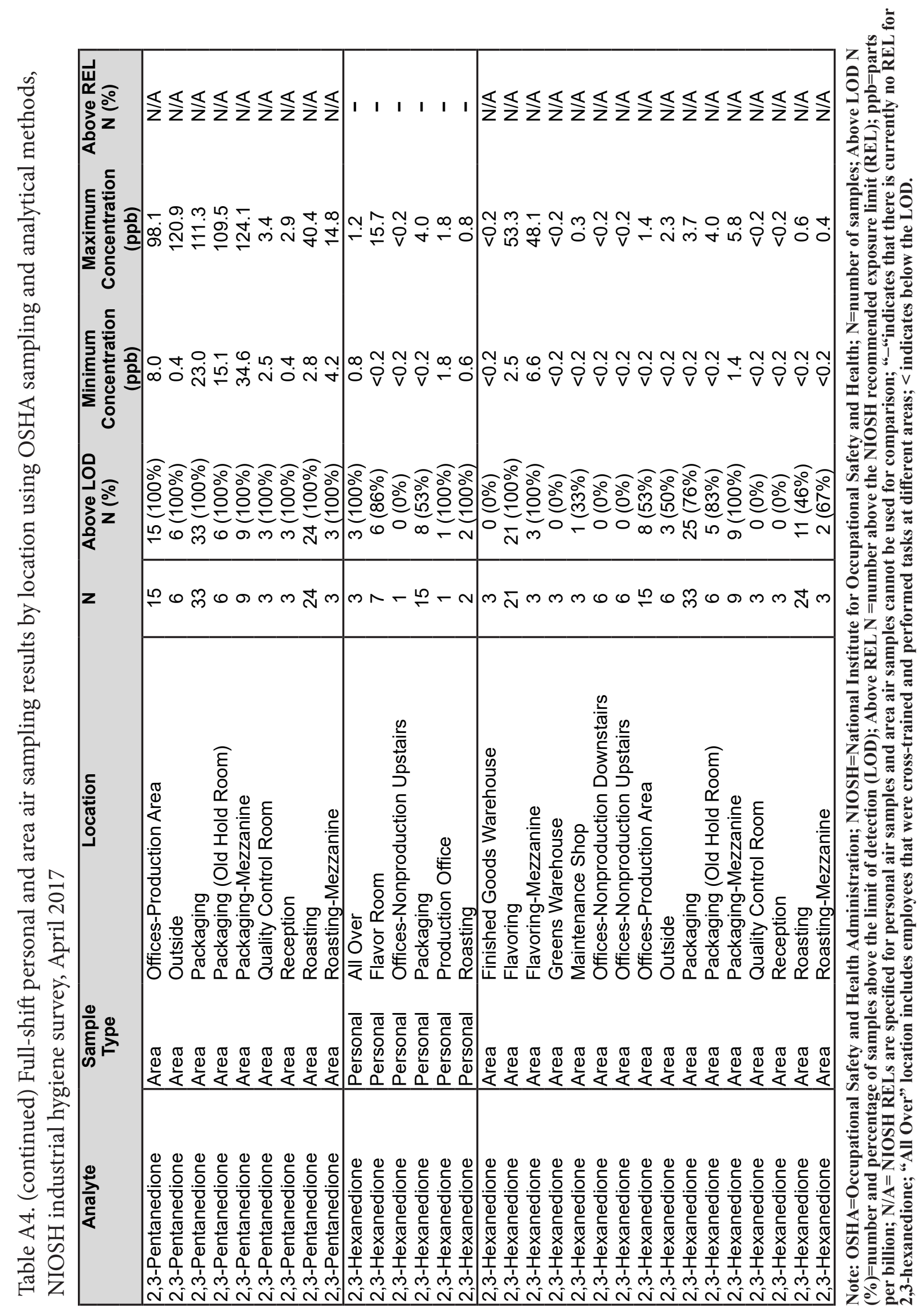


Table A5. Diacetyl area air sampling results by location, NIOSH industrial hygiene surveys in November 2012 and April 2017

\begin{tabular}{|c|c|c|c|c|}
\hline \multirow[t]{2}{*}{ Location } & \multirow[t]{2}{*}{ Year } & \multirow{2}{*}{$\begin{array}{l}\text { Number of } \\
\text { samples }\end{array}$} & \multicolumn{2}{|c|}{$\begin{array}{c}\text { Diacetyl } \\
\text { Parts per billion (ppb) }\end{array}$} \\
\hline & & & Minimum & Maximum \\
\hline \multirow[t]{2}{*}{ Finished Goods Warehouse } & 2012 & 9 & 4.8 & 17 \\
\hline & 2017 & 3 & 11 & 23 \\
\hline \multirow[t]{2}{*}{ Flavoring } & 2012 & 16 & 44 & 144 \\
\hline & 2017 & 21 & 93 & 372 \\
\hline \multirow[t]{2}{*}{ Flavoring-Mezzanine } & 2012 & 4 & 83 & 124 \\
\hline & 2017 & 3 & 181 & 251 \\
\hline \multirow[t]{2}{*}{ Greens Warehouse } & 2012 & 11 & 5.2 & 16 \\
\hline & 2017 & 3 & 12 & 27 \\
\hline \multirow[t]{2}{*}{ Maintenance Shop } & 2012 & 2 & 3 & 10 \\
\hline & 2017 & 3 & 0.8 & 3 \\
\hline \multirow[t]{2}{*}{ Offices-Nonproduction Downstairs } & 2012 & 2 & 3 & 4 \\
\hline & 2017 & 6 & 1 & 3 \\
\hline \multirow[t]{2}{*}{ Offices-Nonproduction Upstairs } & 2012 & 3 & 4 & 4.9 \\
\hline & 2017 & 6 & $<0.3$ & 3 \\
\hline \multirow[t]{2}{*}{ Offices-Production Area } & 2012 & 8 & 34 & 93 \\
\hline & 2017 & 15 & 16 & 129 \\
\hline \multirow[t]{2}{*}{ Outside } & 2012 & 4 & 1.5 & 5 \\
\hline & 2017 & 4 & $<0.3$ & 1.8 \\
\hline \multirow[t]{2}{*}{ Outside-Flavor Room Exhaust } & 2012 & 4 & 7 & 47 \\
\hline & 2017 & 2 & 8 & 18 \\
\hline \multirow[t]{2}{*}{ Packaging } & 2012 & 15 & 68 & 112 \\
\hline & 2017 & 33 & 46 & 147 \\
\hline \multirow[t]{2}{*}{ Packaging-Old Hold Room } & 2012 & 1 & 78 & 78 \\
\hline & 2017 & 6 & 33 & 110 \\
\hline \multirow[t]{2}{*}{ Packaging-Mezzanine } & 2012 & 5 & 103 & 248 \\
\hline & 2017 & 9 & 67 & 176 \\
\hline \multirow[t]{2}{*}{ Quality Control Room } & 2012 & 4 & 6 & 10 \\
\hline & 2017 & 3 & 3 & 4 \\
\hline \multirow[t]{2}{*}{ Reception } & 2012 & 1 & 3 & 3 \\
\hline & 2017 & 3 & 0.5 & 0.8 \\
\hline \multirow[t]{2}{*}{ Roasting } & 2012 & 19 & 10 & 51 \\
\hline & 2017 & 24 & 4 & 50 \\
\hline \multirow[t]{2}{*}{ Roasting-Mezzanine } & 2012 & 4 & 11 & 25 \\
\hline & 2017 & 3 & 7 & 17 \\
\hline
\end{tabular}

Note: NIOSH=National Institute for Occupational Safety and Health. 
Table A6. 2,3-Pentanedione area air sampling results by location, NIOSH industrial hygiene surveys in November 2012 and April 2017

\begin{tabular}{|c|c|c|c|c|}
\hline \multirow[t]{2}{*}{ Location } & \multirow[t]{2}{*}{ Year } & \multirow{2}{*}{$\begin{array}{l}\text { Number of } \\
\text { samples }\end{array}$} & \multicolumn{2}{|c|}{$\begin{array}{l}\text { 2,3-Pentanedione } \\
\text { Parts per billion (ppb) }\end{array}$} \\
\hline & & & Minimum & Maximum \\
\hline \multirow[t]{2}{*}{ Finished Goods Warehouse } & 2012 & 9 & 2.5 & 2.8 \\
\hline & 2017 & 3 & 5 & 14 \\
\hline \multirow[t]{2}{*}{ Flavoring } & 2012 & 16 & 49 & 273 \\
\hline & 2017 & 21 & 224 & 1285 \\
\hline \multirow[t]{2}{*}{ Flavoring-Mezzanine } & 2012 & 4 & 151 & 206 \\
\hline & 2017 & 3 & 725 & 2060 \\
\hline \multirow[t]{2}{*}{ Greens Warehouse } & 2012 & 11 & 3 & 5 \\
\hline & 2017 & 3 & 6 & 14 \\
\hline \multirow[t]{2}{*}{ Maintenance Shop } & 2012 & 2 & 2.5 & 2.6 \\
\hline & 2017 & 3 & 0.6 & 8 \\
\hline \multirow[t]{2}{*}{ Offices-Nonproduction Downstairs } & 2012 & 2 & 2.7 & 2.8 \\
\hline & 2017 & 6 & 1 & 11 \\
\hline \multirow[t]{2}{*}{ Offices-Nonproduction Upstairs } & 2012 & 3 & 2.6 & 2.8 \\
\hline & 2017 & 6 & 0.6 & 8 \\
\hline \multirow[t]{2}{*}{ Offices-Production Area } & 2012 & 8 & 10 & 47 \\
\hline & 2017 & 15 & 8 & 98 \\
\hline \multirow[t]{2}{*}{ Outside } & 2012 & 4 & 2.4 & 2.7 \\
\hline & 2017 & 4 & 0.4 & 6 \\
\hline \multirow[t]{2}{*}{ Outside-Flavor Room Exhaust } & 2012 & 4 & 15 & 254 \\
\hline & 2017 & 2 & 36 & 121 \\
\hline \multirow[t]{2}{*}{ Packaging } & 2012 & 15 & 23 & 78 \\
\hline & 2017 & 33 & 23 & 111 \\
\hline \multirow[t]{2}{*}{ Packaging-Old Hold Room } & 2012 & 1 & 52 & 52 \\
\hline & 2017 & 6 & 15 & 109 \\
\hline \multirow[t]{2}{*}{ Packaging-Mezzanine } & 2012 & 5 & 28 & 191 \\
\hline & 2017 & 9 & 35 & 124 \\
\hline \multirow[t]{2}{*}{ Quality Control Room } & 2012 & 4 & 2.5 & 3.4 \\
\hline & 2017 & 3 & 2.5 & 3.4 \\
\hline \multirow[t]{2}{*}{ Reception } & 2012 & 1 & 3 & 3 \\
\hline & 2017 & 3 & 0.4 & 3 \\
\hline \multirow[t]{2}{*}{ Roasting } & 2012 & 19 & 3 & 27 \\
\hline & 2017 & 24 & 3 & 40 \\
\hline \multirow[t]{2}{*}{ Roasting-Mezzanine } & 2012 & 4 & 3 & 7 \\
\hline & 2017 & 3 & 4 & 15 \\
\hline
\end{tabular}

Note: NIOSH=National Institute for Occupational Safety and Health. 


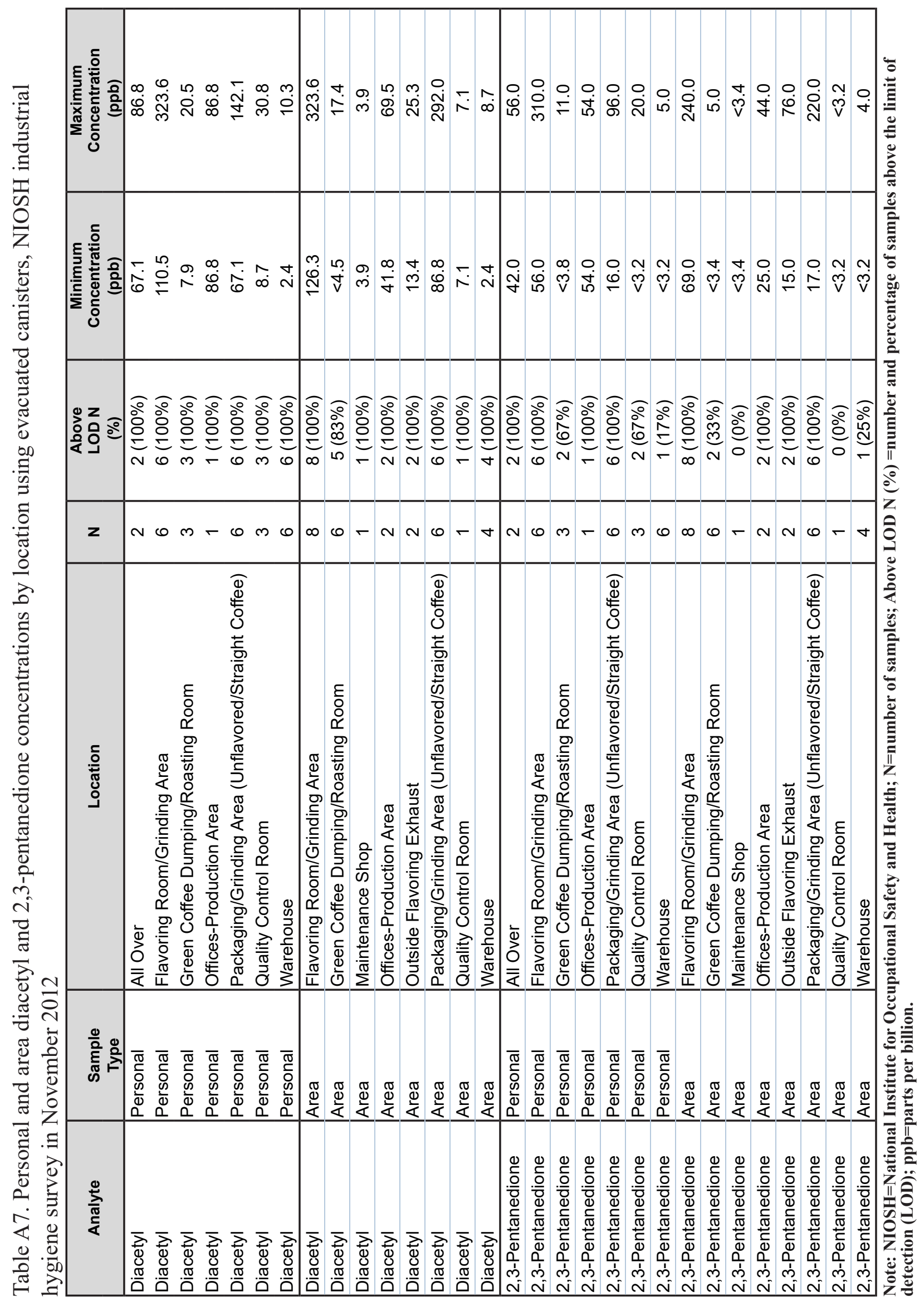




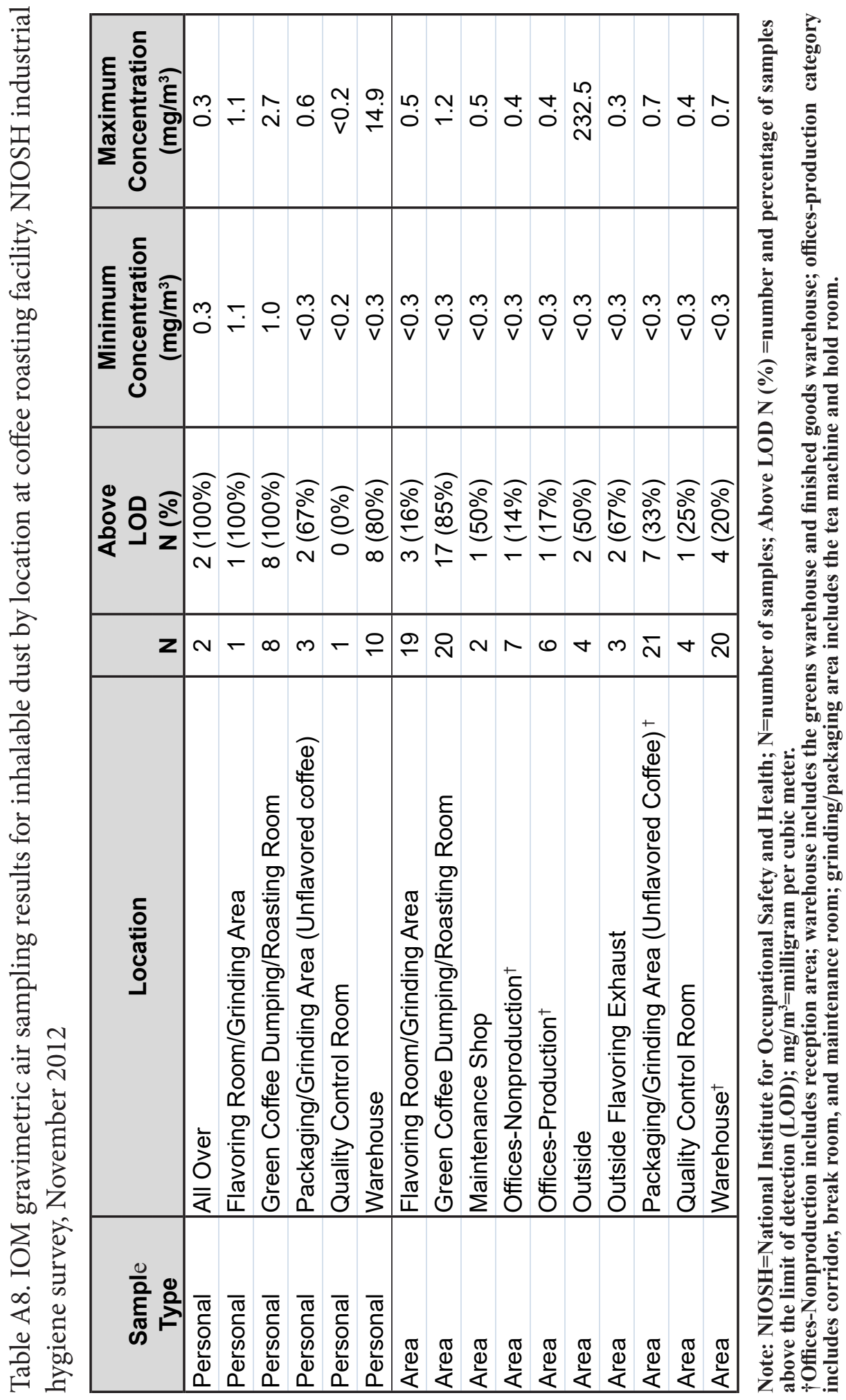


Table A9. Instantaneous* evacuated canister pre-and post-shift background air sampling results, NIOSH industrial hygiene survey, April 2017

\begin{tabular}{|c|c|c|c|c|c|c|c|}
\hline & \multicolumn{7}{|c|}{ Concentrations in parts per billion (ppb) } \\
\hline & \multirow[b]{2}{*}{ Analyte } & \multicolumn{2}{|c|}{$4 / 11 / 2017$} & \multicolumn{2}{|c|}{$4 / 12 / 2017$} & \multicolumn{2}{|c|}{ 4/13/2017 } \\
\hline Location & & $\mathbf{A M}$ & PM & $\mathbf{A M}$ & PM & $\mathbf{A M}$ & PM \\
\hline \multirow[t]{3}{*}{ Flavoring } & Diacetyl & 157.9 & 125.7 & 157.9 & 97.3 & 86.0 & 82.9 \\
\hline & 2,3-Pentanedione & 174.9 & 88.3 & 228.5 & 259.1 & 91.2 & 76.1 \\
\hline & 2,3-Hexanedione & 12.9 & 2.9 & 9.4 & 4.7 & 9.4 & 8.6 \\
\hline \multirow[t]{3}{*}{ Packaging } & Diacetyl & 173.3 & 123.9 & 91.7 & 94.7 & 57.5 & 63.9 \\
\hline & 2,3-Pentanedione & 104.7 & 63.2 & 49.7 & 50.1 & 24.6 & 25.4 \\
\hline & 2,3-Hexanedione & 4.6 & 2.8 & 4.7 & 3.6 & 2.0 & 2.3 \\
\hline \multirow[t]{3}{*}{ Quality Control Room } & Diacetyl & 6.9 & 9.5 & 20.6 & 14.4 & 6.3 & 8.9 \\
\hline & 2,3-Pentanedione & 6.3 & 5.8 & 7.5 & 10.2 & 3.8 & 4.9 \\
\hline & 2,3-Hexanedione & 0.9 & 0.9 & 0.9 & 1.0 & 1.0 & 3.0 \\
\hline \multirow[t]{3}{*}{ Roasting } & Diacetyl & 24.3 & 6.8 & 9.3 & 16.8 & 14.1 & 11.3 \\
\hline & 2,3-Pentanedione & 15.6 & 3.1 & 3.7 & 8.0 & 4.4 & 3.8 \\
\hline & 2,3-Hexanedione & 0.9 & 0.9 & 0.6 & 1.0 & 0.9 & 0.9 \\
\hline \multirow[t]{3}{*}{ Warehouses } & Diacetyl & 29.8 & 24.5 & 20.4 & 12.8 & 24.5 & 9.9 \\
\hline & 2,3-Pentanedione & 18.5 & 11.6 & 8.3 & 6.1 & 15.4 & 4.6 \\
\hline & 2,3-Hexanedione & 2.6 & 1.5 & 0.9 & 0.9 & 0.9 & 0.9 \\
\hline
\end{tabular}

Note: NIOSH=National Institute for Occupational Safety and Health.

*Sampling duration approximately 30 seconds. 


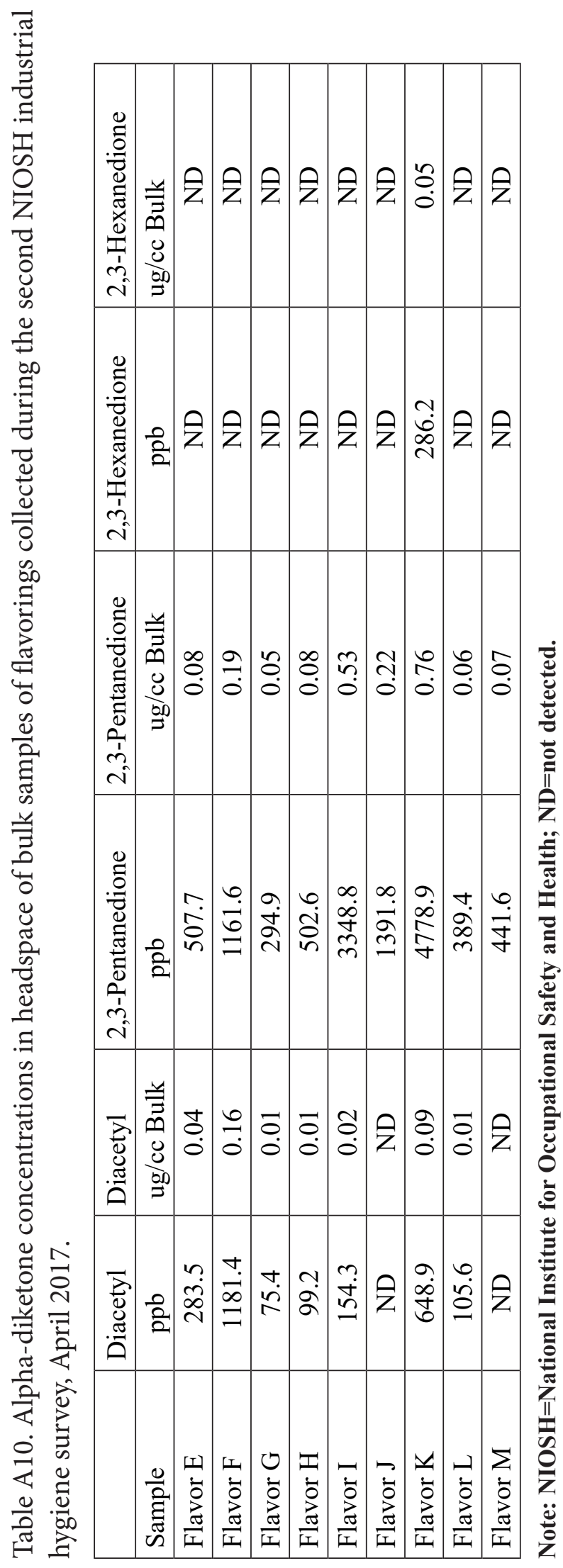


Table A11. Real-time TVOC measurements, NIOSH industrial hygiene survey, November 2012

\begin{tabular}{|c|c|c|c|c|}
\hline \multirow[b]{2}{*}{ Location } & \multirow[b]{2}{*}{ Location Description } & \multicolumn{3}{|c|}{ TVOCs (ppb) } \\
\hline & & Mean & Min & Max \\
\hline Finished Goods Warehouse & Right and left side of warehouse & 275 & 13 & 855 \\
\hline \multirow[t]{3}{*}{ Flavoring } & On top of ribbon elevator & 1968 & 776 & 10667 \\
\hline & Small batch barrel flavoring station & 2258 & 1091 & 4530 \\
\hline & Outside flavoring room exhaust & 530 & 0 & 11353 \\
\hline \multirow[t]{2}{*}{ Greens Warehouse } & Loading dock & 62 & 0 & 1369 \\
\hline & Beside door into roasting room & 068 & 0 & 190 \\
\hline \multirow{6}{*}{$\begin{array}{l}\text { Offices - Non-production } \\
\text { Offices-Production Area } \\
\text { Packaging }\end{array}$} & $2^{\text {nd }}$ floor hallway & 103 & 13 & 208 \\
\hline & Breakroom & 595 & 240 & 16164 \\
\hline & Lines - $5 \& 6$ & 1324 & 681 & 6857 \\
\hline & Lines 7-8 & 2103 & 1122 & 19058 \\
\hline & Mezzanine & 2604 & 861 & 57800 \\
\hline & Hand Pack & 1197 & 634 & 1923 \\
\hline Quality Control Room & Table in center of room & 0 & 135 & 7979 \\
\hline \multirow[t]{5}{*}{ Roasting } & Roaster Line 1 & 343 & 3 & 7717 \\
\hline & Roaster Line 3 & 242 & 69 & 965 \\
\hline & Roaster Line 4 & 522 & 252 & 1302 \\
\hline & Mezzanine & 161 & 31 & 572 \\
\hline & Back wall of Roasting Room & 228 & 45 & 495 \\
\hline
\end{tabular}

Note: NIOSH=National Institute for Occupational Safety and Health; TVOCs=total volatile organic compounds; ppb=parts per billion; $\min =$ minimum value; $\max =$ maximum value. 


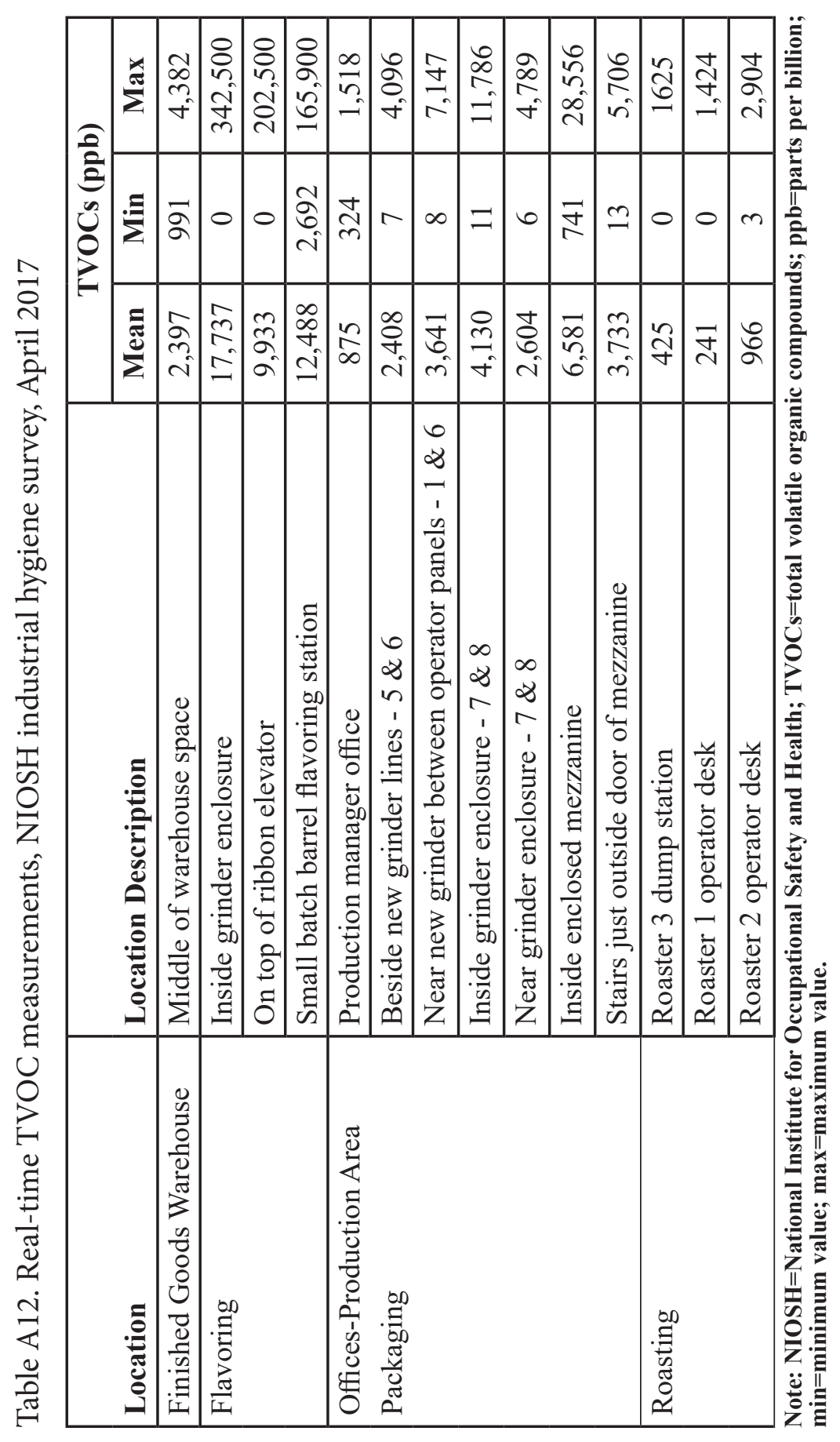




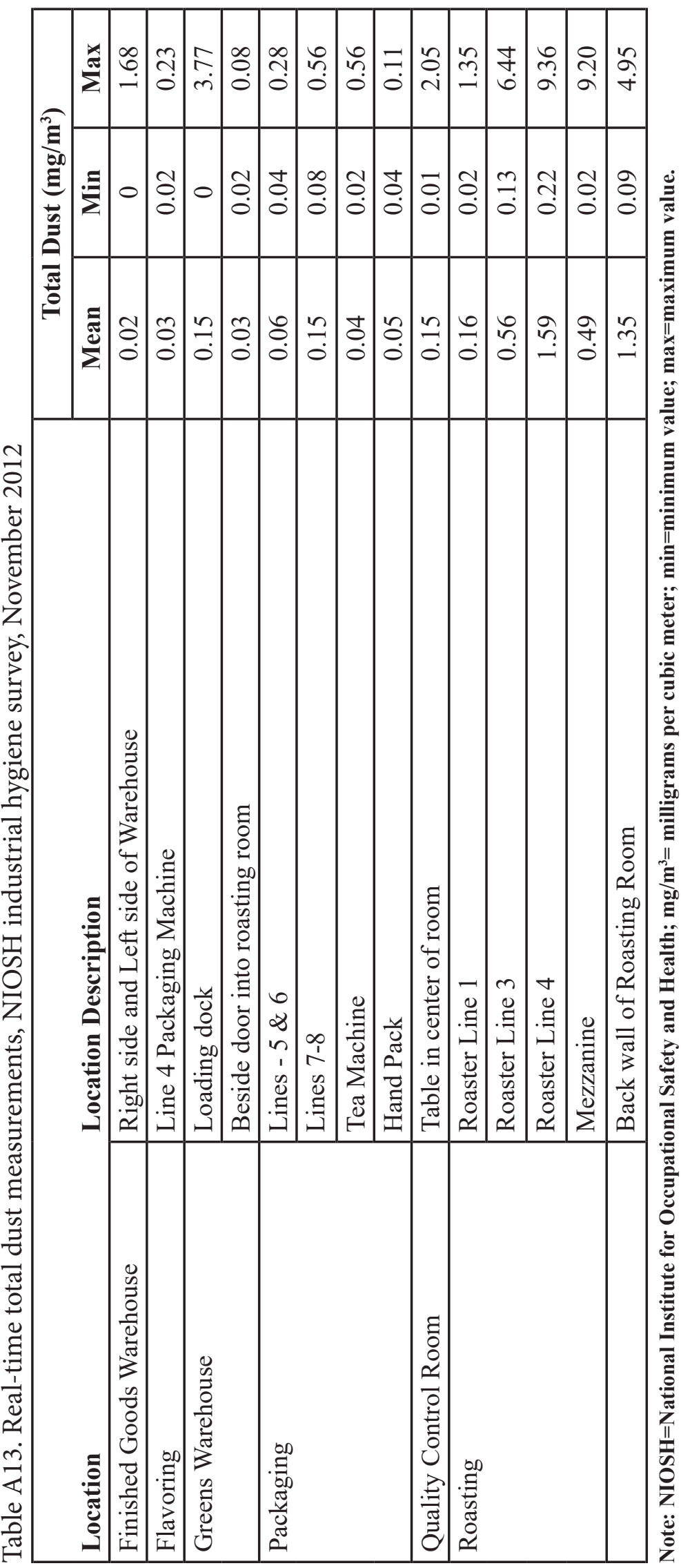




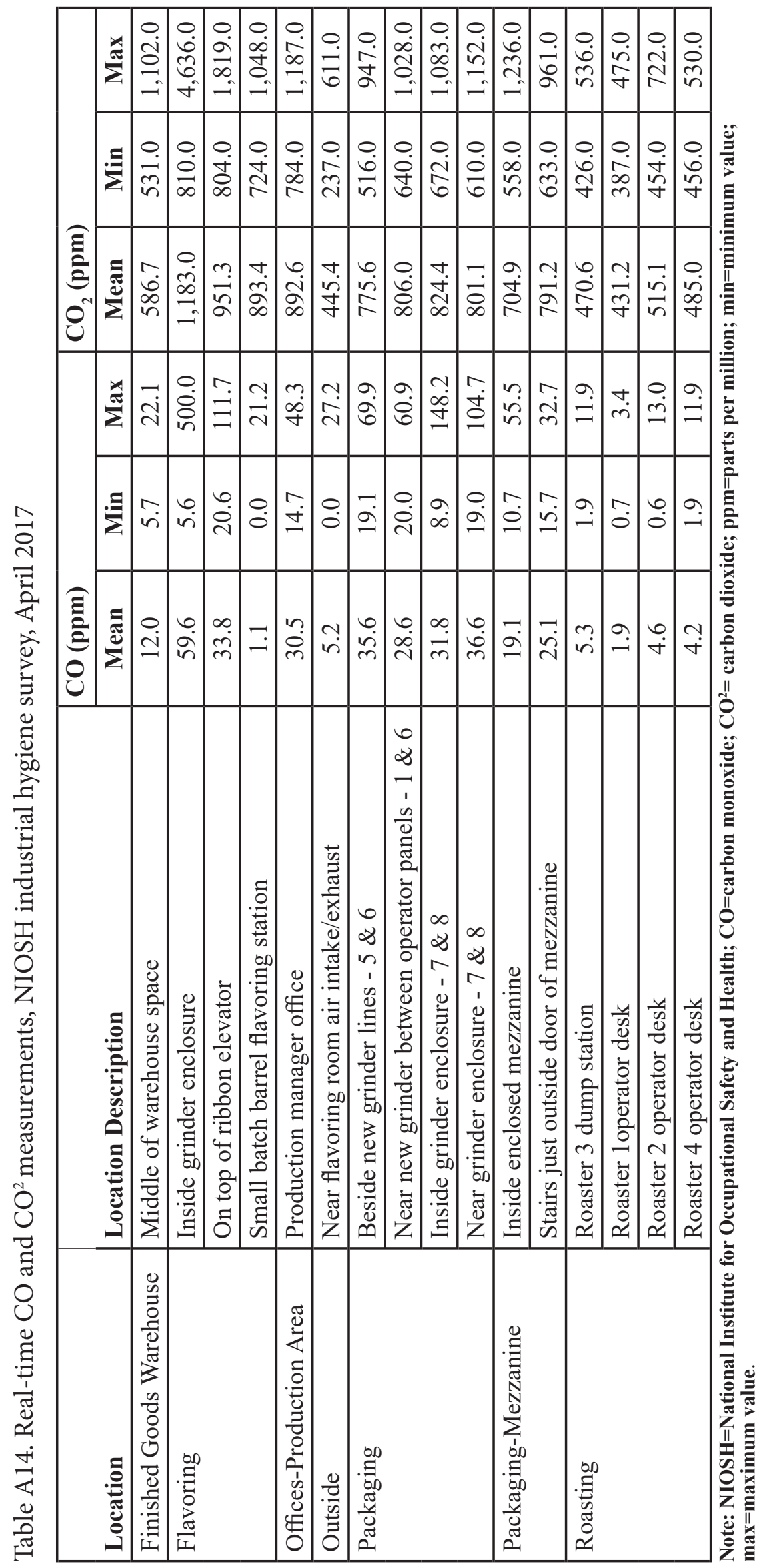


Table A15. Ventilation measurements, NIOSH industrial hygiene survey, November 2012

\section{Outdoor Air Supply}

\begin{tabular}{|c|c|c|c|}
\hline Type & Size (feet) & $\begin{array}{c}\text { Flow } \\
(\mathrm{CFM}) \\
\end{array}$ & Location \\
\hline \multicolumn{4}{|c|}{ Flavoring Room } \\
\hline A/C Grille \# 1 & $1.5 \times 2.0$ & 130 & \multirow{5}{*}{$\begin{array}{l}\text { About } 15 \text { feet high along west wall. Numbers are from } \\
\text { south to north along duct }\end{array}$} \\
\hline A/C Grille \# 2 & $1.5 \times 2.0$ & 190 & \\
\hline A/C Grille \# 3 & $1.5 \times 2.0$ & 370 & \\
\hline A/C Grille \# 4 & $1.5 \times 2.0$ & 460 & \\
\hline A/C Grille \# 5 & $1.5 \times 2.0$ & 440 & \\
\hline \multicolumn{2}{|c|}{$\begin{array}{l}\text { TOTAL } \\
\end{array}$} & 1590 & \\
\hline \multicolumn{4}{|c|}{ Roasting Room and Maintenance Shop } \\
\hline Makeup Air \#1 & $1.5 \times 2.0$ & 1530 & \multirow{3}{*}{$\begin{array}{l}\text { About } 6 \text { feet high along east wall. Numbers are from } \\
\text { south to north in roasting room }\end{array}$} \\
\hline Makeup Air \#2 & $1.5 \times 2.0$ & 1230 & \\
\hline Makeup Air \#3 & $1.5 \times 2.0$ & 3120 & \\
\hline Makeup Air \#4 & $1.5 \times 2.0$ & 2880 & About 6 feet high on east wall of the Maintenance Shop \\
\hline \multicolumn{2}{|c|}{$\begin{array}{l}\text { TOTAL } \\
\end{array}$} & 8760 & \\
\hline
\end{tabular}

\begin{tabular}{l|l|l|l}
\hline Type & Size (feet) & $\begin{array}{c}\text { Flow } \\
\text { (CFM) }\end{array}$ & Location \\
\hline
\end{tabular}

\section{Flavoring Room}

\begin{tabular}{l|c|c|l}
\hline Fan & $4 \times 2$ & 110 & 8 feet high on outside wall between grinder and packaging machine \\
\hline Fan & $2 \times 2$ & 3600 & 27 feet high on outside wall, 43 feet from west wall \\
\hline Fan & $2 \times 2$ & 1250 & 11 feet high on outside wall, 27 feet from east wall \\
\hline LEV & $0.92 \times 0.96$ & 60 & Hood over large batch flavoring station carboy \\
\hline LEV & 0.66 diameter & 180 & Duct from new automatic batch flavoring machine \\
\hline LEV & 0.5 diameter & 190 & Duct for grinder enclosure \\
\hline LEV & $2 \times 2$ & 240 & Hood about 28.5 inches above 55 gallon drum of flavoring \\
\hline Exhaust duct & $0.33 \times 0.66$ & 100 & Grille on duct behind flavoring barrel storage racks \\
\hline Exhaust duct & $0.33 \times 0.66$ & 210 & Grille on duct behind flavoring barrel storage racks \\
\hline Exhaust duct & $0.33 \times 0.66$ & 165 & Grille on duct behind flavoring barrel storage racks \\
\hline LEV & 0.33 diameter & 145 & Duct pulling air from the bottom flavoring storage cabinet \\
\hline LEV & 0.33 diameter & 90 & Duct pulling air from the top flavoring storage cabinet \\
\hline LEV & 0.33 diameter & 70 & Duct at scale for flavorings used at small batch barrels \\
\hline LEV & $7.8 \times 1.2$ & 560 & Hood above small batch barrel flavoring station \\
\hline \multicolumn{5}{|c|}{ TOTAL } & 6970 & \\
\hline Roasting Room * & 350 & Eastern fan near ceiling on north outside wall \\
\hline Fan & $1.75 \times 1.75$ & 420 & Western fan near ceiling on north outside wall \\
\hline Fan & 8970 & \\
\hline Grinding/Packaging Room \\
\hline
\end{tabular}

\begin{tabular}{|c|c|c|c|}
\hline LEV & 1.0 diameter & 705 & Duct for grinder enclosure nearest Flavoring Room \\
\hline LEV & 1.0 diameter & 785 & Duct for grinder enclosure nearest to Finished Goods Warehouse \\
\hline \multicolumn{2}{|c|}{ TOTAL } & $1490 \dagger$ & \\
\hline \multicolumn{4}{|c|}{ QC Room } \\
\hline LEV & 0.5 diameter & 120 & Exhaust hood over stove and roasters \\
\hline
\end{tabular}

Note: $\mathrm{A} / \mathrm{C}=$ air-conditioning; $\mathrm{LEV}=$ local exhaust ventilation; $\mathrm{CFM}=$ cubic feet per minute.

*We were unable to measure airflow through the afterburners in the roasting room or determine the sources of the combustion air. We made no attempt to control the use of afterburners as we collected our ventilation measurements, but instead allowed the afterburners to operate as normal. Thus, we do not understand how afterburner operation and performance may have affected the results presented in the table.

$\uparrow$ Represents the total airflow measured from the two grinding enclosures which is likely an underestimation due to difficulty accessing the duct entry points with the rotating vane anemometer. 
Table A16. Variable frequency drive (VFD) settings tested during NIOSH ventilation assessment

\begin{tabular}{|l|l|}
\hline VFD Setting Hz (Supply/Exhaust) & Pressurization Direction (smoke) \\
\hline $42 / 42$ & Mezzanine neutral to grinding room \\
\hline $25 / 54$ & Mezzanine strongly negative to grinding room \\
\hline $35 / 54$ & Mezzanine moderately negative to grinding room \\
\hline $10 / 54$ & Mezzanine strongly negative to grinding room \\
\hline $\mathbf{3 0 / 6 0}$ & Mezzanine strongly negative to grinding room \\
\hline
\end{tabular}

Note: NIOSH=National Institute for Occupational Safety and Health.

Table A17. Estimated flow rates for exhausted hoods, NIOSH ventilation assessments

\begin{tabular}{|c|l|c|c|}
\hline Exhaust Fan & Location & $\begin{array}{c}\text { Estimated } \\
\text { Flow (cfm) } \\
\text { April 2017 }\end{array}$ & $\begin{array}{c}\text { Estimated } \\
\text { Flow (cfm) } \\
\text { November 2012 }\end{array}$ \\
\cline { 1 - 3 } 1 & Barrel mixing station-left exhaust & 120 & \multirow{2}{*}{560} \\
\cline { 1 - 2 } combined \\
\cline { 1 - 3 } 1 & Barrel mixing station-left center exhaust & 135 & \\
\hline 1 & Barrel mixing station-right center exhaust & 175 & 70 \\
\hline 1 & Barrel mixing station-right exhaust & 205 & 90 \\
\hline 1 & Flavor weighing station-desk top & 60 & 145 \\
\hline 1 & Flavor cabinet storage exhaust upper & 100 & 240 \\
\hline 1 & Flavor cabinet storage exhaust lower & 0 & 162 \\
\hline 1 & Flavor Pumping station & Not evaluated & 210 \\
\hline 1 & Grille behind flavoring barrel storage rack - right & 100 \\
\hline 2 & Grille behind flavoring barrel storage rack - center & Not evaluated & 60 \\
\hline 2 & Grille behind flavoring barrel storage rack - left & Not evaluated & 190 \\
\hline 2 & Flavor pump station-ribbon blender & 0 & 180 \\
\hline
\end{tabular}

Note: $\mathrm{NIOSH}=$ National Institute for Occupational Safety and Health; $\mathrm{cfm}=$ cubic feet per minute. 
Table A18. Characteristics of current worker participants in the NIOSH medical survey at coffee facility, September 2012

\begin{tabular}{|l|c|}
\hline \multicolumn{1}{|c|}{ Variable } & $\mathrm{n}=75$ \\
\hline Mean age (range), years & $35(18-67)$ \\
\hline Median age, years & 34 \\
\hline Mean years employed at current plant (range) & $2.9(0.04-9.3)$ \\
\hline Mean years employed at current and old plant (range) & $4.3(0.04-25.0)$ \\
\hline Race/Ethnicity & \\
Hispanic n, (\%) & $52(69 \%)$ \\
Caucasian n, (\%) & $17(23 \%)$ \\
Other n, (\%) & $6(8 \%)$ \\
\hline Gender & $51(68 \%)$ \\
Males n, (\%) & $24(32 \%)$ \\
Females n, (\%) & \\
\hline Smoking status & $23(31 \%)$ \\
Current smoker n, (\%) & $17(23 \%)$ \\
Former smoker n, (\%) & $35(47 \%)$ \\
Never smoker n, (\%) & \\
\hline
\end{tabular}

Note: NIOSH=National Institute for Occupational Safety and Health. 


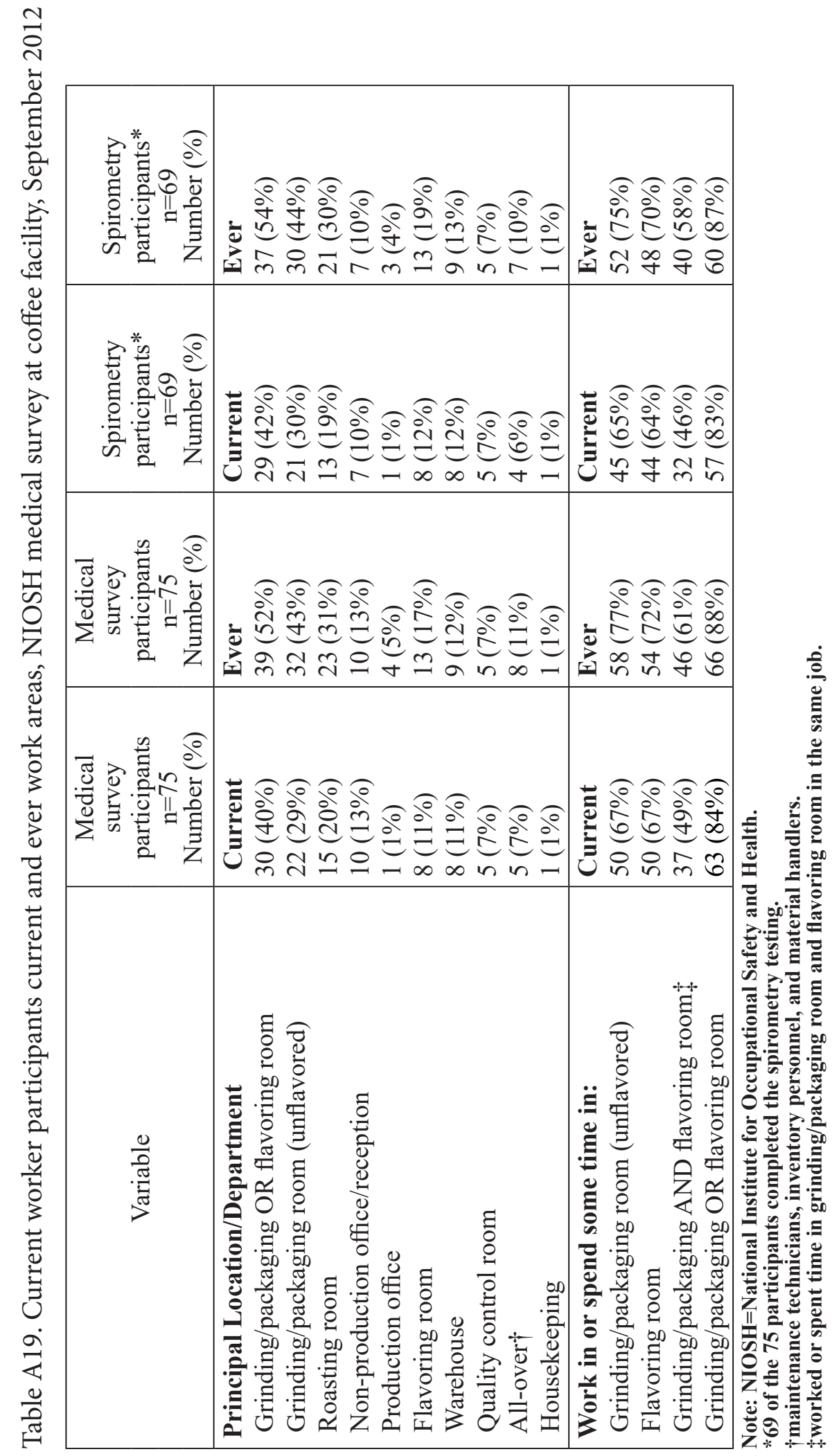


Table A20. Prevalence of health conditions and work-relatedness reported by participants during the previous 12 months at the time of the NIOSH medical survey at coffee facility, September 2012

\begin{tabular}{|c|c|c|c|}
\hline Symptom & $\begin{array}{c}\text { Previous } 4 \\
\text { weeks } \\
\mathrm{N}=75 \\
\text { Number }(\%)\end{array}$ & $\begin{array}{l}\text { Previous } 12 \\
\text { months } \\
\mathrm{N}=75 \\
\text { Number }(\%)\end{array}$ & $\begin{array}{l}\text { Symptom aggravated } \\
\text { by work or better } \\
\text { when away from } \\
\text { work* }\end{array}$ \\
\hline Stuffy, itchy, or runny nose & $21(28 \%)$ & $34(45 \%)$ & 12 of 34 \\
\hline Stinging, burning, irritated nose & $7(9 \%)$ & $9(12 \%)$ & 8 of 9 \\
\hline Watery, itchy eyes & $20(27 \%)$ & $29(39 \%)$ & 15 of 29 \\
\hline Stinging, burning, irritated eyes & $13(17 \%)$ & $16(21 \%)$ & 8 of 16 \\
\hline Sinusitis or sinus problems & $10(13 \%)$ & $19(25 \%)$ & 10 of 19 \\
\hline Cough & $8(11 \%)$ & $12(16 \%)$ & 3 of 12 \\
\hline Awoke with chest tightness & $3(4 \%)$ & $8(11 \%)$ & 3 of 8 \\
\hline Awoke with shortness of breath & $4(5 \%)$ & $8(11 \%)$ & 4 of 8 \\
\hline $\begin{array}{l}\text { Breathing trouble } \\
\text { Rarely have trouble breathing } \\
\text { Regular trouble breathing } \\
\text { Breathing never quite right } \\
\end{array}$ & $\begin{array}{c}8(11 \%) \\
- \\
- \\
-\end{array}$ & $\begin{array}{c}13(17 \%) \\
8 \\
5 \\
0 \\
\end{array}$ & $\begin{array}{l}- \\
- \\
- \\
-\end{array}$ \\
\hline $\begin{array}{l}\text { Shortness of breath on level ground or } \\
\text { walking up a slight hill } \\
\text { Short of breathing walking with } \\
\text { people of own age } \\
\text { Stop for breath when walking at } \\
\text { own pace on level ground } \\
\text { Stop for breath after walking } \\
\text { about a } 100 \text { yards or a few minutes } \dagger\end{array}$ & $\begin{array}{l}- \\
-\end{array}$ & $\begin{array}{l}21(28 \%) \\
9(12 \%) \\
2(3 \%) \\
5(7 \%) \\
\end{array}$ & $\begin{array}{l}- \\
- \\
- \\
-\end{array}$ \\
\hline Chest wheezing or whistling & $8(11 \%)$ & $15(20 \%)$ & 4 of 15 \\
\hline Asthma attack & 0 & $1(1 \%)$ & 1 of 1 \\
\hline Flu-like achiness or achy joints & $13(17 \%)$ & $20(27 \%)$ & 6 of 20 \\
\hline Fever or chills & $6(8 \%)$ & $11(15 \%)$ & 0 \\
\hline Usual tiredness or fatigue & $13(17 \%)$ & $22(29 \%)$ & 10 of 22 \\
\hline Skin rash or skin problems & $8(11 \%)$ & $14(19 \%)$ & 7 of 14 \\
\hline
\end{tabular}

Note: NIOSH=National Institute for Occupational Safety and Health.

*Answered "better" to, "When you are away from this plant on days off or on vacation, is the symptom (inserted) the same, worse, or better?" or "yes" to, "Is there anything at work that causes or aggravates this symptom (inserted)?"

$\dagger$ Three participants answered "yes" to the main question (shortness of breath on level ground or walking up a slight hill) and the third sub-question (Stop for breath after walking about a 100 yards or a few minutes) but "no" to one or both of the first two sub-questions. 
Table A21. Participant-reported physician-diagnosed conditions, NIOSH medical survey at coffee roasting, packaging, and flavoring facility, September 2012

\begin{tabular}{|l|c|c|}
\hline \multicolumn{1}{|c|}{ Health condition } & N=75 & $\begin{array}{c}\text { Diagnosed } \\
\text { post-hire at coffee } \\
\text { company } \\
\text { Number }\end{array}$ \\
\hline Hay fever or nasal allergies & $13(17 \%)$ & 5 \\
\hline Eczema, dermatitis, or skin allergy & $4(5 \%)$ & 2 \\
\hline Gastroesophageal reflux disease & $5(7 \%)$ & 3 \\
\hline Ever asthma & $5(7 \%)$ & 1 \\
\hline Current asthma & $2(3 \%)$ & 2 \\
\hline Chronic bronchitis & $3(4 \%)$ & 1 \\
\hline COPD* & $2(3 \%)$ & 1 \\
\hline Heart disease & $4(5 \%) \dagger$ & 1 \\
\hline
\end{tabular}

Note: NIOSH=National Institute for Occupational Safety and Health.

*Chronic obstructive pulmonary disease.

$\dagger$ One of four participants only reported the year of diagnosis; we were unable to determine if heart disease diagnosis was pre-hire or not. 
Table A22. Disposable respirator usage by task reported by 33 of 75 medical survey participants during NIOSH medical survey at coffee roasting, packaging, and flavoring facility, September 2012

\begin{tabular}{|l|c|c|c|}
\hline \multicolumn{1}{|c|}{ Task } & $\begin{array}{c}\text { Ever wore } \\
\text { disposable } \\
\text { respirator at } \\
\text { facility* } \\
\mathrm{N}=33\end{array}$ & Sometimes & All the time \\
\hline Dumping green coffee beans & 3 & 1 & 2 \\
\hline Roasting coffee beans & 1 & 0 & 1 \\
\hline Grinding unflavored coffee beans & 1 & 0 & 1 \\
\hline Packaging unflavored coffee in \\
cardboard boxes
\end{tabular}

Note: NIOSH=National Institute for Occupational Safety and Health.

*33 of 75 participants reported that they had ever worn a disposable respirator at the facility. Participants were shown pictures of disposable dust respirators when asked if they had ever worn a disposable respirator at the facility. 
Table A23. Adjusted ${ }^{\star}$ comparisons of symptoms and self-reported physician diagnosis among NIOSH medical survey participants at coffee facility to U.S. adult population (NHANES III) $(\mathrm{N}=75)$

\begin{tabular}{|c|c|c|c|}
\hline Health condition & $\begin{array}{c}\text { Observed } \\
\text { Number }\end{array}$ & $\begin{array}{l}\text { Expected } \\
\text { Number }\end{array}$ & $\begin{array}{c}\text { SMR } \\
(95 \% \mathrm{CI})^{\dagger}\end{array}$ \\
\hline Watery, itchy eyes last 12 months & 29 & 24.4 & $1.2(0.83-1.70)$ \\
\hline Stuffy, itchy, or runny nose last 12 months & 34 & 32.0 & $1.1(0.76-1.48)$ \\
\hline Sinus problems last 12 months & 19 & 18.4 & $1.0(0.66-1.61)$ \\
\hline Phlegm 3 consecutive month or more & 6 & 5.0 & $1.2(0.55-2.64)$ \\
\hline Wheeze last 12 months & 15 & 9.8 & $1.5(0.92-2.52)$ \\
\hline Shortness of breath on exertion & 21 & 13.2 & $1.6(1.04-2.44)$ \\
\hline Cough 3 consecutive months or more & 4 & 4.8 & $0.8(0.32-2.14)$ \\
\hline Chronic bronchitis (physician-diagnosed) & 3 & 2.9 & $1.0(0.35-3.03)$ \\
\hline Ever asthma (physician-diagnosed) ${ }^{\beta}$ & 5 & 4.1 & $1.2(0.52-2.83)$ \\
\hline Current asthma (physician-diagnosed) & 2 & 2.5 & $0.8(0.22-2.87)$ \\
\hline
\end{tabular}

Note: $\mathbf{N I O S H}=$ National Institute for Occupational Safety and Health; NHANES=National Health and Nutrition Examination Survey; SMR= standardized morbidity ratio.

*Adjusted for sex, race/ethnicity, age, and smoking categories.

+We used the most recent NHANES survey available for each comparison.

$\$ 95 \%$ confidence intervals (CIs) that exclude one are statistically significantly different from comparison with US adult population and are shown in bold.

BFour $(\mathbf{8 0} \%)$ of five participants ever diagnosed with asthma were diagnosed before they started working at this coffee roasting, flavoring, and packaging facility. 
Table A24. Results of lung function testing for current workers, NIOSH medical survey, coffee facility, September 2012

\begin{tabular}{|l|c|}
\hline \multicolumn{2}{|c|}{ Spirometry (N=69) } \\
\hline FEV1 \% predicted, mean (range) & $97.6(55.4-130.9)$ \\
\hline FVC \% predicted, mean (range) & $99.9(60.8-136.9)$ \\
\hline FEV1/FVC \%, mean (range) & $80.5(51.1-91.6)$ \\
\hline FEF25-75\% predicted, mean (range) & $94.4(27.1-163.0)$ \\
\hline Abnormally low FEF25-75, n (\%) & $8(11.6 \%)$ \\
\hline Obstruction, n (\%) & $5(7 \%)$ \\
\hline Restriction, n (\%) & $2(3 \%)$ \\
\hline \multicolumn{2}{|c|}{ Bronchodilator (N=8) } \\
\hline FEV1 or FVC response, overall, n/N (\%)
\end{tabular}

Note: NIOSH=National Institute for Occupational Safety and Health; FEV1=forced expiratory volume in one second; FVC=forced vital capacity; FEF25-75=forced expiratory flow between $25 \%$ and $75 \%$ of exhaled volume (forced mid-expiratory flow).

*Includes a participant with PD-15 above $635 \mathrm{mg}$ but with a greater than $10 \%$ drop in FEV1 between mannitol doses 6 and 7. 
Table A25. Adjusted ${ }^{\star}$ comparisons of spirometric abnormalities among NIOSH medical survey participants at coffee facility to U.S. adult population (NHANES III), September 2012

\begin{tabular}{|l|c|c|c|c|}
\hline \multicolumn{1}{|c|}{$\begin{array}{c}\text { Spirometry } \\
\text { Result }\end{array}$} & $\begin{array}{c}\text { Observed } \\
\text { Number }\end{array}$ & $\begin{array}{c}\text { Expected } \\
\text { Number }\end{array}$ & $\begin{array}{c}\text { SMR } \\
\text { Ratio }\end{array}$ & $95 \% \mathrm{CI} \dagger$ \\
\hline $\begin{array}{l}\text { Restrictive } \\
\text { pattern }\end{array}$ & 2 & 4.6 & 0.4 & $0.1-1.6$ \\
\hline Obstruction & 5 & 1.8 & $\mathbf{2 . 7}$ & $\mathbf{1 . 2 - 6 . 4}$ \\
\hline
\end{tabular}

Note: NIOSH=National Institute for Occupational Safety and Health; NHANES=National Health and Nutrition Examination Survey; SMR= standardized morbidity ratio.

*Adjusted for gender, race, age, and smoking categories. Restrictive pattern also adjusted for body mass index. $\uparrow 95 \%$ confidence intervals (CIs) that exclude one are statistically significantly different from comparison with US adult population and are shown in bold. 


\section{References}

ACGIH [2019]. 2019 TLVs ${ }^{\circledR}$ and BEIs ${ }^{\circledR}$ : Threshold limit values for chemical substances and physical agents and biological exposure indices. Cincinnati, $\mathrm{OH}$ : American Conference of Governmental Industrial Hygienists.

Akiyama M, Murakami K, Ohtani N, Iwatsuki K, Sotoyama K, Wada A, Tokuno K, Iwabuchi H, Tanaka K [2003]. Analysis of volatile compounds released during the grinding of roasted coffee beans using solid-phase microextraction. J Agric Food Chem 51(7):1961-1969, https:// doi.org/10.1021/jf020724p.

Akpinar-Elci M, Travis WD, Lynch DA, Kreiss K [2004]. Bronchiolitis obliterans syndrome in popcorn production plant workers. Eur Respir J 24(2):298-302, https://doi.org/10.1183/090 31936.04.00013903.

Anderson BA, Shimoni E, Liardon R, Labuza P [2003]. The diffusion kinetics of carbon dioxide in fresh roasted and ground coffee. J Food Eng 59(1):71-78, https://doi.org/10.1016/ $\underline{\mathrm{S} 0260-8774(02) 00432-6 .}$

Anderson SD, Brannan JD [2003]. Methods for "indirect" challenge tests including exercise, eucapnic voluntary hyperpnea, and hypertonic aerosols. Clin Rev Allergy Immunol. 24(1):27-54, https://doi.org/10.1385/CRIAI:24:1:27.

Burney PG, Luczynska C, Chinn S, Jarvis D [1994]. The European community respiratory health survey. Eur Respir J 7(5):954-960, https://doi.org/10.1183/09031936.94.07050954.

Cavalcanti Zdo R, Albuquerque Filho AP, Pereira CA, Coletta EN [2012]. Bronchiolitis associated with exposure to artificial butter flavoring in workers at a cookie factory in Brazil. J Bras Pneumol 38(3):395-399, https://doi.org/10.1590/s1806-37132012000300016.

Chetambath R, Shivashankaran S, Kumar J, Ravindran D, Khalam AA [2020]. Bronchiolitis obliterans in a coffee processing unit worker from Wayanad: report of a rare case. EC Pulmonary and Respiratory Medicine 9(3):01-04, https://www.ecronicon.com/ecprm/pdf/ ECPRM-09-00554.pdf.

CDC [1996]. Third National Health and Nutrition Examination Survey, 1988-1994, NHANES III Examination Data File. Hyattsville, Maryland: U.S. Department of Health and Human Services, Centers for Disease Control and Prevention, https://wwwn.cdc.gov/nchs/ nhanes/nhanes3/Default.aspx.

CDC [2018]. Carbon monoxide. Cincinnati, OH: U.S. Department of Health and Human Services, Centers for Disease Control and Prevention, National Institute for Occupational Safety and Health, https://www.cdc.gov/niosh/topics/co-comp/default.html.

CDC [2013]. Obliterative bronchiolitis in workers in a coffee-processing facility-Texas, 
2008-2012. MMWR 62(16):305-307, https://www.cdc.gov/mmwr/preview/mmwrhtml/ mm6216a3.htm.

CDC [2019]. Smoking \& tobacco use: quit smoking, https://www.cdc.gov/tobacco/quit smoking/index.htm.

CFR. Code of Federal Regulations. Washington, DC: U.S. Government Printing Office, Office of the Federal Register.

Daglia M, Papetti A, Aceti C, Sordelli B, Spini V, Gazzani G [2007]. Isolation and determination of $\alpha$-dicarbonyl compounds by RP-HPLC-DAD in green and roasted coffee. J Agric Food Chem 55(22):8877-8882, https://doi.org/10.1021/jf0719171.

Day G, LeBouf R, Grote A, Pendergrass S, Cummings K, Kreiss K, and Kullman G [2011]. Identification and measurement of diacetyl substitutes in dry bakery mix production. J Occup Environ Hyg 8(2):93-103, https://doi.org/10.1080/15459624.2011.547148.

ECRHS [2014]. Questionnaires, protocols and instructions. European Community Respiratory Health Survey, http://www.ecrhs.org/Quests.htm.

EAACI Task Force on Occupational Rhinitis, Moscato G, Vandenplas O, Gerth Van Wijk R, Malo JL, Quirce S, Walusiak J, Castano R, De Groot H, Folletti I, Gautrin D, Yacoub MR, Perfetti L, Siracusa A [2008]. Occupational rhinitis. Allergy 63(8):969-980, https://doi. org/10.1111/j.1398-9995.2008.01801.X.

FDA [2008]. Direct food subtances affirmed as generally recognized as safe. 21CFR184.1848.

Food and Drug Administration, https://www.accessdata.fda.gov/scripts/cdrh/cfdocs/cfcfr/ $\underline{\text { CFRSearch.cfm? } \mathrm{fr}=184.1848}$

Ferris BG [1978]. Epidemiology standardization project. Am Rev Respir Dis 118(Suppl):1-53.

Figley KD, Rawling FF [1950] Castor bean: an industrial hazard as a contaminant of green coffee dust and used burlap bags. J Allergy 21(6):545-553, https://doi.org/10.1016/0021$\underline{8707(50) 90106-7 .}$

Ghanei M, Tazelaar HD, Chilosi M, Harandi AA, Peyman M, Akbari HM, Shamsaei H, Bahadori M, Aslani J, Mohammadi A [2008]. An international collaborative pathologic study of surgical lung biopsies from mustard gas-exposed patients. Respir Med 102(6):825-830, https://doi.org/10.1016/j.rmed.2008.01.016.

Hankinson JL, Odencrantz JR, Fedan KB [1999]. Spirometric reference values from a sample of the general U.S. population. Am J Respir Crit Care Med 159(1):179-187, https://doi. 
org/10.1164/ajrccm.159.1.9712108.

Harvey RR, Hawley BM, Korbach EJ, Rawal AX, Roggli VL, Bailey RL, Cox-Ganser JM, Cummings KJ [2018]. Flavoring Related Lung Disease in a Worker at a Coffee Roasting and Packaging Facility. Am J Respir Crit Care Med 197:A6075.

Harvey RR, Fechter-Leggett ED, Bailey RL, Edwards NT, Fedan, KB, Virji MA, Nett RJ, Cox-Ganser JM, Cummings KJ [2020]. The burden of respiratory abnormalities among workers at coffee roasting and packaging facilities. Front. Public Health, Front. Public Health 8:5, https://doi.org/10.3389/fpubh.2020.00005.

Hawley B, Cox-Ganser JM, Cummings KJ [2017]. Carbon monoxide exposure in workplaces, including coffee processing facilities. Am J Respir Crit Care Med 196(8):10801081, https://doi.org/10.1164/rccm.201703-0513LE.

Henneberger PK, Redlich CA, Callahan DB, Harber P, Lemière C, Martin J, Tarlo SM, Vandenplas O, Torén K; ATS Ad Hoc Committee on Work-Exacerbated Asthma [2011]. An official American Thoracic Society statement: work-exacerbated asthma. Am J Respir Crit Care Med 184(3):368-378, https://doi.org/10.1164/rccm.812011ST.

Hubbs AF, Cumpston AM, Goldsmith WT, Battelli LA, Kashon ML, Jackson MC, Frazer DG, Fedan JS, Goravanahally MP, Castranova V, Kreiss K, Willard PA, Friend S, SchweglerBerry D, Fluharty KL, Sriram K [2012]. Respiratory and olfactory cytotoxicity of inhaled 2,3-pentanedione in Sprague-Dawley rats. Am J Pathol 181(3):829-844, https://doi. org/10.1016/j.ajpath.2012.05.021.

Kanwal R, Kullman G, Piacitelli C, Boylstein R, Sahakian N, Martin S, Fedan K, Kreiss K [2006]. Evaluation of flavorings-related lung disease risk at six microwave popcorn plants. J Occup Environ Med. 48(2):149-157, https://doi.org/10.1097/01.jom.0000194152.48728.fb.

Kanwal R, Kullman G, Fedan KB, Kreiss K [2011]. Occupational lung disease risk and exposure to butter-flavoring chemicals after implementation of controls at a microwave popcorn plant. Public Health Rep. 126(4):480-494, https://doi. org/10.1177/003335491112600405.

Karr RM, Davies RJ, Butcher BT, Lehrer SB, Wilson MR, Dharmarajan V, Salvaggio JE [1978]. Occupational asthma. J Allergy Clin Immunol 61(1):54-65, https://doi. org/10.1016/0091-6749(78)90474-8.

Kim TJ, Materna BL, Prudhomme JC, Fedan KB, Enright PL, Sahakian NM, Windham GC, Kreiss K [2010]. Industry-wide medical surveillance of California flavor manufacturing workers: Cross-sectional results. Am J Ind Med 53(9):857-865, https://doi.org/10.1002/ ajim.20858.

King MS, Eisenberg R, Newman JH, Tolle JJ, Harrell FE Jr, Nian H, Ninan M, Lambright 
ES, Sheller JR, Johnson JE, Miller RF [2011]. Constrictive bronchiolitis in soldiers returning from Iraq and Afghanistan. N Engl J Med 365(3):222-230, https://doi.org/10.1056/ NEJMoa1101388.

Kreiss K, Gomaa A, Kullman G, Fedan K, Simoes EJ, Enright PL [2002]. Clinical bronchiolitis obliterans in workers at a microwave-popcorn plant. N Engl J Med 347(5):330338, https://doi.org/10.1056/NEJMoa020300.

Kreiss K, Fedan KB, Nasrullah M, Kim TJ, Materna BL, Prudhomme JC, Enright PL [2012]. Longitudinal lung function declines among California flavoring manufacturing workers. Am J Ind Med. 55(8):657-668, https://doi.org/10.1002/ajim.21013.

Langford NJ [2005]. Carbon dioxide poisoning. Toxicol Rev 24(4):229-235, https://doi. org/10.2165/00139709-200524040-00003.

LeBouf RF, Stefaniak AB, Virji, MA [2012]. Validation of evacuated canisters for sampling volatile organic compounds in healthcare settings. J Environ Monit 14(3):977-983, https:// doi.org/10.1039/c2em10896h.

LeBouf R, Simmons M [2017]. Increased sensitivity of OSHA method analysis of diacetyl and 2,3-pentanedione in air. J Occup Environ Hyg 14(5):343-348, https://doi.org/10.1080/15 $\underline{459624.2016 .1252846 .}$

LeBouf RF, Aldridge M [2018]. Carbon monoxide emission rates from roasted whole bean and ground coffee. J Air Waste Manag Assoc 69(1):89-96, https://doi.org/10.1080/10962247. $\underline{2018.1515125 .}$

LeBouf RF, Hawley B, Cummings KJ [2019]. Potential hazards not communicated in safety data sheets of flavoring formulations, including diacetyl and 2,3-pentanedione. Ann Work Expo Health 63(1):124-130, https://doi.org/10.1093/annweh/wxy093.

Lehrer SB, Karr RM, Salvaggio JE [1978]. Extraction and analysis of coffee bean allergens. Clin Allergy 8(3):217-226, https://doi.org/10.1111/j.1365-2222.1978.tb03217.x.

Macintyre N, Crapo RO, Viegi G, Johnson DC, van der Grinten CP, Brusasco V, Burgos F, Casaburi R, Coates A, Enright P, Gustafsson P, Hankinson J, Jensen R, McKay R, Miller MR, Navajas D, Pedersen OF, Pellegrino R, Wanger J [2005]. Standardisation of the single-breath determination of carbon monoxide uptake in the lung. Eur Respir J 26(4):720-735, https:// doi.org/10.1183/09031936.05.00034905.

Markopoulou KD, Cool CD, Elliot TL, Lync DA, Newell JD Jr, Hale VA, Brown KK, Schwarz MI, Tuder RM [2002]. Obliterative bronchiolitis: varying presentations and clinicopathological correlation. Eur Resir J 19(1):20-30, https://doi.org/10.1183/09031936.02 .00282001 . 
Martyny JW, Van Dyke MV, Arbuckle S, Towle M, Rose CS [2008]. Diacetyl Exposures in the flavor manufacturing industry. Journal of Occupational and Environmental Hygiene, 5(11): 679-688, https://doi.org/10.1080/15459620802368463

Miller A, Thornton JC, Warshaw R, Anderson H, Teirstein AS, Selikoff IJ [1983]. Single Breath Diffusing Capacity in a Representative Sample of the Population of Michigan, a Large Industrial State. Predicted Values, Lower Limits of Normal, and Frequencies of Abnormality by Smoking History. Am Rev Respir Dis, 127(3):270-277, https://doi.org/10.1164/ arrd.1983.127.3.270

Miller MR, Hankinson J, Brusasco V, Burgos F, Casaburi R, Coates A, Crapo R, Enright P, van der Grinten CP, Gustafsson P, Jensen R, Johnson DC, MacIntyre N, McKay R, Navajas D, Pedersen OF, Pellegrino R, Viegi G, Wanger J, ATS/ERS Task Force [2005]. Standardisation of spirometry. Eur Respir J 26(2):319-338, https://doi.org/10.1183/09031936 $\underline{.05 .00034805 .}$

Modi P, Yadava V, Sreedhar R, Khasawaneh F, Balk RA [2008]. A case of flavor-induced lung disease. South Med J 101(5):541-542, https://doi.org/10.1097/SMJ.0b013e31816bead7.

Morgan DL, Jokinen MP, Price HC, Gwinn WM, Palmer SM, Flake GP [2012]. Bronchial and bronchiolar fibrosis in rats exposed to 2,3-pentanedione vapors: implications for bronchiolitis obliterans in humans. Toxicol Pathol 40(3):448-465, https://doi. org/10.1177/0192623311431946.

Morgan DL, Jokinen MP, Johnson CL, Price HC, Gwinn WM, Bousquet RW, Flake GP [2016]. Chemical reactivity and respiratory toxicity of the $\alpha$-diketone flavoring agents: 2,3-butanedione, 2,3-pentanedione, and 2,3-hexanedione. Toxicol Pathol 44(5):763-783, https://doi.org/10.1177/0192623316638962.

Newton J [2002]. Carbon monoxide exposure from coffee roasting. Appl Occup Environ Hyg 17(9):600-602, https://doi.org/10.1080/10473220290095899.

NIOSH [1994]. NIOSH Manual of Analytical Methods (NMAM®). 4th ed. Schlecht PC O'Connor PF, eds. US Department of Health and Human Services, Centers for Disease Control and Prevention, National Institute for Occupational Safety and Health, DHHS (NIOSH) Publication No. 94-113 (August, 1994), 3rd Supplement 2003-154.

NIOSH [2008]. Report on fixed obstructive lung disease in workers at a flavoring manufacturing plant. By Bailey R, McKernan LT, Dunn KH, Sahakian N, Kreiss K. Morgantown, WV: U.S. Department of Health and Human Services, Centers for Disease Control and Prevention, National Institute for Occupational Safety and Health, Health Hazard Evaluation Report No. 2007-0033-3074, Health Hazard Evaluation Report No. 2007-00333074, https://www.cdc.gov/niosh/hhe/reports/pdfs/2007-0033-3074.pdf.

NIOSH [2004]. NIOSH respirator selection logic. Cincinnati, OH: U.S. Department of 
Health and Human Services, Centers for Disease Control and Prevention, National Institute for Occupational Safety and Health, DHHS (NIOSH) Publication No. 2005-100, https:// www.cdc.gov/niosh/docs/2005-100/pdfs/2005-100.pdf.

NIOSH [2012]. Flavoring-related lung disease: Information for Healthcare Providers. Cincinnati, OH: U.S. Department of Health and Human Services, Centers for Disease Control and Prevention, National Institute for Occupational Safety and Health, DHHS (NIOSH) Publication 2012-148, http://www.cdc.gov/niosh/docs/2012-148/.

NIOSH [2016a]. Criteria for a recommended standard: occupational exposure to diacetyl and 2,3-pentanedione. By McKernan LT, Niemeier RT, Kreiss K, Hubbs A, Park R, Dankovic D, Dunn KH, Parker J, Fedan K, Streicher R, Fedan J, Garcia A, Whittaker C, Gilbert S, Nourian F, Galloway E, Smith R, Lentz TJ, Hirst D, Topmiller J, Curwin B. Cincinnati, OH: U.S. Department of Health and Human Services, Centers for Disease Control and Prevention, National Institute for Occupational Safety and Health, DHHS (NIOSH) Publication No. 2016-111, https://www.cdc.gov/niosh/docs/2016-111/.

NIOSH [2016b]. NIOSH pocket guide to chemical hazards, http://www.cdc.gov/niosh/npg/.

NIOSH [2017]. Work-related asthma, Cincinnati, OH: U.S. Department of Health and Human Services, Centers for Disease Control and Prevention, National Institute for Occupational Safety and Health, https://www.cdc.gov/niosh/topics/asthma/default.html

NIOSH [2018]. Volatile organic compounds, C1 to C10, Canister method: Method 3900. In Ashley K, O'Connor PF, eds. NIOSH manual of analytical methods (NMAM®). 5th ed. Cincinnati, OH: U.S. Department of Health and Human Services, Public Health Service, Centers for Disease Control and Prevention, National Institute for Occupational Safety and Health, https://www.cdc.gov/niosh/nmam/pdf/3900.pdf

Nishimura F, Abe S, Fukunaga T [2003]. Carbon monoxide poisoning from industrial coffee extraction. JAMA 290(3):334, https://jamanetwork.com/journals/jama/articleabstract/196935.

Ohashi Y, Motojima S, Fukuda T, Makino S [1992]. Airway hyperresponsiveness, increased intracellular spaces of bronchial epithelium, and increased infiltration of eosinophils and lymphocytes in bronchial mucosa in asthma. Am Rev Respir Dis 145(6):1469-76, https://doi. org/10.1164/ajrccm/145.6.1469.

Oldenburg M, Bittner C, Baur X [2009]. Health risks due to coffee dust. Chest 136(2):536544, https://doi.org/10.1378/chest.08-1965.

OSHA [1993]. Compliance and enforcement activities affected by the PELs decision. Washington, DC: U.S. Department of Labor, Occupational Safety and Health Administration, https://www.osha.gov/laws-regs/standardinterpretations/1993-08-05 
OSHA [2003]. Enforcement policy for respiratory hazards not covered by OSHA permissible exposure limits. Washington, DC: U.S. Department of Labor, Occupational Safety and Health Administration, https://www.osha.gov/laws-regs/standardinterpretations/2018-11-02.

OSHA [2008a]. Sampling and analytical methods: Method 1013 -Acetoin and diacetyl. Washington, DC: U.S. Department of Labor, Occupational Safety and Health Administration, https://www.osha.gov/dts/sltc/methods/validated/1013/1013.html

OSHA [2008b]. Sampling and analytical methods: Method 1012 - Acetoin and diacetyl. Washington, DC: U.S. Department of Labor, Occupational Safety and Health Administration, https://www.osha.gov/dts/sltc/methods/validated/1012/1012.html.

OSHA [2010]. Sampling and analytical methods: Method 1016 - 2,3-pentanedione. Washington, DC: U.S. Department of Labor, Occupational Safety and Health Administration, https://www. osha.gov/dts/sltc/methods/validated/1016/1016.html

OSHA [2012]. Hazard communication, 29 CFR 1910.1200. Occupational Safety and Health Administration, U.S. Department of Labor, https://www.osha.gov/laws-regs/regulations/ standardnumber/1910/1910.1200

OSHA [2013]. Spirometry testing in occupational health program. Washington, D.C.: U.S. Department of Labor, Occupational Safety and Health Administration, OSHA 3637-03 2013, https://www.osha.gov/Publications/OSHA3637.pdf.

OSHA [2014]. OSHA fact sheet: Do you have work-related asthma? A guide for you and your doctor. Washington, D.C.: U.S. Department of Labor, Occupational Safety and Health Administration, https://www.osha.gov/Publications/OSHA3707.pdf.

OSHA [2019]. Permissible exposure limits - annotated tables. Washington, D.C.: U.S. Department of Labor, Occupational Safety and Health Administration, https:/www.osha.gov/ dsg/annotated-pels/index.html.

Pellegrino R, Viegi G, Brusasco V, Crapo RO, Burgos F, Casaburi R, Coates A, van der Grinten CP, Gustafsson P, Hankinson J, Jensen R, Johnson DC, MacIntyre N, McKay R, Miller MR, Navajas D, Pedersen OF, Wanger J [2005]. Interpretative strategies for lung function tests. Eur Respir J 26(5):948-968, https://doi.org/10.1183/09031936.05.00035205.

Pharmaxis, Inc [2012]. Memorandum to health care providers. Subject: ARIDOL® challenge cut offs for mild, moderate and severe bronchial hyperresponsiveness (BHR). May 2012.

Raffel JB, Thompson J [2013]. Carbon monoxide from domestic coffee roasting: a case report. Ann Intern Med 159(11):795-796, https://doi.org/10.7326/0003-4819-159-11-201312030-00023.

Rondón C, Campo P, Galindo L, Blanca-López N, Cassinello MS, Rodriguez-Bada JL, Torres MJ, Blanca M [2012]. Prevalence and clinical relevance of local allergic rhinitis. Allergy. 
67(10):1282-1288, https://doi.org/10.1111/all.12002.

Rondón C, Bogas G, Barrionuevo E, Blanca M, Torres MJ, Campo P [2017]. Nonallergic rhinitis and lower airway disease. Allergy 72(1):24-34, https://doi.org/10.1111/all.12988.

Rose JJ, Wang L, Xu Q, McTiernan CF, Shiva S, Tejero J, Gladwin MT [2017]. Carbon monoxide poisoning: pathogenesis, management, and future directions of therapy. Am J Respir Crit Care Med 195(5):596-606, https://doi.org/10.1164/rccm.201606-1275CI.

Sahay S, Gera K, Bhargava SK, Shah A [2016]. Occurrence and impact of sinusitis in patients with asthma and/or allergic rhinitis. J Asthma 53(6):635-643, https://doi.org/10.3109/ $\underline{02770903.2015 .1091005 .}$.

Sakwari G, Mamuya SH, Bråtveit M, Moen BE [2013]. Respiratory symptoms, exhaled nitric oxide, and lung function among workers in Tanzanian coffee factories. J Occup Environ Med 55(5):544-551, https://doi.org/10.1097/JOM.0b013e318285f453.

Shaaban R, Zureik M, Soussan D, Neukirch C, Heinrich J, Sunyer J, Wjst M, Cerveri I, Pin I, Bousquet J, Jarvis D, Burney PG, Neukirch F, Leynaert B [2008]. Rhinitis and onset of asthma: a longitudinal population-based study. Lancet. 372(9643):1049-1057, https://doi. org/10.1016/S0140-6736(08)61446-4.

Tarlo SM, Lemiere C [2014]. Occupational asthma. N Engl J Med 370:640-649, https://doi. org/10.1056/NEJMra1301758.

Tarlo SM [2016]. Update on work-exacerbated asthma. Int J Occup Med Environ Health 29(3):369-374, https://doi.org/10.13075/ijomeh.1896.00676.

Thomas KE, Trigg CJ, Baxter PJ, Topping M, Lacey J, Crook B, Whitehead P, Bennett JB, Davies RJ [1991]. Factors relating to the development of respiratory symptoms in coffee process workers. Br J Ind Med 48(5):314-322, https://doi.org/10.1136/oem.48.5.314.

Townsend MC and Occupatioal and Environmental Lung Disorders Committee [2011]. Spirometry in the occupational health setting - 2011 update. J Occup Enivron Med 53(5):569-584, https://doi.org/10.1097/JOM.0b013e31821aa964.

Zuskin E, Valić F, Skurić Z [1979]. Respiratory function in coffee workers. Br J Ind Med 36(2):117-122, https://doi.org/10.1136/oem.36.2.117.

Zuskin E, Kanceljak B, Skurić Z, Butković D [1985]. Bronchial reactivity in green coffee exposure. Br J Ind Med 42(6):415-420, https://doi.org/10.1136/oem.42.6.415.

Zuskin E, Schachter EN, Kanceljak B, Witek TJ Jr, Fein E [1993]. Organic dust disease of airways. Int Arch Occup Environ Health 65(2):135-140, https://doi.org/10.1007/ BF00405733. 
This page left intentionally blank 
Keywords: NAICS 311920 (Coffee roasting), Texas, diacetyl, 2,3-pentanedione, 2,3-hexanedione, flavorings, coffee, roasting, carbon monoxide, carbon dioxide, volatile organic compounds (VOCs), asthma, obliterative bronchiolitis, lung disease 


\section{NIOSH Health Hazard Program Description}

The Health Hazard Evaluation Program investigates possible health hazards in the workplace under the authority of the Occupational Safety and Health Act of 1970 (29 U.S.C. § 669(a) (6)). The Health Hazard Evaluation Program also provides, upon request, technical assistance to federal, state, and local agencies to investigate occupational health hazards and to prevent occupational disease or injury. Regulations guiding the Program can be found in Title 42, Code of Federal Regulations, Part 85; Requests for Health Hazard Evaluations (42 CPR Part 85).

\section{Disclaimer}

The recommendations in this report are made on the basis of the findings at the workplace evaluated and may not be applicable to other workplaces.

Mention of any company or product in this report does not constitute endorsement by the National Institute for Occupational Safety and Health (NIOSH).

Citations to Web sites external to NIOSH do not constitute NIOSH endorsement of the sponsoring organizations or their programs or products. NIOSH is not responsible for the content of these Web sites. All Web addresses referenced in this document were accessible as of the publication date.

\section{Acknowledgments}

Desktop Publisher: Barbara Elbon

Data Analysis Support: Nicole Edwards, Kathleen Fedan, and Brian Tift

Laboratory Support: Toni Bledsoe, Dru Burns, Brett Green, Kyle Hatcher, Anand Ranpara

Site Visit Team Members: Walter Alarcon, Rachel Bailey, Ana Barbero, Mike Beaty, Randy Boylstein, Diana Cale, Cammie Chaumont Menendez, Matthew Duling, Kevin H. Dunn, Nicole Edwards, Diana Freeland, Steve Game, Elizabeth Garza, Cara Halldin, Robert Lawrence, Ryan LeBouf, Stephen Martin, Anne-Binney McCague, Tia McClelland, Chris Piacitelli, Marcia Stanton, Brian Tift

\section{Availability of Report}

Copies of this report have been sent to the employer and employees at the facility. The state health department and the Occupational Safety and Health Administration Regional Office have also received a copy. This report is not copyrighted and may be freely reproduced.

This report is available at http://www.cdc.gov/niosh/hhe/reports/pdfs/2012-0170-3372.pdf.

All other Health Hazard Evaluation Reports may be found at https://www2a.cdc.gov/hhe/ search.asp.

\section{Recommended citation for this report:}

$\mathrm{NIOSH}$ [2020]. Evaluation of exposures and respiratory health at a coffee roasting, flavoring, and packaging facility. By Bailey RL, Duling MG, Martin SB, Stanton ML, McClelland TL, LeBouf RF, Edwards NT, Fedan KB, Cox-Ganser JM. Morgantown, WV: U.S. Department of Health and Human Services, Centers for Disease Control and Prevention, National Institute for Occupational Safety and Health, NIOSH HHE Report No. 20120170-3372. 
Delivering on the Nation's promise:

Safety and health at work for all people through research and prevention

To receive documents or other information about occupational safety and health topics, contact NIOSH

Telephone: 1-800-CDC-INFO (1-800-232-4636)

TTY: 1-888-232-6348

email: cdcinfo@cdc.gov

or visit the NIOSH website at http://www.cdc.gov/niosh

SAFER • HEALTHIER - PEOPLE ${ }^{\text {TM }}$ 